\title{
NBSIR 74-366
}

\section{STUDY OF CRYOGENIC PROPELLANT SYSTEMS FOR LOADING THE SPACE SHUTTLE}

R.O. Voth, W.G. Steward, and W.J. Hall

Cryogenics Division

Institute for Basic Standards

National Bureau of Standards

Boulder, Colorado 80302

Interim Report

April 1974

Prepared for

National Aeronautics and Space Administration

John F. Kennedy Space Center

Kennedy Space Center, Florida 32899 



\section{NBSIR 74-366}

\section{STUDY OF CRYOGENIC PROPELLANT SYSTEMS FOR LOADING THE SPACE SHUTTLE}

R.O. Voth, W.G. Steward, and W.J. Hall

Cryogenics Division

Institute for Basic Standards

National Bureau of Standards

Boulder, Colorado 80302

Interim Report

April 1974

The results of this report are not to be used for advertising or promotional purposes, or to indicate endorsement or disapproval of the product(s) by the National Bureau of Standards.

Prepared for

National Aeronautics and Space Administration John F. Kennedy Space Center

Kennedy Space Center, Florida 32899

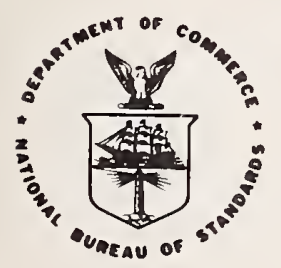

U.S. DEPARTMENT OF COMMERCE, Frederick B. Dent, Secretary 

1. Introduction ................... 1

1. 1 Objectives ..................... 2

2. Graphic Display Computer Terminal ......... 4

2. 1 Description of Equipment ......... 4

2. 2 Description of the Minicomputer Software.... 4

2.3 Instructions for $\log -$ In . . . . ...... 10

2. 4 Instructions for Initiation of Computation in the Automatic Mode............ 12

2. 5 Reloading the Minicomputer Programs .... 15

3. Computation Options--Cooldown Period ........ 17

3. 1 Option 1 - Thermal Stresses - calculates stresses due to rapid cooldown of flanges, or bowing of pipeline due to stratification in the case of low

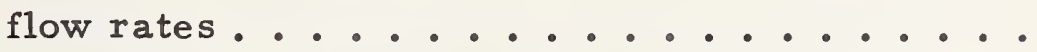

3. 2 Option 2 - Valve Opening Surges - surges due to rapid vaporization when a valve is opened preceding a free wheeling pump. Also calculated is the peak due to water hammer as the liquid impinges on a free wheeling pump .......

3. 3 Option 3 - Cooldown Time - length cooled down, flow rate, and pressure drop across the pump

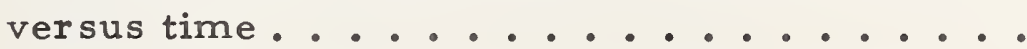

3. 4 Option 4 - Pump Start-Up Cooldown Surges surges due to rapid vaporization when a pump is started upstream from a warm line..... 
4. Computation Options--Post-Cooldown Period ......

4. 1 Option 5 - Water Hammer - pressure spikes due to water hammer when valves are closed in a flowing liquid stream ..........

4. 2 Option 6 - Cold Flow - steady flow operation and transient response to changes in operating conditions..................... 39

5. General References .............. 50

5. 1 System Reference Manuals......... 51 APPENDIX A. Heat-Mass Transfer Correlations for Uninsulated LOX Transfer Lines .... 52 APPENDIX B. Cooldown Surge ......... 72 APPENDIX C. Loading of the Minicomputer ...... 


\section{LIST OF FIGURES}

Page

Figure 1. Graphic display terminal and mini-computer . . 5

Figure 2.

Log-in sequence .............

Figure 3.

General input data ............ 13

Figure 4.

Selection of computation options . . . . . . 16

Figure 5.

Option 1 - Thermal stresses input display ...

Figure 6.

Option 2 - Valve opening surges input display .

Figure 7.

Option 2 - Valve opening surges input display

(continued) ...............

Figure 8.

Option 2 output.

Figure 9.

Option 3 - Cooldown time input display . . . .

Figure 10.

Option 3 output .

Figure 11.

Option 3 output (continued)..........

Figure 12.

Option 3 output (continued)..........

Figure 13.

Option 4 - Pump start-up cooldown surges

input display ... . . . . . . . . . .

Figure 14.

Option 4 output .

Figure 15.

Option 5 - Water hammer input display .....

Figure 16.

Option 5 - Water hammer input display

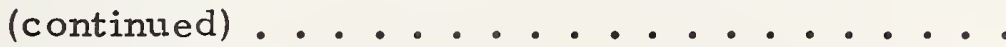

Figure 17.

Option 5 output.

Figure 18.

Option 6 - Cold flow input display .......

Figure 19.

Option 6 - Cold flow input display

(continued).

Figure 20.

Option 6 output .

Figure 21.

Option 6 output (continued).

Figure 22.

Option 6 output (continued)

Figure 23.

Option 6 output (continued). 
Figure 24. Option 6 output (continued) ......... 48

Figure 25. Option 6 output (continued) ........ 49

Figure A1. Comparison of calculated (dashed lines) steady

state heat flux with the experimental data of

Richards, et al. [1962] for liquid nitrogen

cooled test section .............

Figure A2. Comparison of calculated steady state heat flux with the experimental data of Ruccia and Mohr [1960] for a liquid oxygen cooled vertical

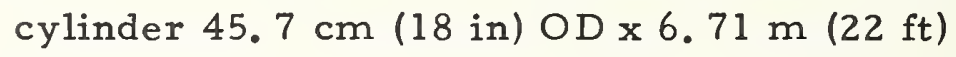

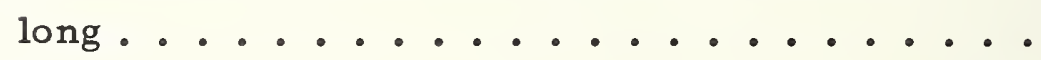

Figure Bl. Peak surge pressure for liquid nitrogen in a $61 \mathrm{~m}$ $(200 \mathrm{ft}), 1.6 \mathrm{~cm}(0.625 \mathrm{in}) \mathrm{OD}$ copper tube

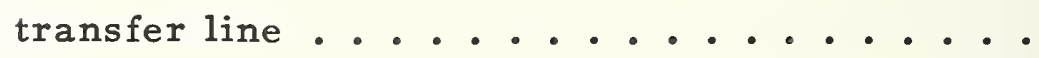

Figure B2. Peak surge pressure for subcooled nitrogen in a $46 \mathrm{~m}$ (150 ft), $1.6 \mathrm{~cm}(0.625 \mathrm{in})$ OD copper

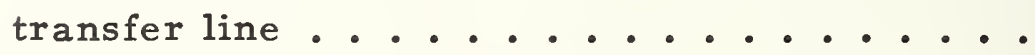

Figure B3. Peak surge pressure for liquid nitrogen in a $25 \mathrm{~m}(82 \mathrm{ft}), 1.6 \mathrm{~cm}(0.625 \mathrm{in}) \mathrm{OD}$ copper

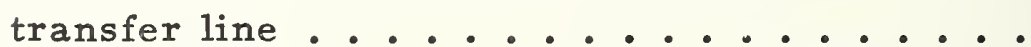

Figure B4. Peak surge pressure for liquid nitrogen in a $7.6 \mathrm{~m}(25 \mathrm{ft}), 1.6 \mathrm{~cm}(0.625 \mathrm{in})$ OD copper

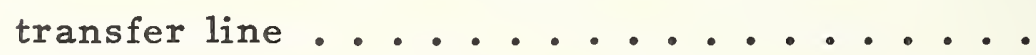

Figure B5. Peak surge pressure for liquid hydrogen in a $61 \mathrm{~m}(200 \mathrm{ft}), 1.6 \mathrm{~cm}(0.625 \mathrm{in})$ OD copper

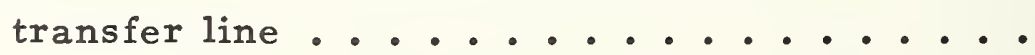




\section{LIST OF TABLES}

Page

Table A1. Calculated steady state heat flux for the experimental conditions of Richards, et a1. [1962] ............... 65

Table A2. Summary of heat flux calculations calculated for the experimental conditions of Ruccia and

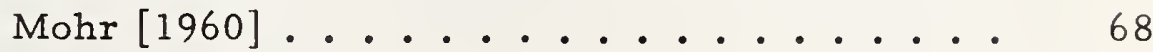



Study of Cryogenic Propellant Systems for Loading

the Space Shuttle*

R. O. Voth, W. G. Steward, and W. J. Hall

Computer programs have been written to model the liquid oxygen loading system for the space shuttle. The programs allow selection of input data through graphic displays which schematically depict the part of the system being modeled. The computed output is also displayed in the form of graphs and printed messages. Any one of six computation options may be selected. The first four of these pertain to thermal stresses, pressure surges, cooldown times, flow rates and pressures during cooldown. Options five and six deal with possible water hammer effects due to closing of valves, steady flow and transient response to changes in operating conditions after cooldown.

Procedures are given for operation of the graphic display unit and minicomputer.

Key words: Computer modeling; cooldown; cryogenic flow; stresses; surges; transient flow; water hammer.

\section{Introduction}

This is a final report under NASA Contract No. CC-03420A.

Loading of the space shuttle with liquid oxygen, using the existing ground support equipment at the Kennedy Space Center (KSC), will require alterations in the current cooldown and loading procedures. Also minor modifications of the existing loading system may be required. Since acceptable loading rates, minimum loading times, and liquid capacities for the shuttle have not been fixed, the loading procedure and loading sequence has not been determined. Even after the shuttle capacities, etc., have been determined,

* This work was conducted at the National Bureau of Standards under the sponsorship of Kennedy Space Center - NASA. 
changes to the loading procedure will probably occur as experience is gained. Any changes in the cooldown procedure can cause excessive cooldown pressure spikes and/or excessive temperature induced stresses in components of the ground support system during the cooldown period. Also, flow rates of both liquid oxygen and vented gaseous oxygen during loading operations that follow cooldown are important. The study supplies the necessary mathematical and system analysis and hardware and computer software so that any proposed cooldown and loading sequence can be simulated; thus, the consequences and/or benefits of altering established procedures can be determined before a wet test of the system is initiated. The present study is for the liquid oxygen system.

\subsection{Objectives}

The objective of the study is to supply the KSC with the necessary analysis, hardware, and computer software to provide a computerized model of the liquid oxygen system. By means of these programs, cooldown and loading procedures can be checked mathematically to determine thermal stresses, cooldown pressure surges, cooldown times, and loading rates before a wet test of the actual system is conducted. This work is an extension of a recently completed study in which a mathematical model of the $35.6 \mathrm{~cm}(14-\mathrm{inch}) \mathrm{cross}$ country piping system was developed for the calculation of cooldown pressure surges. Specific objectives are:

(1) Purchase of a graphical display unit with the hardware necessary to interface the display unit with an existing computer at KSC. 
(2) Develop a mathematical model and computer program to calculate thermal stresses in major components of the ground support equipment during the cooldown period. The major components include the liquid oxygen pumps and other massive components such as pipe flanges.

(3) Develop a mathematical model and computer program to calculate cooldown times for the various configurations of the ground support equipment.

(4) Develop a mathematical model and computer program to calculate flow rates and pressures at selected points on the ground support equipment after the cooldown period. The flows and pressures shall be related to pump speed, supply tank liquid level, system configuration, and valve characteristics. 


\section{Graphic Display Computer Terminal}

\section{1 Description of Equipment}

The system consists of a graphical display terminal interfaced with the KSC timeshare computer through a 8000 word storage minicomputer and MODEM. Figure 1 shows the graphical display unit and minicomputer.

Software for communication between the display unit and the KSC computer, routines for schematic displays, input-output, and graphing are programmed into the minicomputer. These routines are also stored on punched paper tape from which they may be reloaded if necessary. The programs and subroutines used in the calculations are catalogued in the KSC computer and are called as needed through the minicomputer software routines.

\section{2 Description of the Minicomputer Software}

The programs contained in the minicomputer control the information flow between the graphical display unit and the KSC timesharing computer. Besides the control function, the minicomputer has the input schematics with the associated input data and programs to interpret the responses received from the KSC timesharing computer (during execution of the oxygen ground support computer program) in its memory.

The communication between the minicomputer system and the KSC compute $\mathrm{r}$ is carried over a high speed telephone data line. The MODEM properly conditions the signals for the high speed data transmission.

Data is transmitted in various sized blocks. Each character of data in the block is accompanied by a parity bit and each block of data is accompanied by a parity character to make the parity of each word and parity of the entire block being transmitted correct. The receiving 


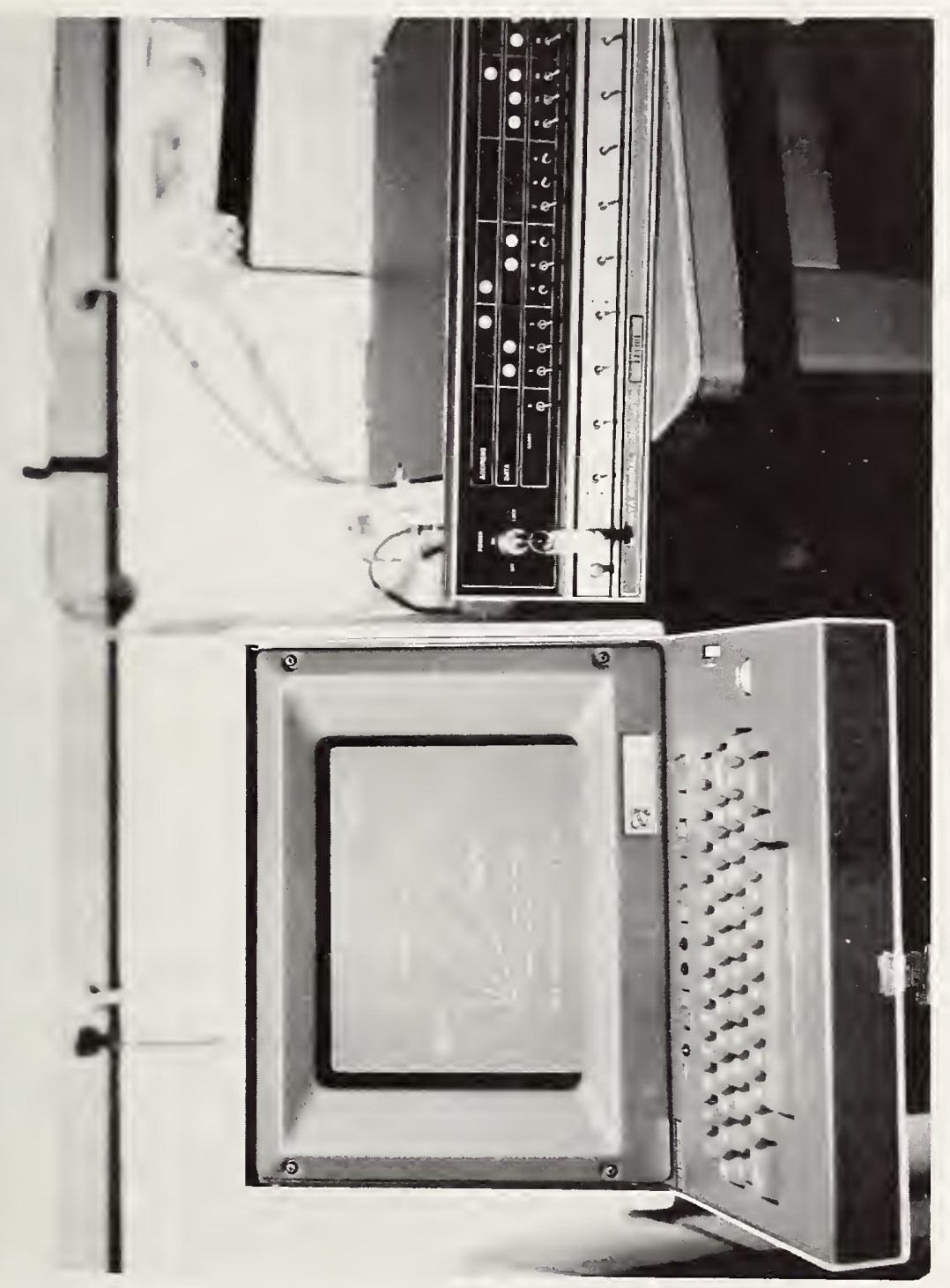

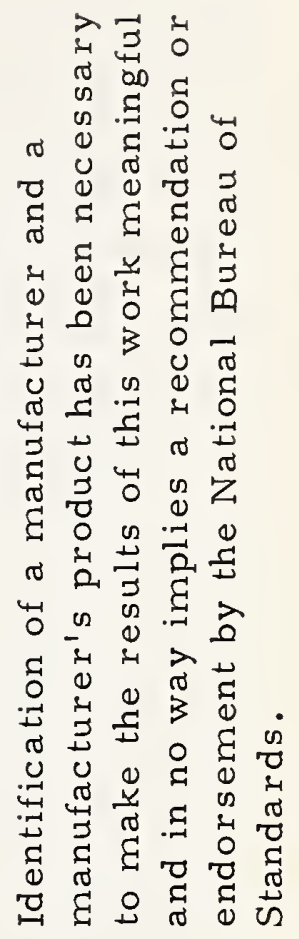

त्ठ

$\lambda$

त्ष

光

U 0

$\because$

तิ द्

迥

-1
0
3
3
0.1
-1
-1 
station checks the parity of the incoming block of data and if the parity is correct, the transmission is accepted and an acknowledgment is returned to the sending station. If the parity of the received information is not correct, due to noise or other problems with the telephone line, the receiving station requests a retransmission. The sending station will then automatically retransmit the data. In some rare instances, the retransmission request is lost and the data must be manually retransmitted.

The minicomputer software has two basic modes of operation using the graphical display keyboard. The first mode, termed the manual mode, allows conversation with the KSC computer in a manner similar to a normal teletype except that the communication is at high speed. The second mode of operation, termed the automatic mode, is used to run the computer programs simulating the oxygen ground support equipment. Much of the communication between the minicomputer and the timesharing computer in the second mode is automatic, with no operator input required.

During operation in either mode, the graphical display te rminal will emit an audible "beep" whenever an acknowledgment is received from the timesharing computer. This "beep" will inform the operator that a data block has been successfully sent and new information can be entered or a return can be expected from the timesharing computer. Until a successful transmission is affected, the keyboard of the graphical display unit is locked except to a control B, as explained in a later paragraph.

Operation in the manual mode allows for normal log-in procedures and the use of any subsystems on the KSC computer. Fortran, basic or the editing subsystem, may. be employed in the manual mode. 
Since the graphical display-minicomputer combination is connected to the Datanet-760 terminal of the KSC timesharing system, operation in the manual mode is very similar to the general operation of the Datanet system as described in the Honeywell manual [1971]. * Log-on procedures as described for the Datanet are also valid for the graphic display unit.

During operation of the graphics unit, data entered on the screen of the graphics display are also entered into the memory of the minicomputer and when a carriage return is depressed, the data from the computer memory is transmitted to the timesharing computer. More than one line of data may be transmitted in a block if each line entered on the screen is terminated by a line feed and the entire block is terminated by a carriage return for transmission.

Typing errors can be corrected by using a control A which causes the cursor to be backspaced once and lowered one line. The character typed in the lower position replaces the original character in the minicomputer memory and will be transmitted when the carriage return is depressed. Since the graphics display unit is connected to the Datanet760 terminal, other characteristics unique to the Datanet system effect the operation of the display unit. As an example, the timesharing computer counts the lines of output during its data transmission and after sufficient lines have been sent to fill the screen of a Datanet-760 system, data transmission is terminated. The stop in data transmission is indicated by the ASCII code characters $\wedge *$ on the screen of the graphics unit. To receive additional data, the operator must transmit a blank line by depressing the carriage return on the keyboard.

The automatic mode of operation interacts with the specific oxygen system simulation programs available in the Fortran subsystem of the timesharing computer. During automatic operation, the minicomputer

* Identification of a manufacturer and a manufacturer's product has been necessary to make the results of this work meaningful and in no way implies a recommendation or endorsement by the National Bureau of Standards. 
will request a run of a specified program, send the required data when an equal sign is received, and interpret and display returning data from the timesharing computer on the graphical display unit. Usually, the returning data will be displayed in graphical form. Since the oxygen simulation programs are in the Fortran subsystem, the KSC computer must be in the Fortran subsystem before the automatic mode of operation is entered with the graphical display unit. The Fortran subsystem of the timesharing compute $r$ is indicated by an asterisk displayed on the screen.

Several control characters are used during normal operation of the graphic display unit to help the operator during the execution of the various programs. A control character is used during communication between the graphic display unit and the minicomputer and need not be followed by a carriage return to effect a transmission. A control character is executed by depressing and holding down the control key on the keyboard and then depressing the desired alpha-numeric key. Thus, a control D means that the control key was depressed and held, and then the letter $D$ was depressed. The following is a description of the control characters available for use on the graphic display unit.

Control A: Control A allows the operator to correct a typing error before a block of data is sent to the timesharing computer. Any time before the carriage return is depressed, a change can be made to previously typed material. This change is made by depressing the control A an appropriate number of times until the cursor is located below the character to be changed, entering the new character and then proceding to enter subsequent characters in the line. 
Control B: Depressing control B will cause the minicomputer to issue a $\$ * \$ B R K$ command to the timeshare computer and return the minicomputer to the manual mode of operation. The function of the \$*\$BRK command is described in the Honeywell Information Manual [1971] Control $\mathrm{B}$ can be used any time even during a transmission when the keyboard is locked to other input.

Control G: Control G causes the minicomputer to enter the automatic mode of operation. Entering the automatic mode of operation should not be attempted unless the KSC timeshare computer is operating in the Fortran subsystem and an asterisk (*) is displayed as the last received character on the graphic display unit.

Control P: Depressing the control P causes the minicomputer software to interpret data returning from the timesharing computer into graphical output. This option was supplied with the minicomputer to allow graphical output from any Fortran programs written in the manual mode. In order to graph the results of any program written in the manual mode, the output from the program must be supplied to the ASCII coded Fortran subroutine called PLOT currently available on the timesharing computer. Along with the data, labeling information can also be supplied to PLOT. The program DEMO currently loaded in the timesharing computer can be listed to obtain instructions on how to use subroutine PLOT. After writing a program for which a graphical output is expected the program is run in the manual mode, except that after all input data has been supplied and an acknowledge received as indicated by a "beep;" control P should be depressed. A graph of the returning data will then appear on the graphical display unit. 


\section{3 Instructions for Log-In}

The log-in routine for the minicomputer is accomplished in the manual mode. The procedure is to turn on the Modem (switch located inside the front cover), the minicomputer (key switch on front panel), and the graphics display unit (switch located on the front of the pedestal below the keyboard). The line-local switch on the graphics display keyboard should be set to line. After a short warm-up period, the screen on the graphics display unit will light up. The page key on the display unit should be depressed to prepare the screen for reception of messages. The starting address of the software program in the minicomputer is 00002 in octal (switch 14 on the top row of toggle switches up, all others down). After setting the top switches to the starting address, depress RESET and then START on the momentary contact control switches from the lower row of switches of the minicomputer. The timesharing computer can now be dialed on the telephone. After the computer carrier signal (a continuous tone) is confirmed, the telephone data switch can be actuated. As soon as the minicomputer software confirms the computer interconnection, the words PLEASE LOG IN will appear on the graphics display screen. If these words do not appear, a fault has developed in the minicomputer software, or the telephone interconnection was not achieved. The program should be reloaded as described in appendix C. The normal log-in procedure for the Datanet 760 system as described in the Honeywell manual [1971] can now proceed. A carriage return should be supplied after each input to transmit the information to the timesharing computer. Figure 2 shows the appropriate log-in sequence as it would appear on the screen of the graphics display unit. Computer supplied messages are underlined. 


\section{PLEASE LOG IN}

$\$ * \$ M D$ PASSWD, 26, DAC, TSS

****** CONNECT REQUEST SENT TO CP

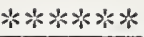

KSC 635 AT CIF ON 03/06/74 AT 10.281 CHANNEL 4424

USER ID -

$3 \mathrm{MX002}$

PASSWORD - -

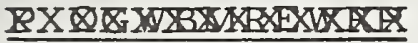

NBS

9 BLOCKS FILE SPACE AVAILABLE

**TSS SIZE 54K CARDIN 25K

SYSTEM ?

FORT

OLD OR NEW-

NEW

READY

本

Figure 2. Log-in sequence. 
2. 4 Instructions for Initiation of Computation in the Automatic Mode

In order to perform calculations in the automatic mode using the oxygen simulations programs, the Fortran subsystem of the timesharing computer must be available. On figure 2, the Fortran subsystem was entered by entering Fortran for the required system and new for the type of program. After an asterisk (*) appears on the screen as the last reception, control G can be depressed to enter the automatic mode of calculation. After initiation of the automatic mode, the universal figure (fig. 3$)^{1}$ will appear on the screen of the graphics terminal. This figure is used to define the general characteristics of the piping system.

Pipe lengths under Entry 1 in the General Input Data may include equivalent length to account for the added restrictions of pipe fittings, filters, or other restrictions. If this is done, the pipe wall thickness entered into the specific input data of option 3 must be altered correspondingly in order to provide the correct mass of material to be cooled down. Entry 7, "Supply Ullage Pressure" requires some clarification. For computation options, except option 6, there is no differentiation between the ullage pressure during storage and during the transfer process. For option 6, the pressure specified in the general input data is taken to be the ullage pressure during storage and it is assumed that the supply liquid becomes saturated at that pressure. The specific input data for option 6 allows a "Supply Ullage Pressure During Transfer" to be selected which may be different from the ullage pressure during storage.

When the figure appears, the input variables will contain the numbers used in the previous run of the program. Any or all of the

1 The figures shown here are actual photographs of the graphic display as they will appear during operation of the system. 


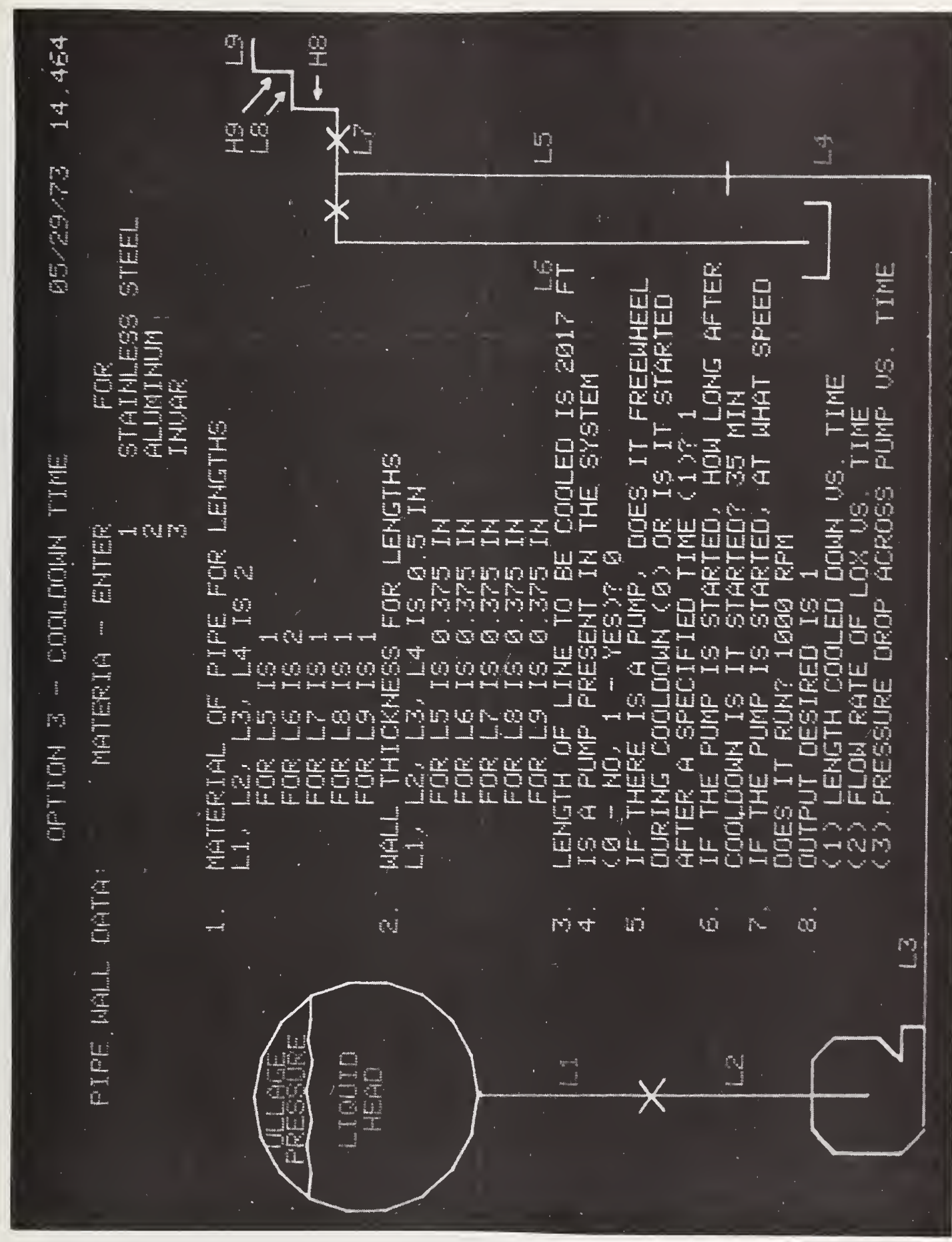


input numbers may be changed. A change is accomplished by moving the horizontal cursor to the line containing the number to be changed, pressing the "RUB OUT" key, then typing the new number in the blank space which will appear. After pressing "RETURN" the operator may move the cursor and make further changes. Even though the schematic will not change, the computer programs will accept zero for lengths 4 and $5(L 4, L 5)$ to eliminate the vertical rise if desired and will accept a single pipe length equal to the total pipe length and a single diameter. At the upper right on the figure, the current date and time will appear. This date and time will remain the same and will appear on all subsequent figures to be used as an identification number to correlate hardcopy output. After all input parameters have been adjusted to acceptable values, and the ALT MODE key is depressed, the system will proceed to the next page.

This page (fig. 4) allows a choice of the computer program to be run with the previous input data. After this choice is made by placing the option number in the appropriate blank and depressing ALT MODE, the terminal will display the first page of that option. The first page of each option, plus as many as two more pages will appear, allowing for more specialized input data. Typical display figures are shown in the following sections. After the input data has been adjusted as previously described and ALT MODE depressed for each input figure, the output of each option will appear after a short period of time. During this time interval, several "beeps" will be heard as input data is supplied to the timesharing computer. In some instances, when multiple output is expected, a choice of output curves will be made available. Each output curve will fill the entire screen. When the output curve appears, it will be possible to make a hard copy and/or digitize any point on the curve by placing the vertical cursor on the desired point and depressing the space bar. 
Restarting with the input display is accomplished by depressing ALT MODE. At this time the operator may choose another computation option with the previous input values, he may change the input, or he may terminate computation by selecting option 7 from the second page (RETURN TO MONITOR). Of course, if the operator chooses to start calculations on a new system, a new date and time will appear on all figures, allowing him to maintain correlation between the input and the output figures.

2. 5 Reloading the Minicomputer Programs

Several paper tapes have been supplied with the system. Some of the tapes were supplied by the manufacturer of the minicomputer and can be used to debug the hardwired functions of the minicomputer. The function of the manufacturer's supplied tapes are described in accompanying literature. Other paper tapes can be used to reload the existing minicomputer program. The paper tape loading procedure, using an appropriate teletype unit, is described in Appendix C. 


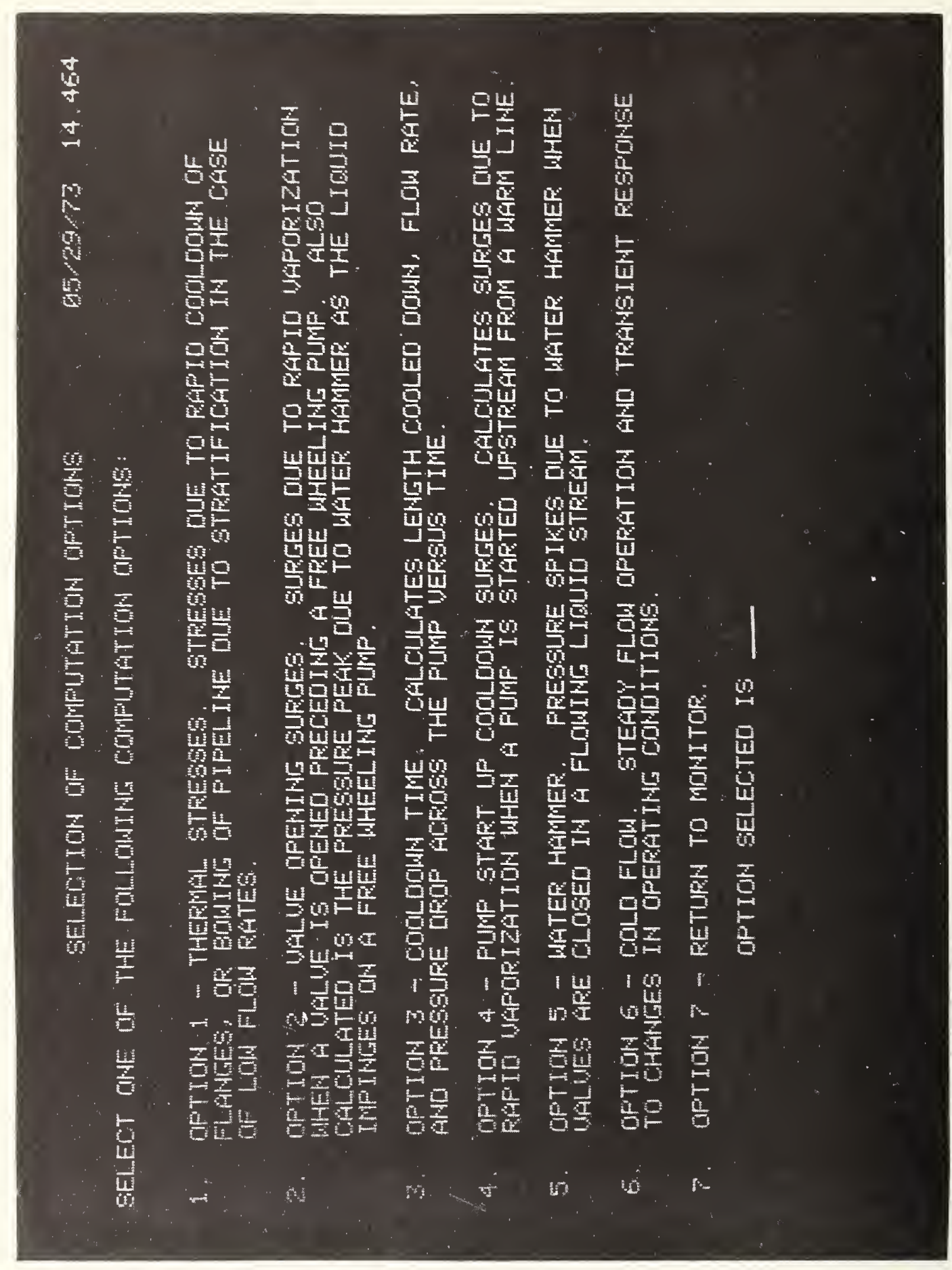




\section{Computation Options--Cooldown Period}

\subsection{Option 1 - Thermal Stresses}

Calculates stresses due to rapid cooldown of flanges, or bowing of pipeline due to stratification in the case of low flow rates.

\section{1 .1 Applications}

This computation determines low and high limits of flow rates during cooldown from the standpoint of the resulting stresses in the piping system and flanged joints. For very high flow rates and rapid cooling excessive thermal stresses may be created in flanges due to the large radial temperature gradients. On the other hand very low flow rates might result in stratified flow with liquid lying along the bottom of the pipe. The resulting circumferential temperature gradients could cause a pipeline to bow significantly.

\subsubsection{Input Data Entries}

Section 2.3 describes the general log-in procedure for the graphic display system. After the initial log-in has been accomplished, and Option 1 has been selected, a display similar to figure 5 appears. The input required for this option in addition to the general input data of figure 3 is shown in figure 5. These are the outside diameter of the pipe flange, the outside and inside diameters of the pipeline and the material of the pipeline.

\section{1 .3 Output}

The output for this calculation is alpha numeric only but will be displayed on the screen just as other output data. The values given will be the maximum cooldown flow rate which will allow the stress in the flanges to remain below the yield point, and the minimum flow rate which will prevent stratified flow from occurring with the given input conditions. 


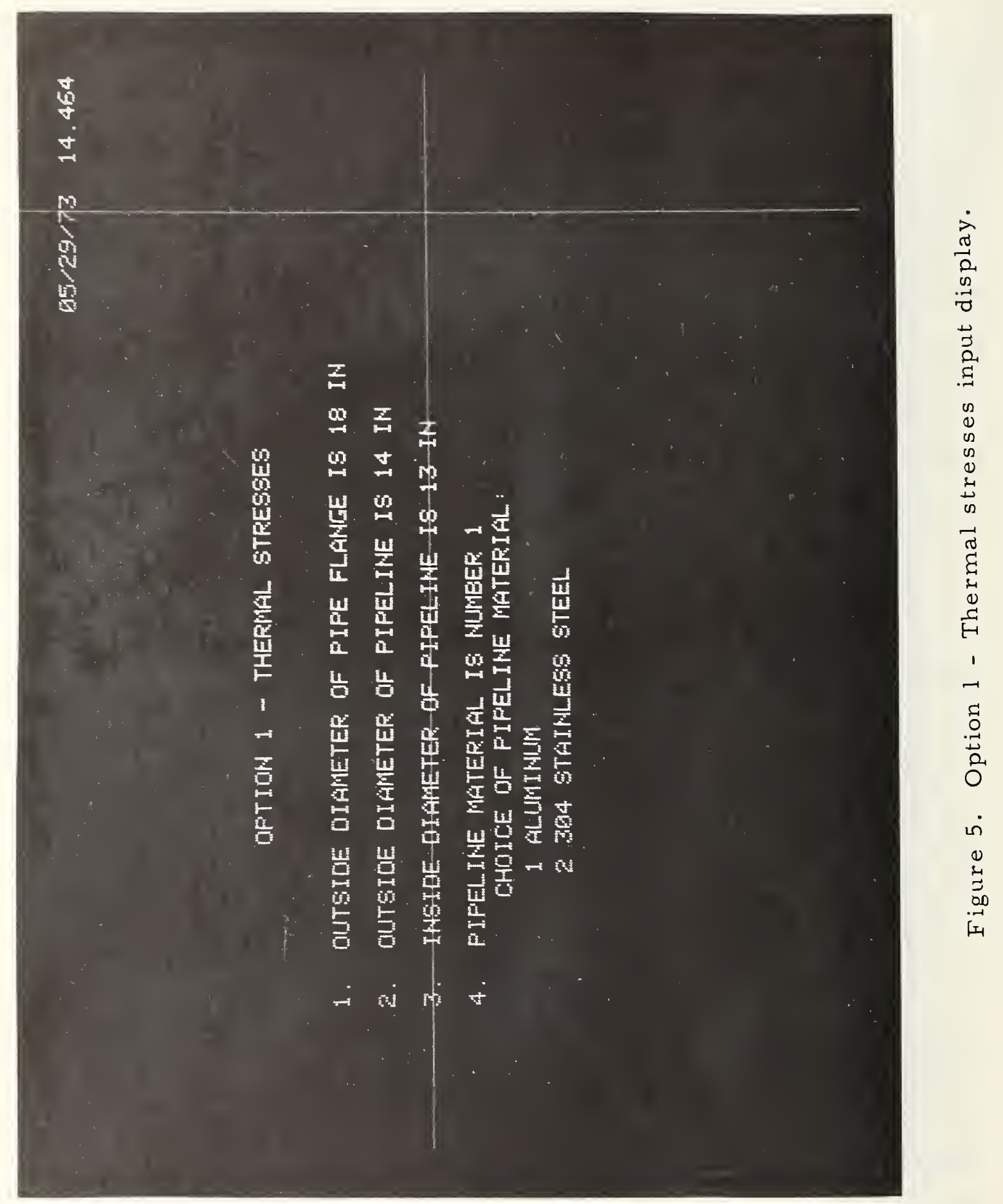




\subsection{Option 2 - Valve Opening Surges}

Surges due to rapid vaporization when a valve is opened preceding a free wheeling pump, or water hammer as the liquid impinges on a free wheeling pump.

\subsubsection{Applications and Limitations}

This computation applies to the opening of a valve preceding a warm section of pipe and a pump. It computes pressure surges which might develop from one of two causes: (1) rapid vaporization in the warm pipe (model discussed in Appendix B), or (2) a water hammer effect due to impingement of liquid on a free wheeling pump. When the vaporization surge occurs, it is accompanied by a slowing or reversal of the liquid flow so that the water hammer would not occur or would be greatly diminished. The program estimates the time at flow reversal due to vaporization and the time of liquid impingement at the pump in order to determine which of the two kinds of surges to compute. Details of the computation of these pressure surges and a computer listing of program VOS are given in Supplement A (1974). The derivation of the pressure surge correlation is given in Appendix B.

\subsubsection{Input Data Entries}

Section 2.3 describes the general log-in procedure for the graphic display system. After the initial log-in has been accomplished and the Option 2 has been selected, first a display similar to figure 6 appears and after ALT mode is depressed figure 7 will appear. If desired, input variables may be examined and changed in the display as explained in Section 2. 4. The variables in figure 6 and 7 apply only to Option 2 and are in addition to those of the general input data of figure 3. 


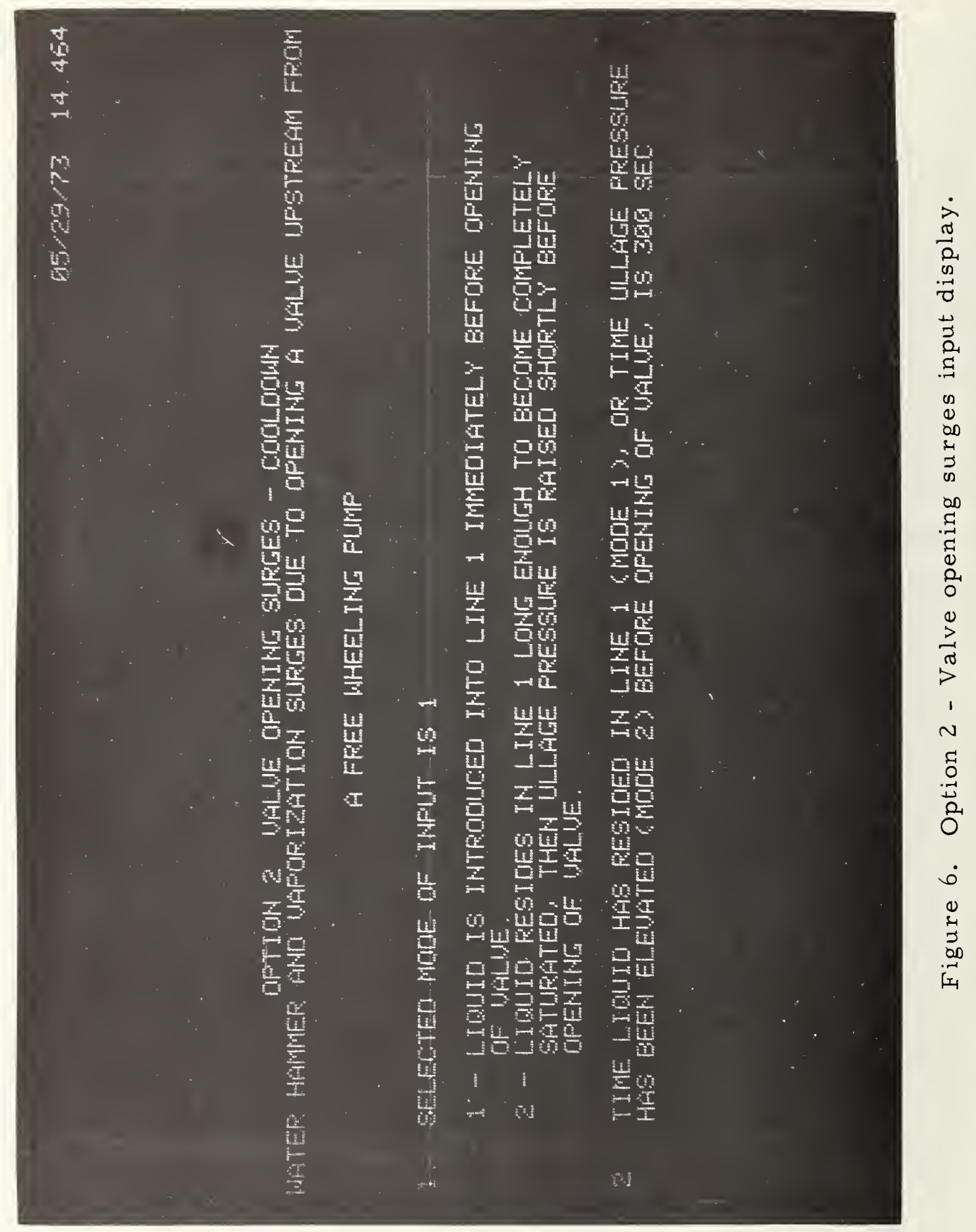


जै

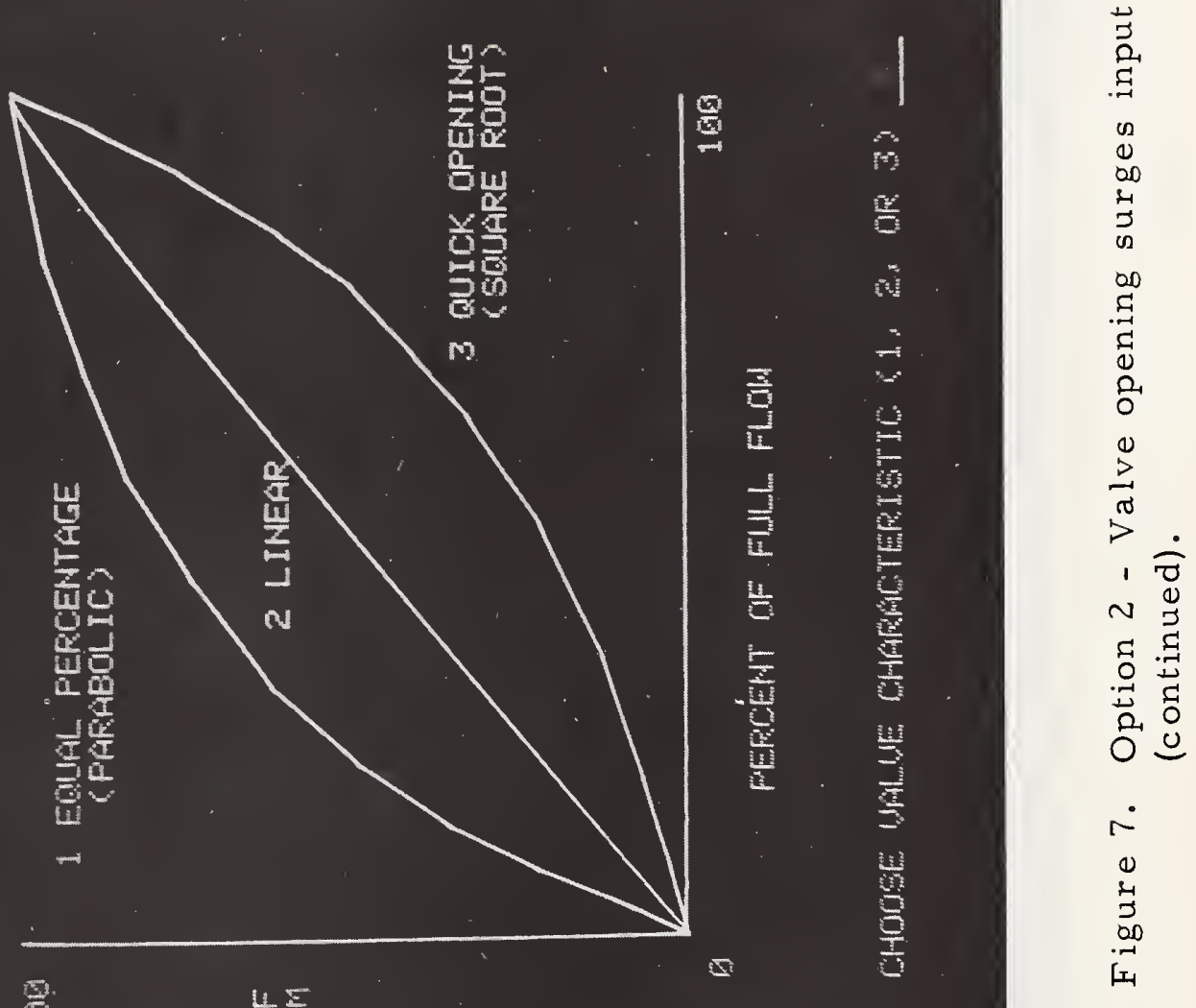




\subsubsection{Output}

The output of the computation is a graph of peak surge pressure as a function of valve opening time. A typical example is shown in figure 8. As the valve opening time is shortened, the peaks increase to a maximum amplitude at a critical value of the opening time, as discussed in Appendix B. Further decrease in the opening time has no effect on the peaks. The maximum pressure and corresponding critical opening time are indicated in the graph. If the water hammer surge is applicable, no graph is displayed, but a single amplitude of the pressure spike is given. 


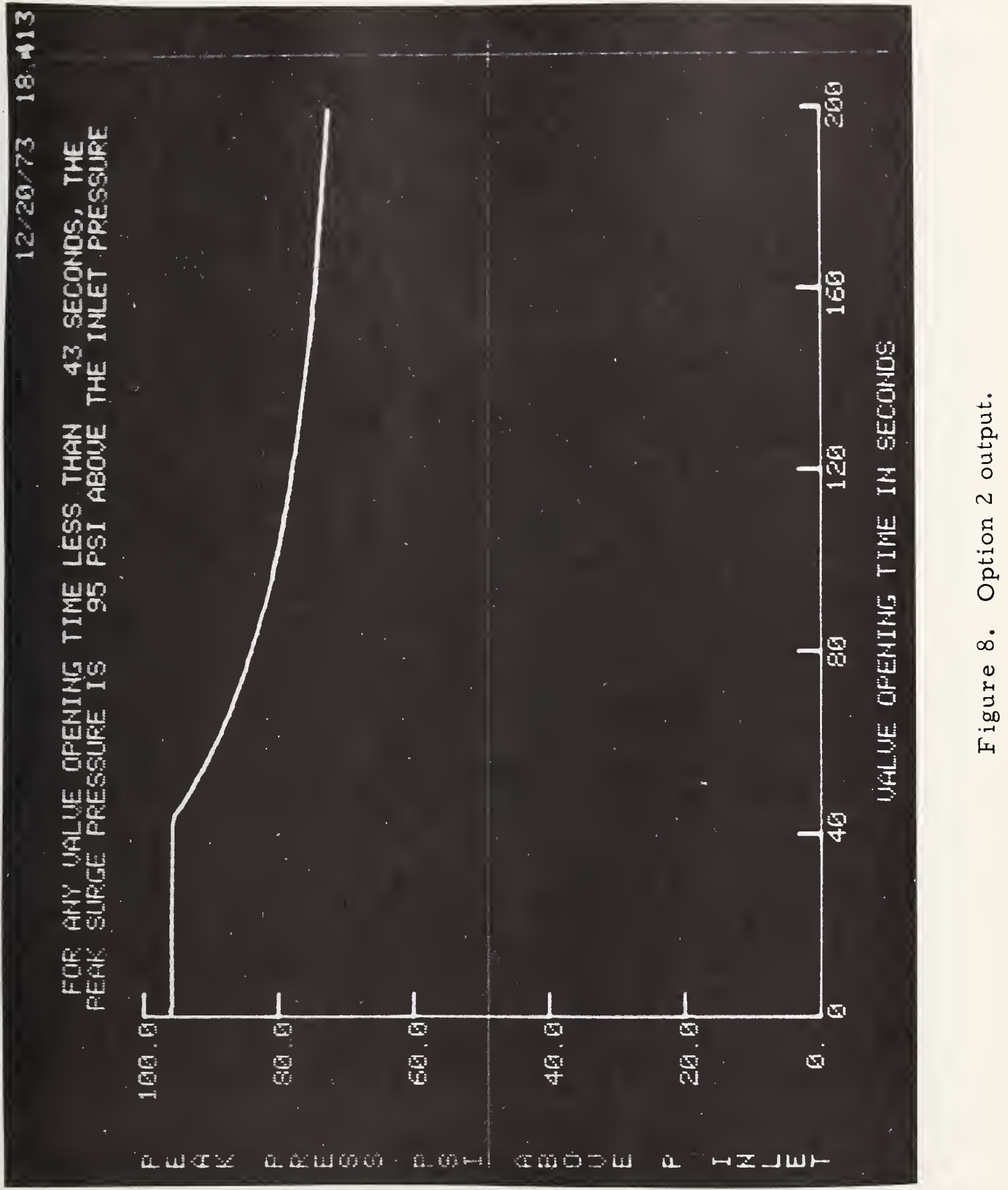


3. 3 Option 3 - Cooldown Time - length cooled down, flow rate, and pressure drop across the pump versus time.

\subsubsection{Application}

As a cryogenic liquid flows or is pumped from a reservoir into a warm pipeline, vapor forms at the leading end of the liquid stream. Frictional resistance to the flow of this vapor is the principle limiting factor in the rate of cooling pipelines of large length-to-diameter ratios. The slow moving liquid is evaporated and vapor is warmed to near the initial temperature of the pipe in a short distance relative to the length of pipe. When the pipeline is uninsulated, the heat transfer to the cold part of the pipe adds to the vaporization rate and thus further retards the progress of the liquid. The cooldown model based on this cold front concept and listing of the computer subroutine (CDT) are discussed in Supplement A (1974). The heat-mass transfer correlations are discussed in Appendix A.

\section{3.2 Input Data Entries}

Section 2. 3 describes the $\log$-in procedure for the graphic display system. After the initial log-in has been accomplished and option 3 "Cooldown Time" has been selected, a display similar to Figure 9 appears. If desired, input variables pertinent to the cooldown time computation may be viewed and changed on this display as explained in Section 2. 4. The variables in figure 9 apply only to Option 3 and are in addition to those of the general input data of figure 3. As discussed in Section 2.4, if equivalent pipe lengths have been added to account for line restrictions, the pipe wall thickness should be decreased correspondingly such that the total mass of material remains unchanged. Concentrated masses such as valves, pumps, and fittings should be compensated for by specifying additional pipe wall thickness provided the calculated cooldown time desired is to include the time needed to completely cool these concentrated masses. 


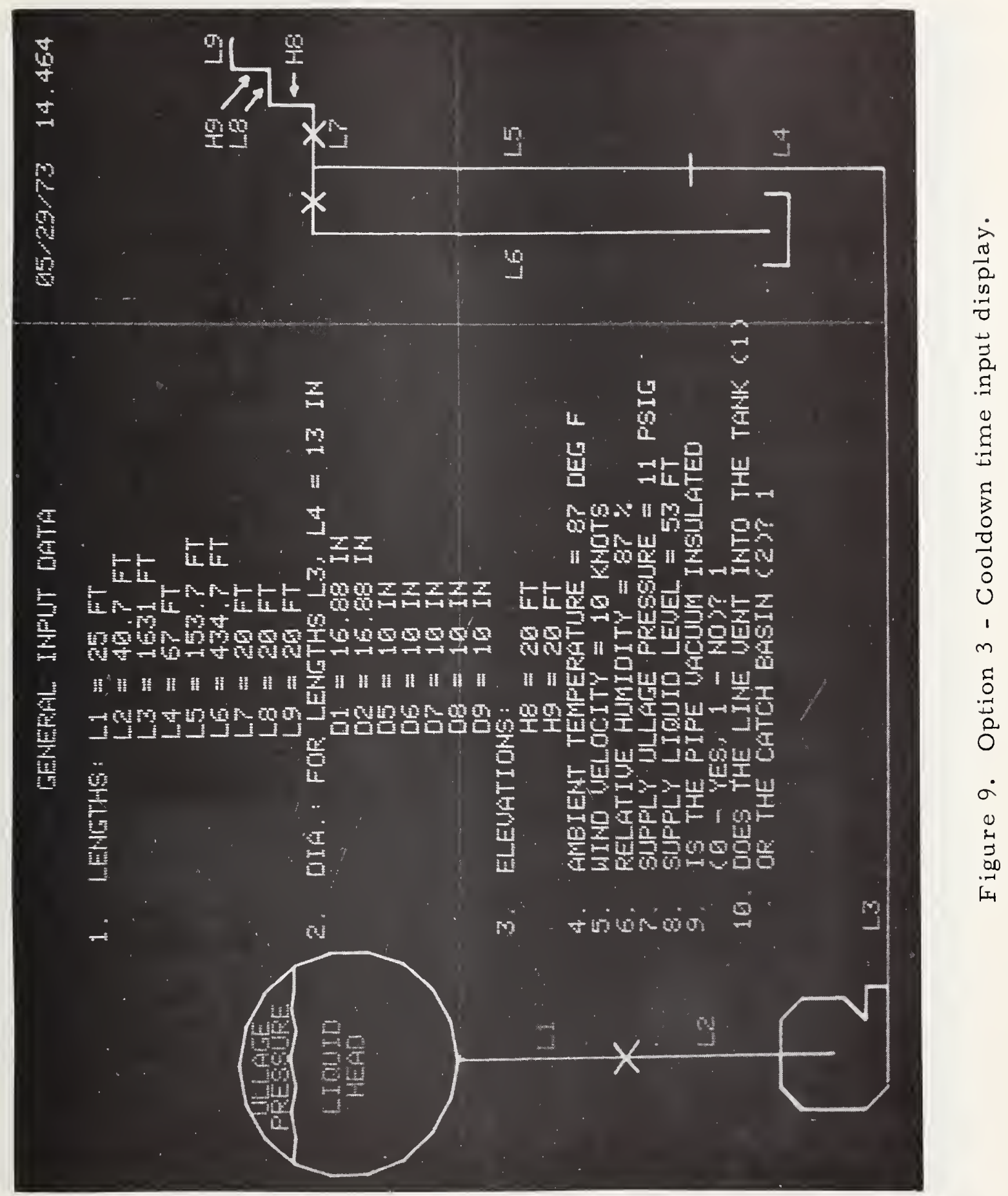




\section{3 .3 Output}

The outputs of the computation are: (1) Length Cooled Down versus

Time, (2) Flow Rate of LOX versus Time, and (3) Pressure Drop across the Pump versus Time. Typical examples are shown in figures 10, 11 , and 12. 


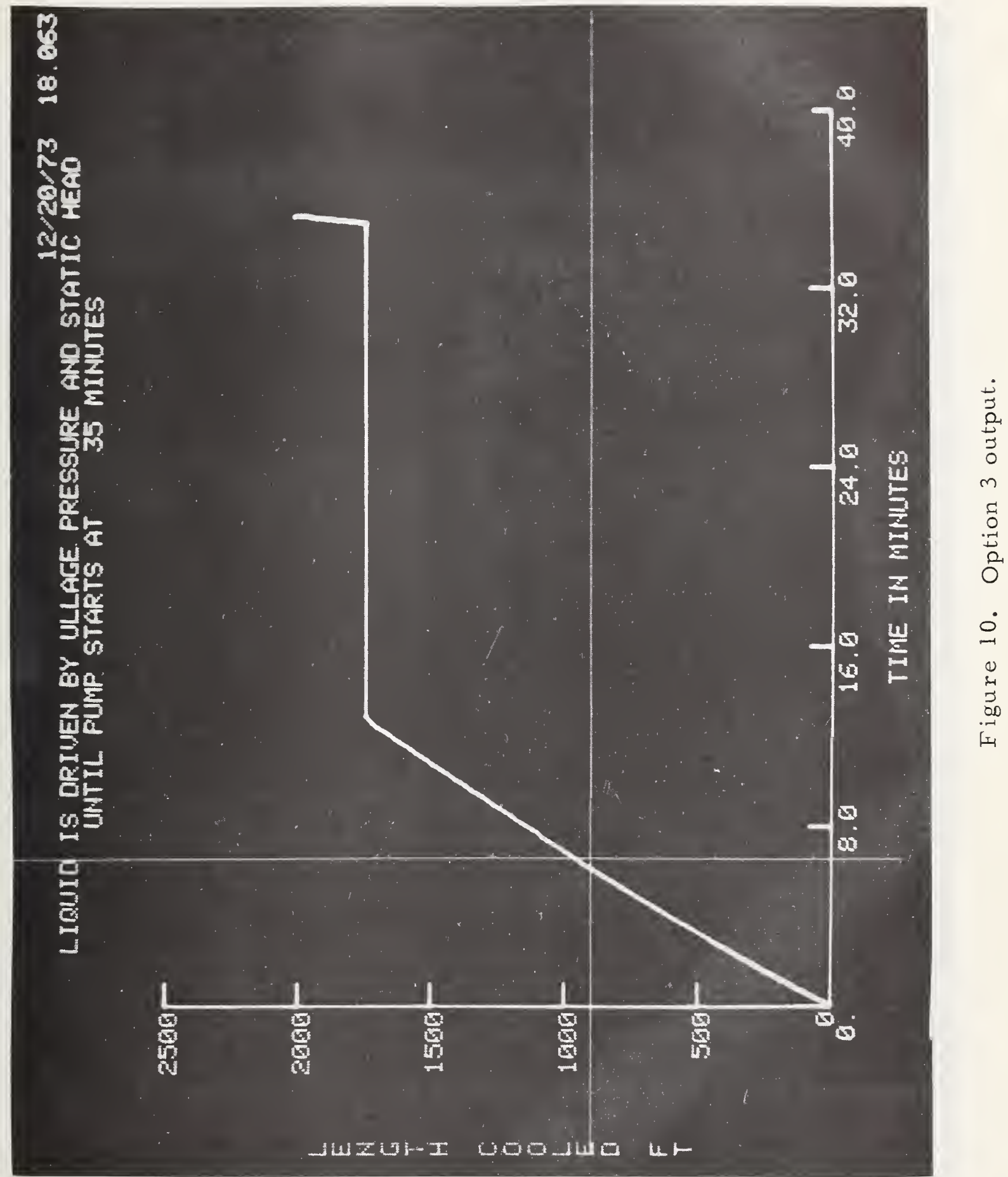




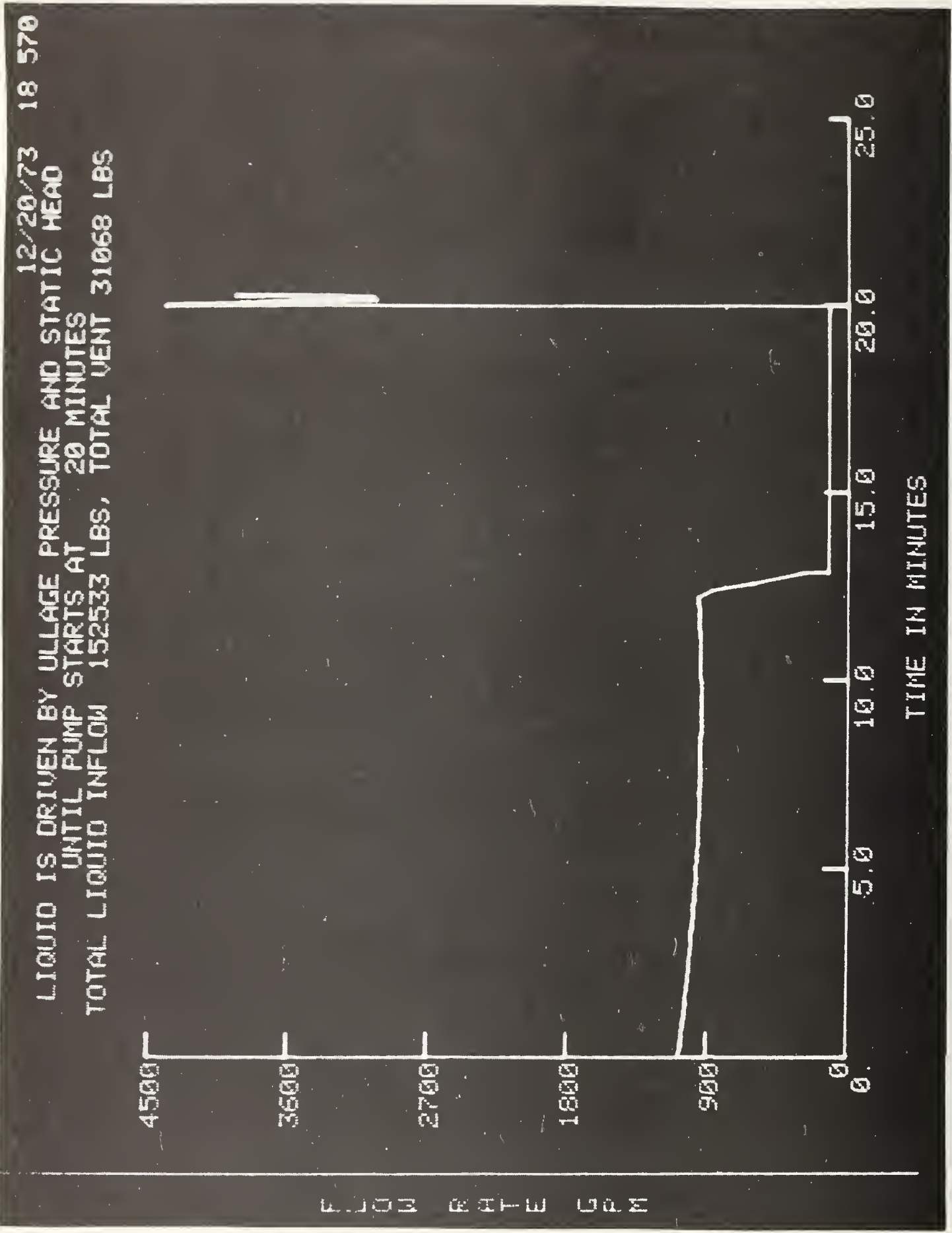

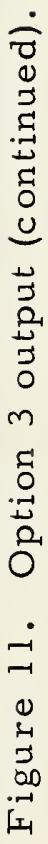




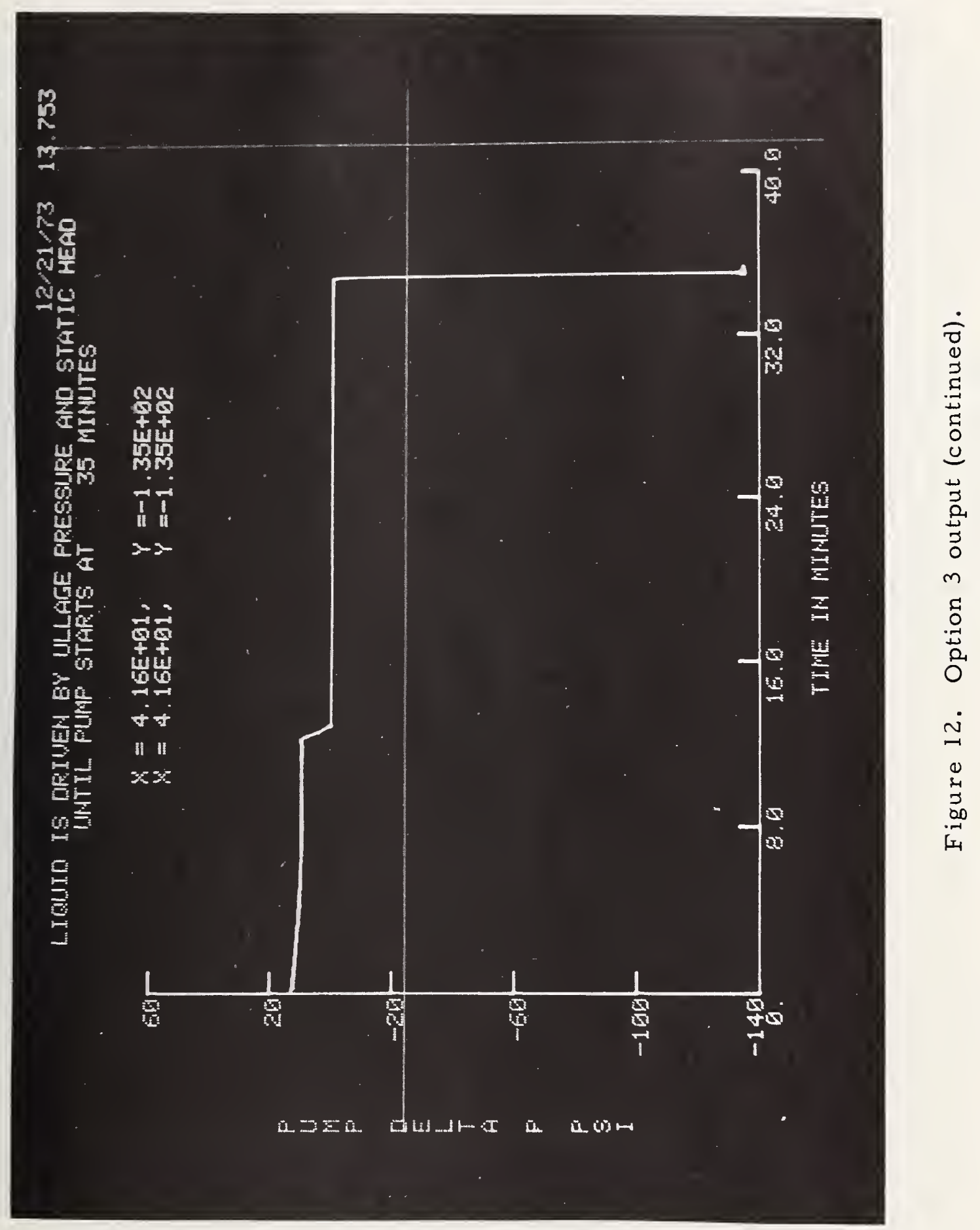


3.4 Option 4 - Pump Start-up Cooldown Surges - surges due to rapid vaporization when a pump is started upstream from a warm line.

\subsubsection{Application}

The computation applies to the starting of a pump in a line which is partially or totally warm. By the correlation discussed in Appendix B it computes pressure surges due to rapid vaporization when liquid enters a warm line.

\subsubsection{Input Data Entries}

Section 2.3 describes the general log-in procedure for the graphic display system. After the initial log-in has been accomplished and the Option 4 has been selected, a display similar to figure 13 appears. If desired, the input variables may be examined and changed in the display as explained in Section 2.4. Only two variables, length of cold line and final pump RPM , are shown in this display. The remaining values for this calculation were taken from the general input data of figure 3. 


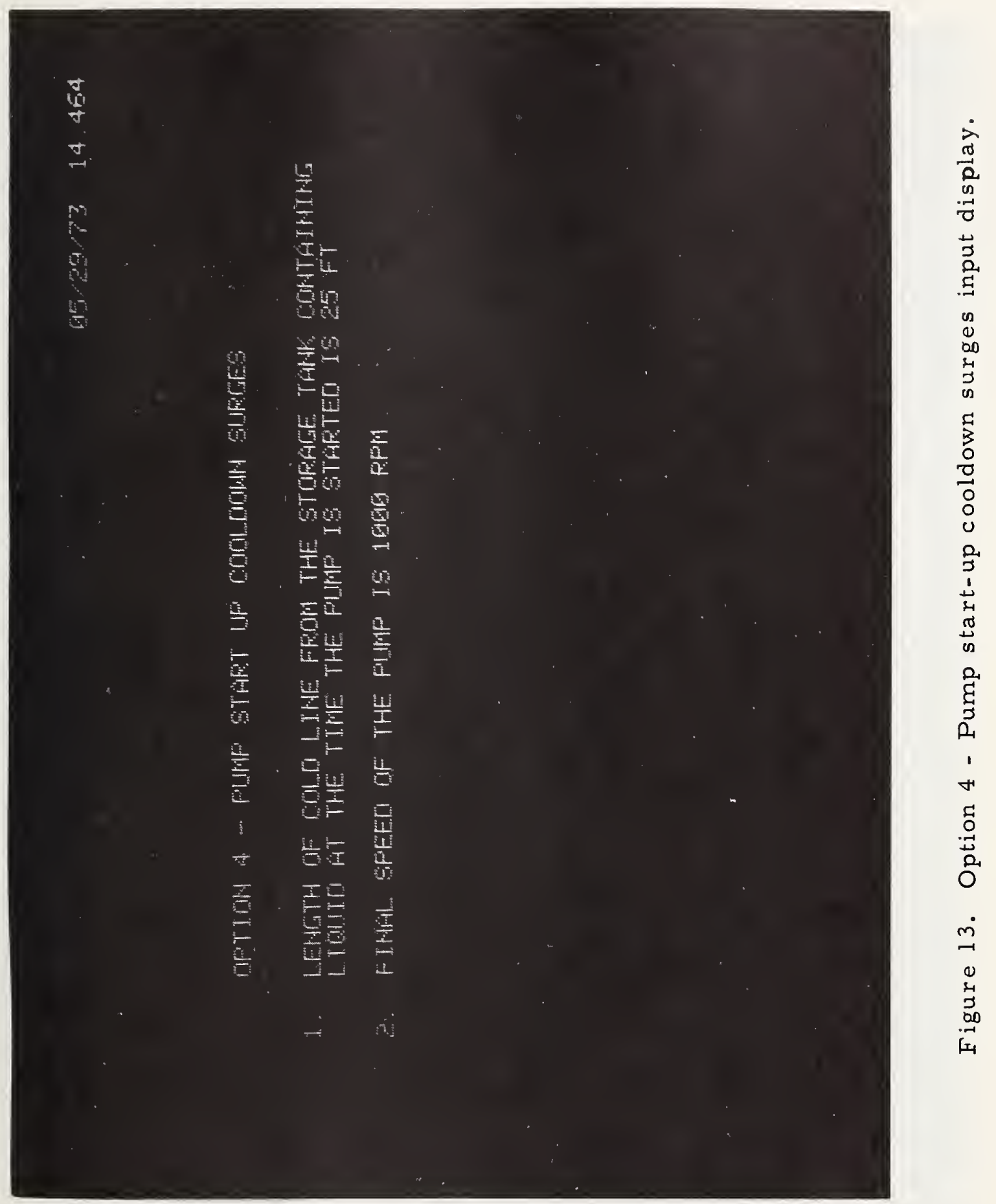




\subsubsection{Output}

The output of this computation is a graph of peak surge pressure as a function of pump start-up time. A typical example is shown in figure 14. As the pump start-up time (time to bring the pump from rest to operating speed) is shortened, the amplitude of the peaks increases until a maximum is reached at the critical value of the start-up time. Further decrease in the start-up time has no effect on the peak amplitude. The maximum pressure and corresponding critical pump start-up time are indicated in the output graph. 


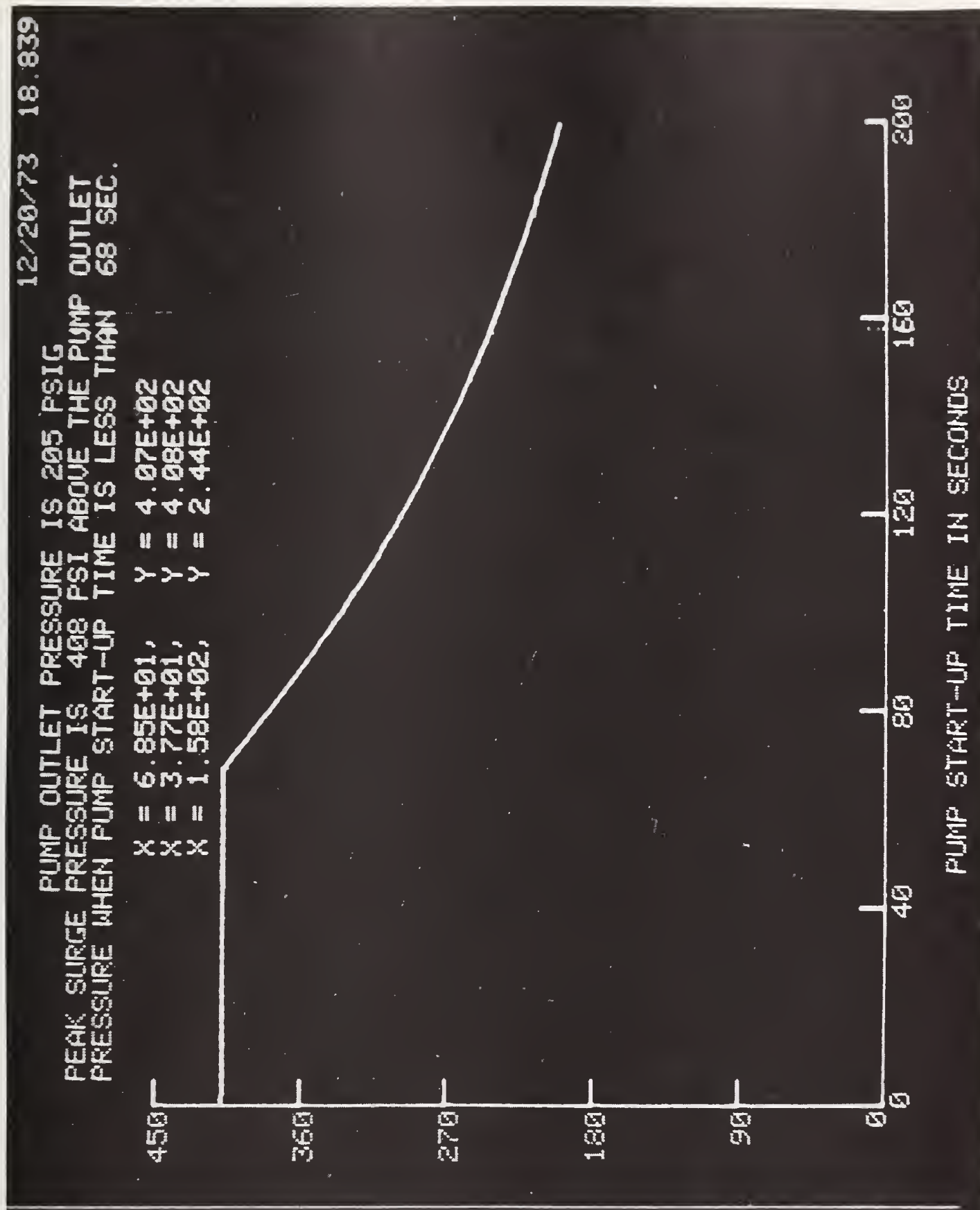

aW 


\section{Computation Options, Post-Cooldown Period}

4. 1 Option 5 - Water Hammer - pressure spikes due to water hammer when valves are closed in a flowing liquid stream.

\section{1. 1 Application}

This computation applies to the case in which a downstream valve is closed against a flowing liquid stream. Deceleration of the liquid due to impingement in the closing valve can lead to a sudden large pressure spike. The amplitude of the pressure spike is a function of the valve closing time. Details of the computation and computer listing are given in Supplement A (1974).

\section{1.2 Input Data Entries}

Section 2. 3 describes the general log-in procedure by which the Option 5 is selected. After this selection has been made, a display similar to figures 15 and 16 will appear in sequence. In the display, if desired, the input variables may be examined and changed by the procedure explained in Section 2. 4. 


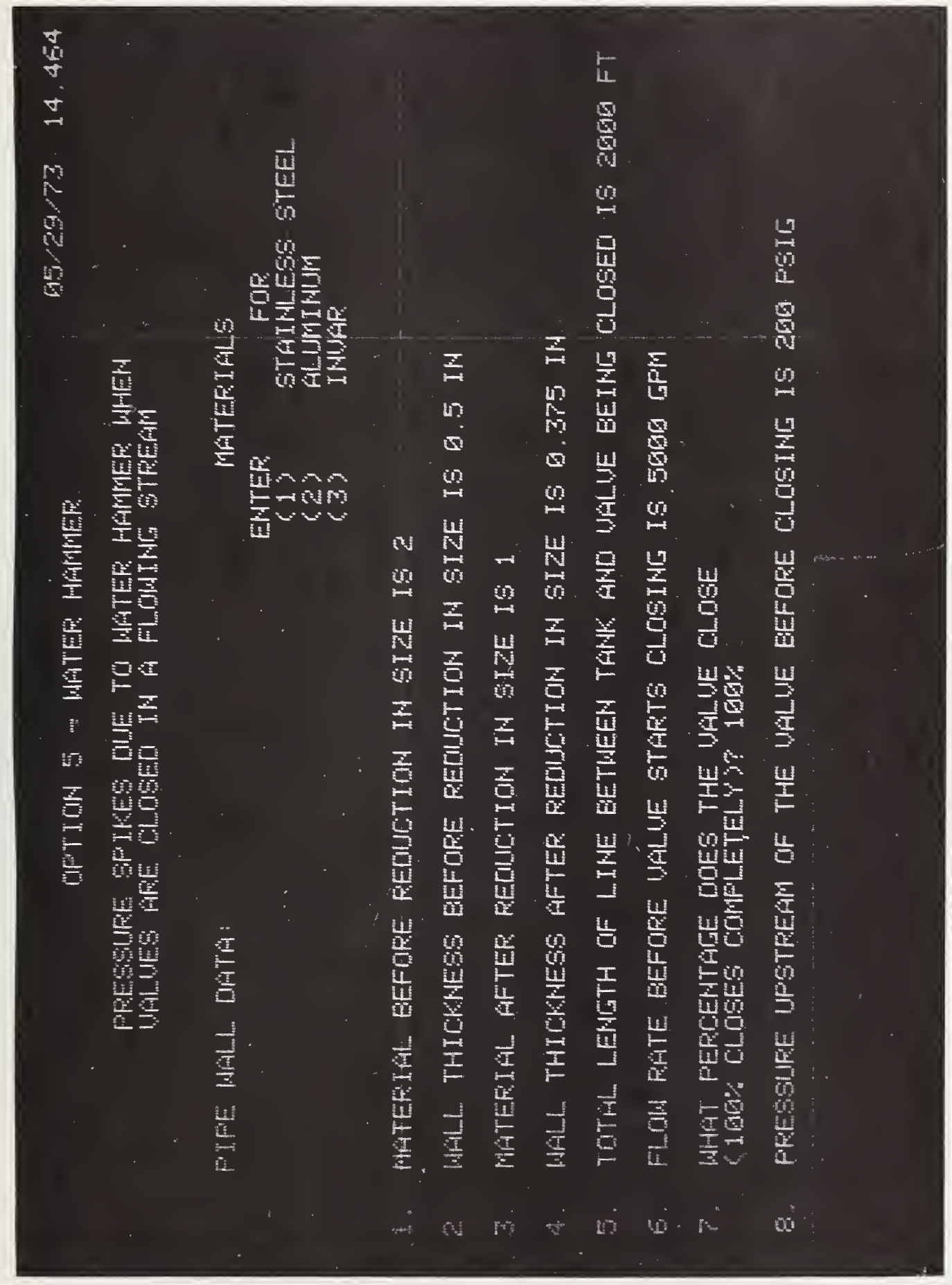

त) 
बิ

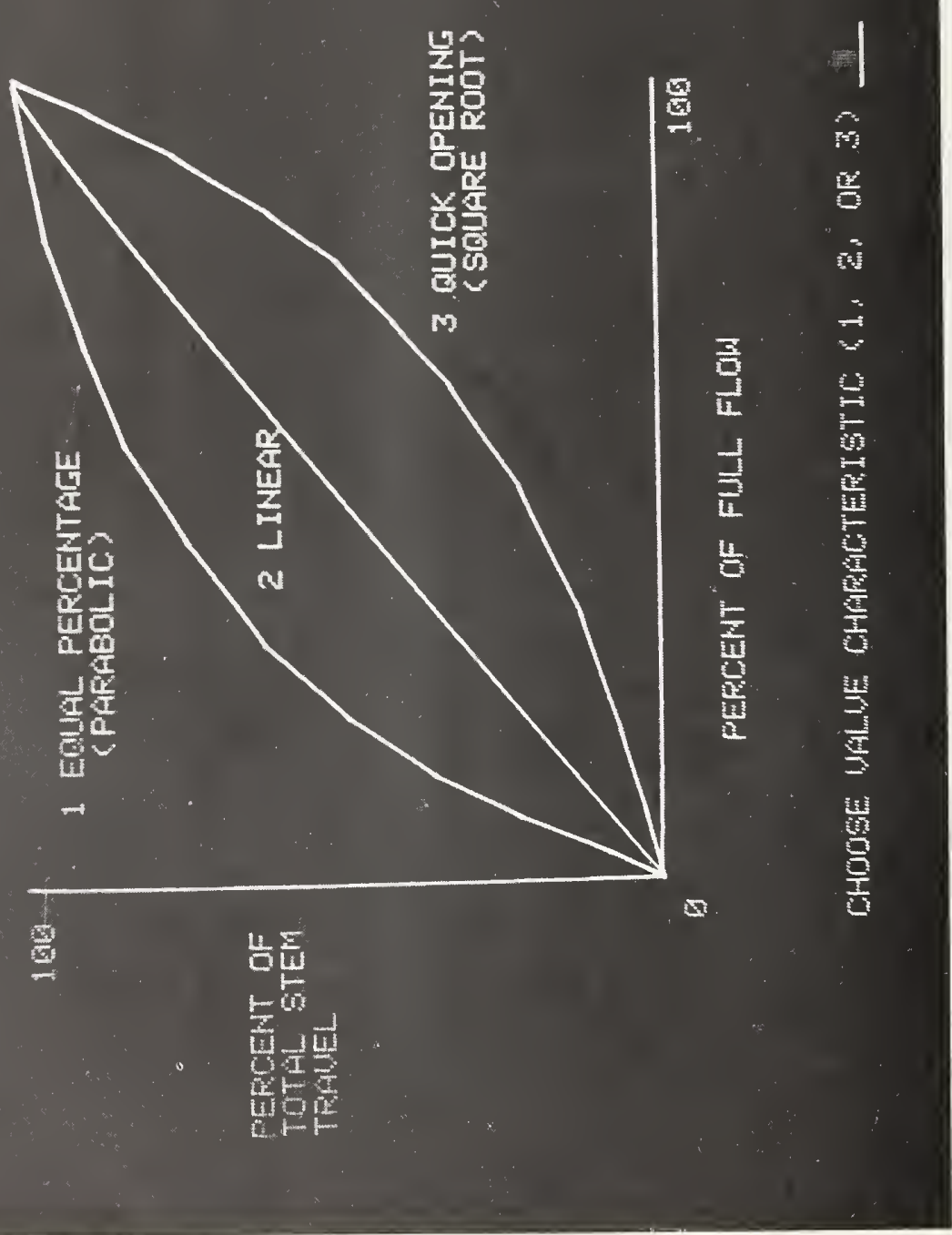

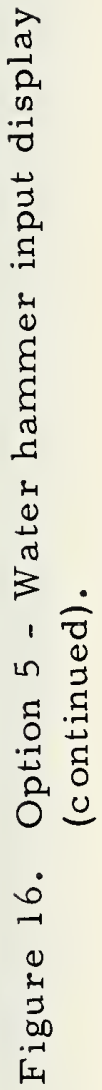




\section{1.3 Output}

Typical graphs of the amplitude of water hammer pressure spikes as a function of the valve closing time is shown in figure 17. 


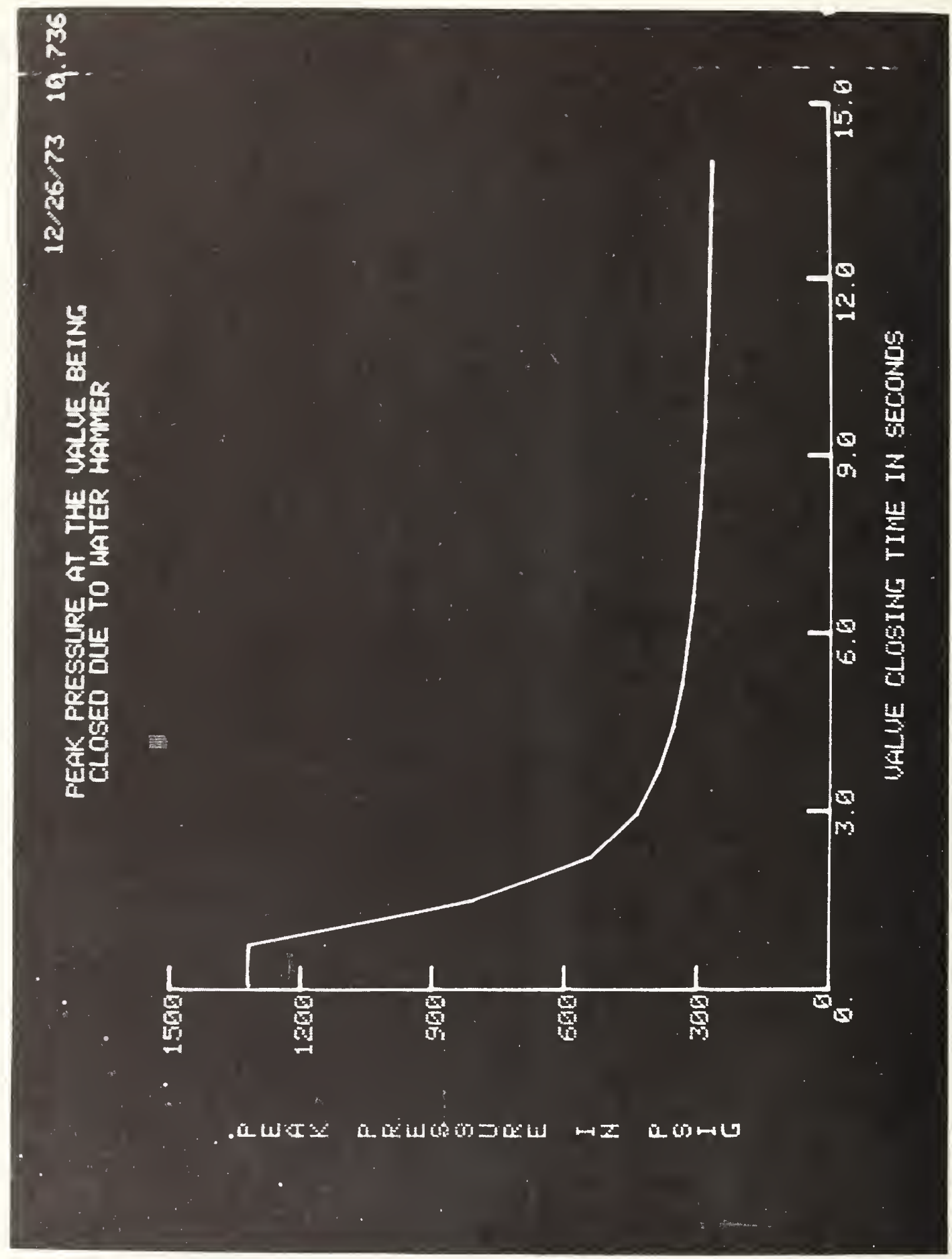

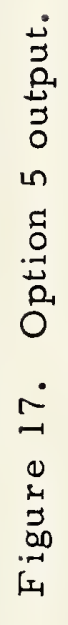


4. 2 Option 6 - Cold Flow. Steady flow operation and transient response to changes in operating conditions.

\subsubsection{Application}

This computation applies after the transfer line has reached operating temperature. It deals with response to changes in operating conditions but does not deal with cooldown transients. The latter are treated separately in Section 3. The flow rate and liquid discharge temperature (or two phase quality) are calculated as functions of the pump speed, ambient air conditions, valve settings, and pipe geometry. The accumulated liquid, change in supply liquid level, and pump discharge pressure are also computed. Pump speed and valve settings are allowed to vary with time. Details of the computation and computer program listing are given in Supplement A (1974).

\subsubsection{Input Data Entries}

Section 2. 3 describes the general $\log$-in procedure for the graphic display system. After the Option 5 is selected, a display similar to figure 18 and 19 will appear. If desired, input variables may be examined and changed in the display by the procedure explained in Section 2. 4 except in the table of numbers showing time, valve opening, and pump speed, where the vertical and horizontal cursors must be positioned before depressing the space bar.

Entry 1 allows a supply ullage pressure during transfer to be selected which may or may not be different from the ullage pressure during storage. (The storage pressure is taken as that pressure which was selected previously under General Input Data.) Entry 1 along with entry 2 relates to the subcooling of the inlet liquid. This subcooling enters into the calculation of discharge liquid temperature, or fraction of vapor being discharged. Entry 4 allows for the selection of a schedule 
of changes in operating conditions. That is, the pump RPM or the discharge valve setting may be specified at six times. RPM and valve setting change linearly from one specified time to the next. The program carries out the computation to ten seconds beyond the last entry in the schedule.

The third entry under Cold Flow allows the selection of computed quantities to be displayed. The desired quantities are selected as numbers 1 through 6. Striking ALT MODE initiates the calculation, and the next display is the selected output graph. 


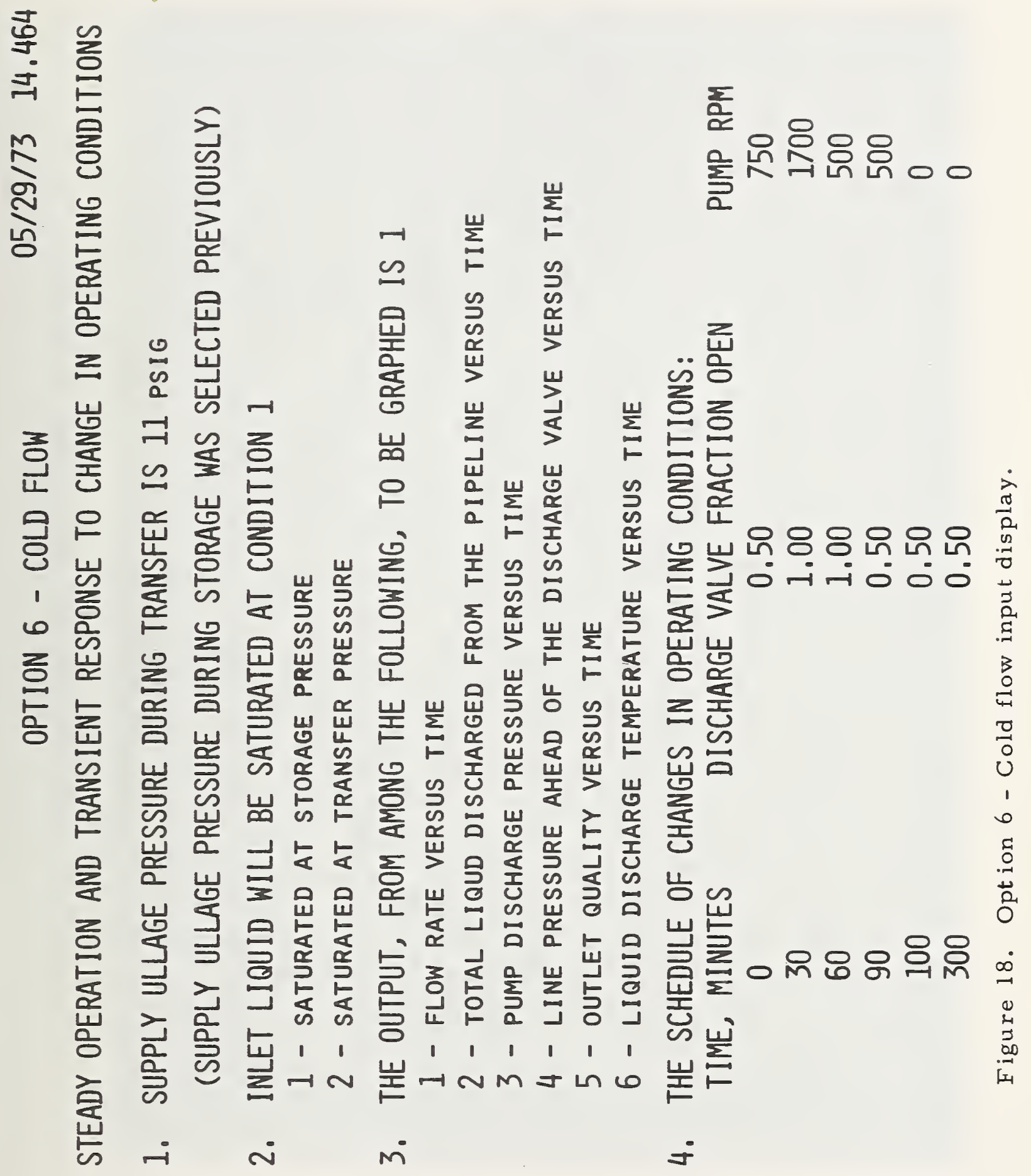


ำ

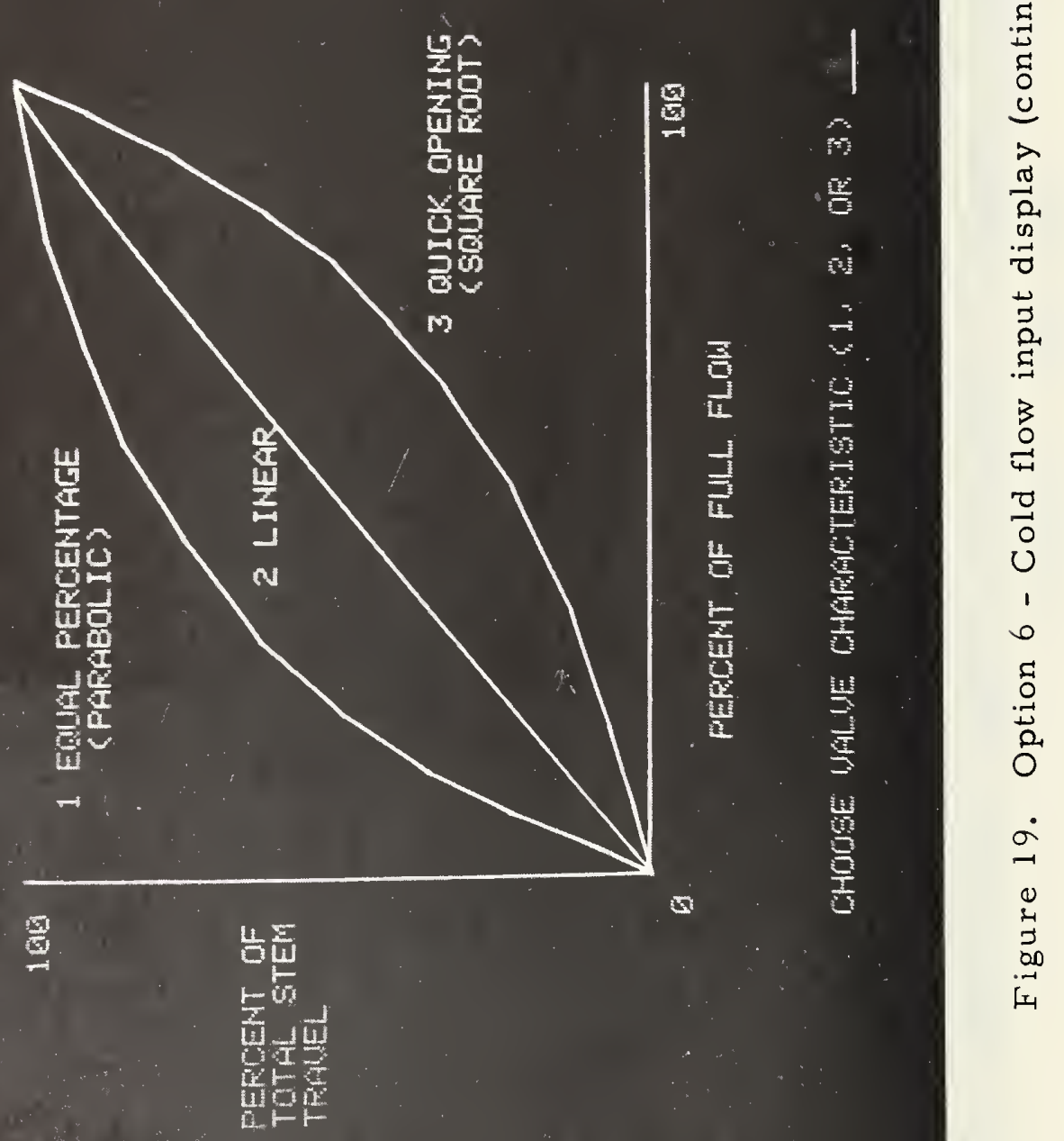




\subsection{Output}

Typical output graphs are shown in Figures 20 through 25. The following variables may be plotted as functions of time:

Fig. 20. Flow rate

Fig. 21. Total accumulated liquid discharged into the receiver after subtracting off the quantity vaporized

Fig. 22. Pump discharge pressure

Fig. 23. The line pressure ahead of the discharge valve

Fig. 24. Final vapor fraction

Fig. 25. Fluid discharge temperature . 


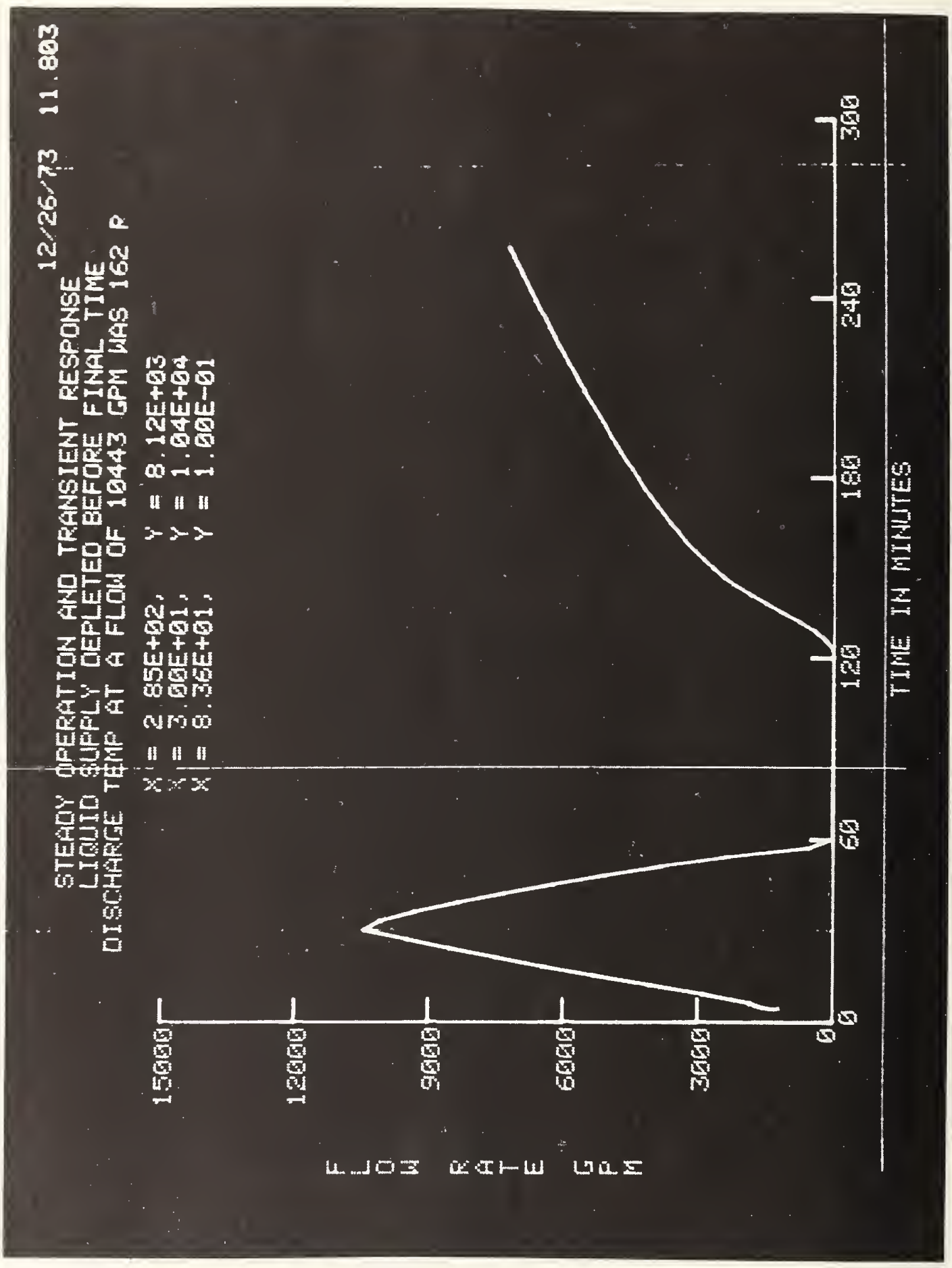

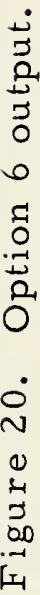




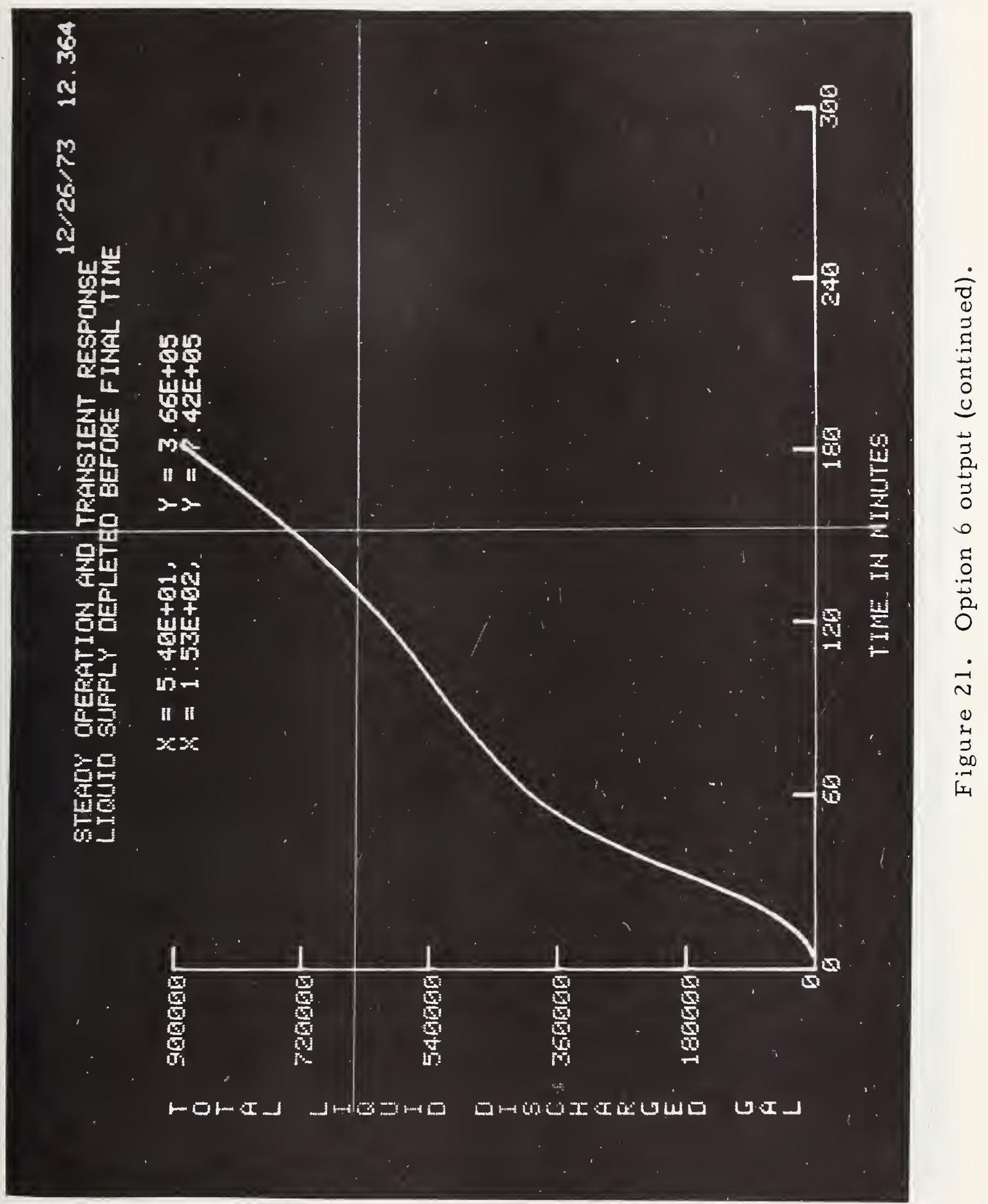




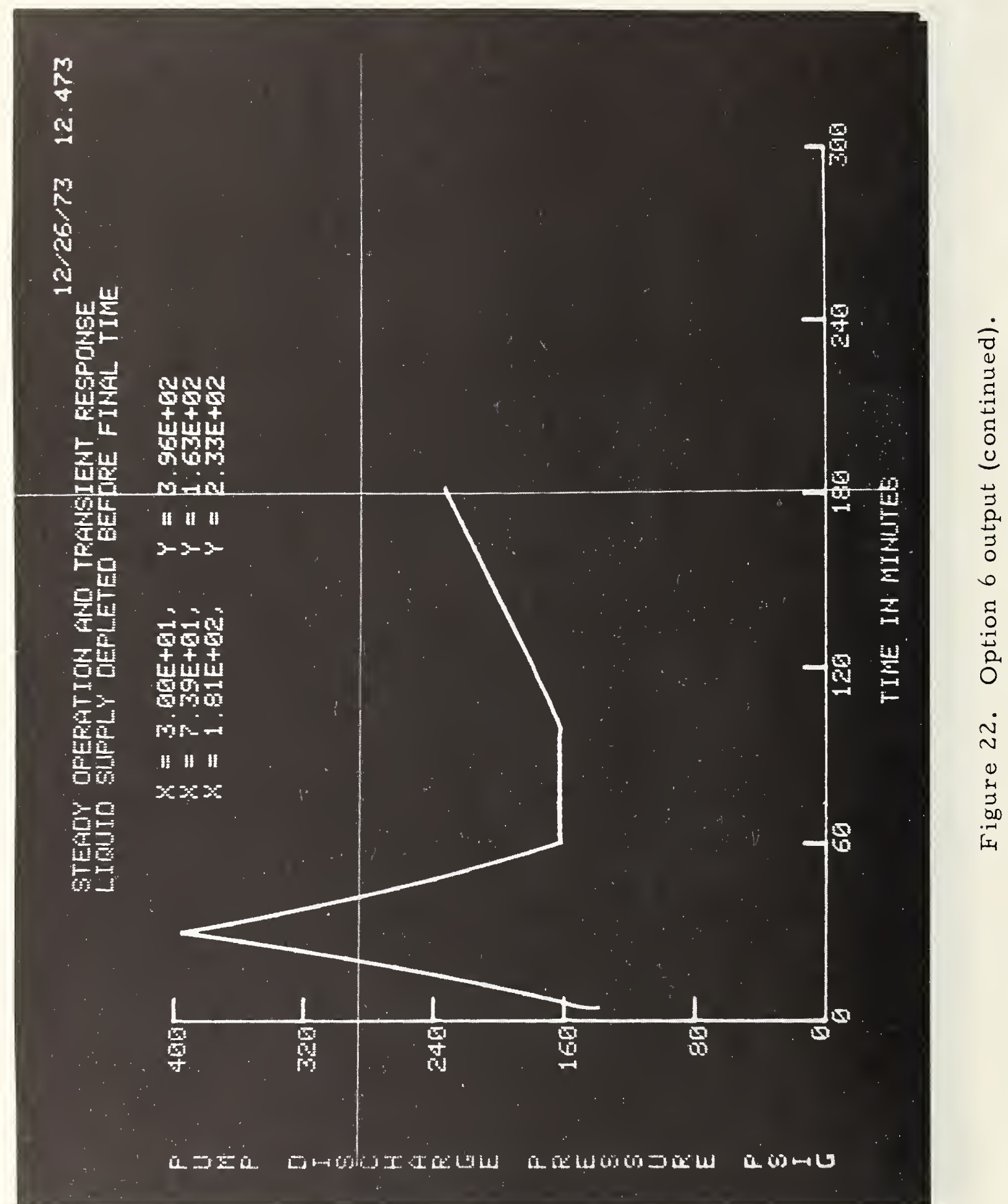




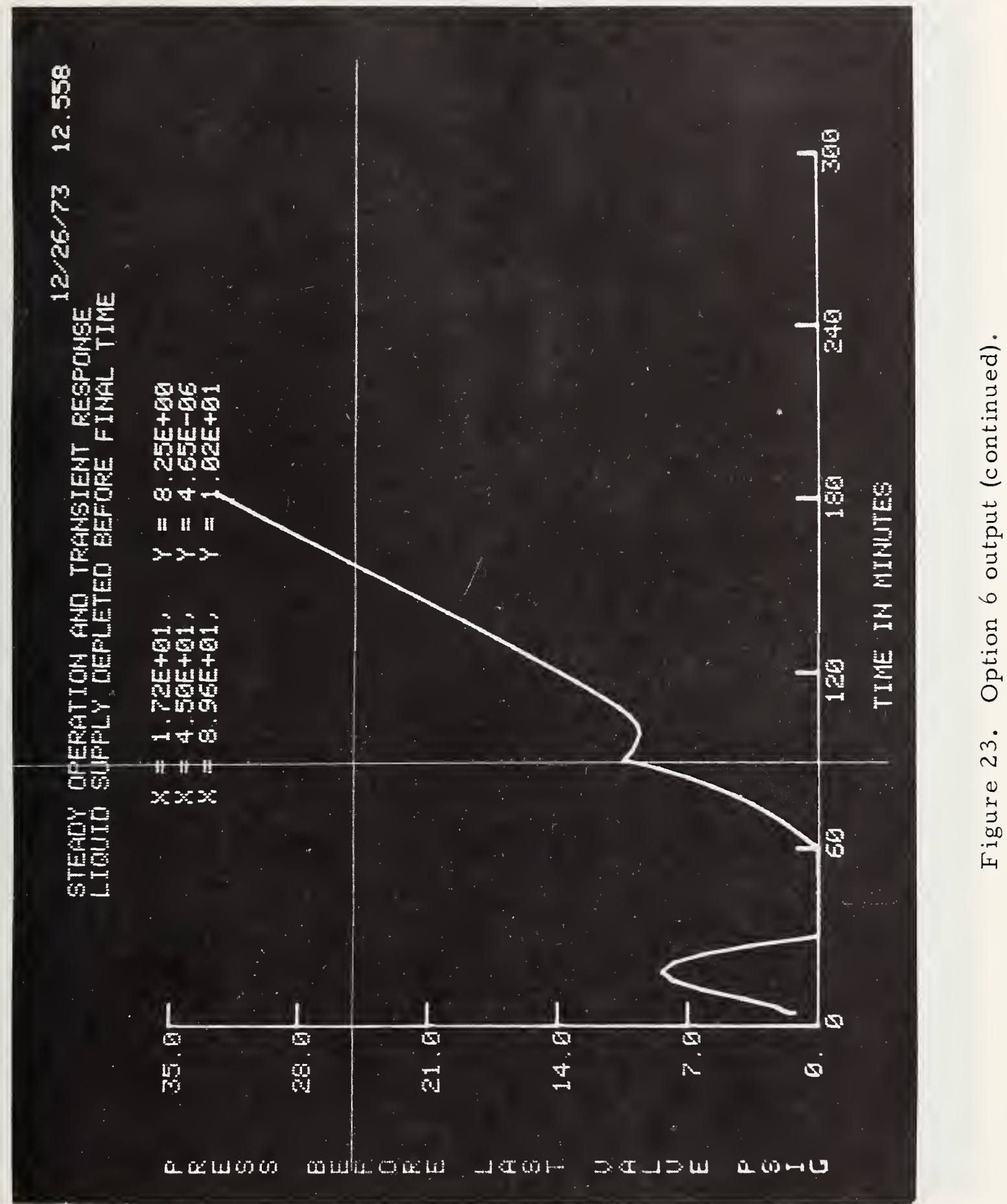




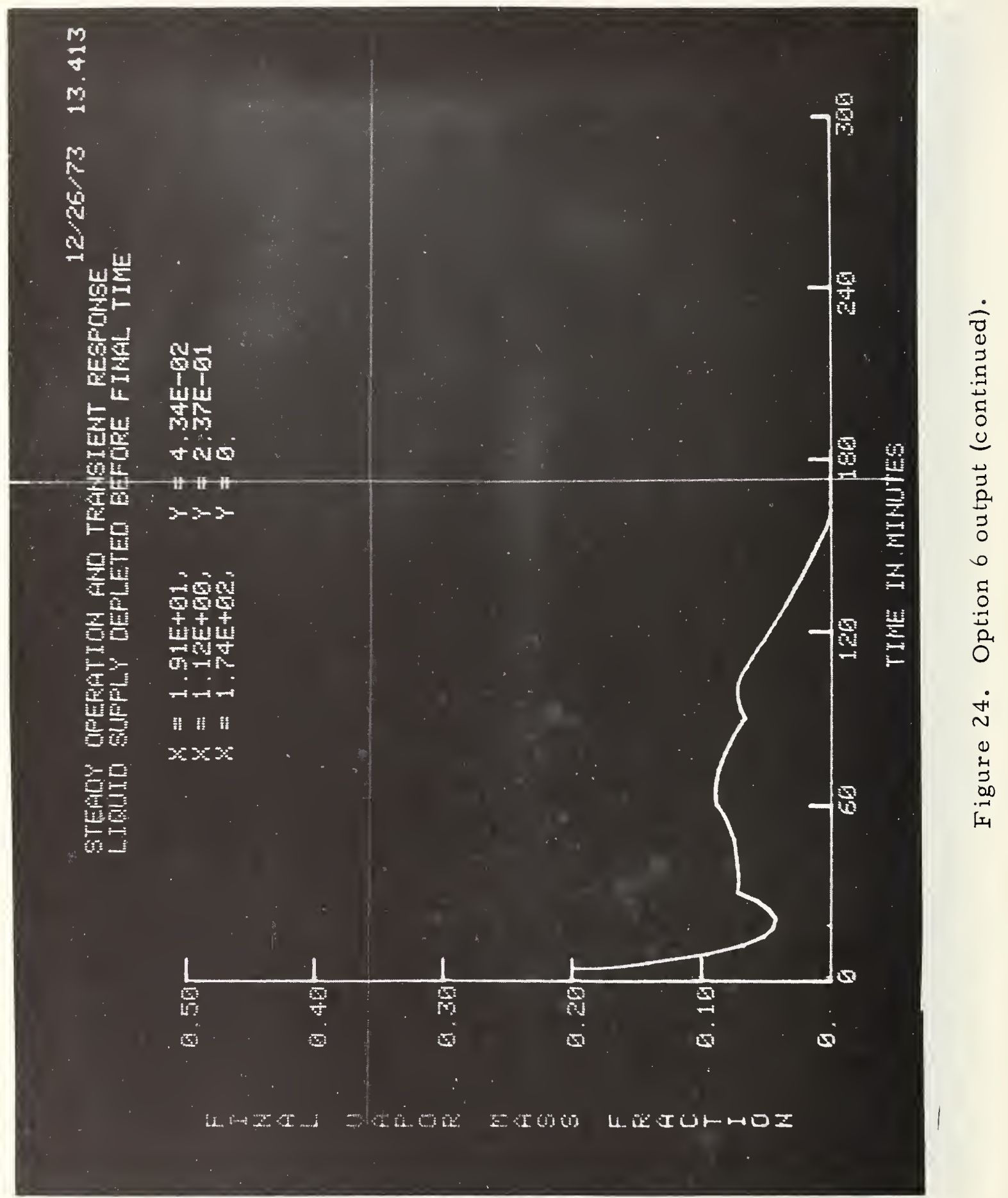




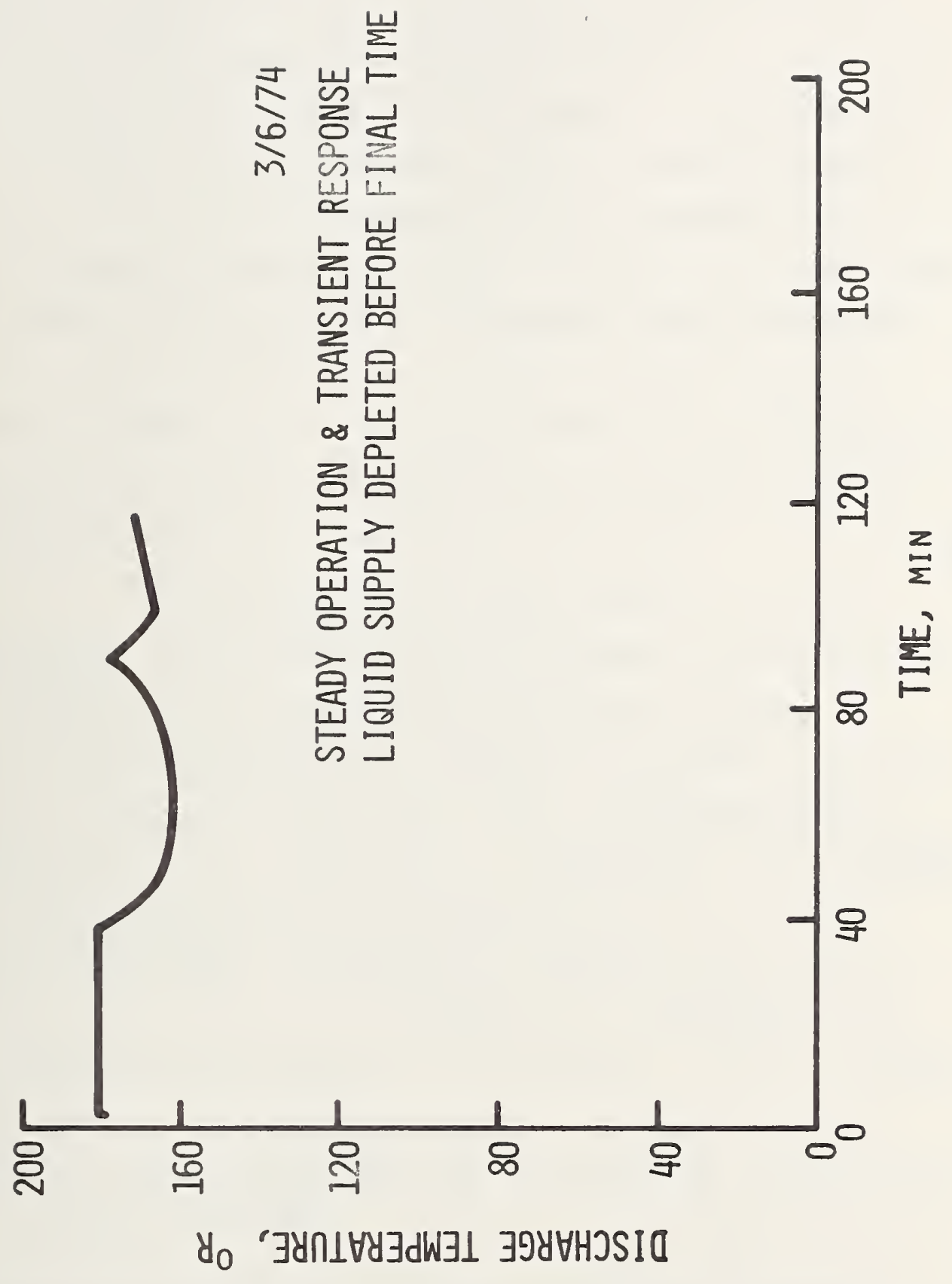




\section{General References}

Brentari, E. G., Giarratano, P. J., and Smith, R. V., Boiling Heat Transfer for Oxygen, Nitrogen, Hydrogen, and Helium, Nat. Bur. Stand. (U.S.), Tech. Note 317 (September 1965). Holten, D. C. , A study of heat and mass transfer to uninsulated liquid oxygen containers, Book, Advances in Cryogenic Engineering 6, Ed. K. D. Timmerhaus, pp. 499-508 (Plenum Press, New York, N. Y., 1961).

Lange, N. A., and Forker, G. M. Handbook of Chemistry, Tenth Edition (McGraw-Hill Book Company, Inc., New York, Toronto, London, 1961).

McAdams, W. H., Heat Transmission, Second Edition (McGrawHill Book Company, Inc., New York, Toronto, London, 1942). Novak, J. K. , Cooldown flow rate limits imposed by thermal stresses in liquid hydrogen or nitrogen pipelines, Book, Advances in Cryogenic Engineering 15, Ed. K. D. Timmerhaus, pp. $346-353$ (Plenum Press, New York, N. Y., 1970).

Rich, G. R., Hydraulic Transients, Second Edition, pp. 1-73 (Dover Publications, Inc., New York, N. Y., 1961).

Richards, R. J., Edmonds, K., and Jacobs, R. B., Heat Transfer Between A Cryo-Surface and a Controlled Atmosphere, International Institute of Refrigeration, Commissions 2, 3, 4, 6a, Washington, D. C. (1962).

Rohsenow, W. M., and Choi, H., Heat Mass and Momentum Transfer (Prentice-Hall, Inc., Englewood Cliffs, New Jersey, 1961). Ruccia, F. E., and Mohr, C. M., Atmospheric heat transfer to vertical tanks filled with liquid oxygen, Book, Advances in Cryogenic Engineering 4, Ed. K. D. Timmerhaus, pp. 307-318 (Plenum Press, New York, N. Y., 1960). 


\section{General References (Continued)}

Salisbury, K. J., Kent's Mechanical Engineers Handbook, pp. 5-17,

18 (John Wiley and Sons, Inc., New York, N. Y., 1950).

Steward, W. G., Transfer line surge, Book, Advances in Cryogenic

Engineering 10, Ed. K. D. Timmerhaus, pp. 313-322,

(Plenum Press, New York, N. Y., 1965).

Steward, W. G., Smith, R. V., and Brennan, J. A., Cooldown time

for simple cryogenic pipelines. Developments in Mechanics,

Proc. of the 10th Midwestern Mechanics Conference, pp. 1513-

1525 (Johnson Publishing Company, Boulder, Colorado, 1968).

Steward, W. G., Transient Flow of Cryogenic Fluids, Ph. D. Dissertation, Colorado State University (1968).

Voth, R. O., Cooldown pressure surges (Part II of unpublished NBS

Report: Ludtke, P. R., and Voth, R. O., A Study of LC-39

Cryogenic Systems - Final Report, 1971).

\section{1. System Reference Manuals *}

General Electric, DATANET-760, Programmers Reference Manual,

General Electric Information Systems Division (1967).

General Electric, DATANET-760, Keyboard/Display Subsystem

Manual, General Electric Information Systems Division (1969).

Honeywe11, GECOS III, Time-Sharing Fortran, Honeywell Information

Systems Inc., Doc. No. CPB-1566B (1971).

Honeywell, GECOS III, Time-Sharing General Information Manual,

Honeywell Information Systems Inc., Doc. No. CPB-1643A

(1971).

Supplement A. Oxygen Loading Simulation Computer Programs (1974). Available on request.

* Identification of a manufacturer and a manufacturer's product has been necessary to make the results of this work meaningful and in no way implies a recommendation or endorsement by the National Bureau of Standards. 
Appendix A. Heat-Mass Transfer Correlations for Uninsulated LOX Transfer Lines

Expressions for heat flux from the atmosphere to uninsulated LOX lines are needed for estimations of fluid enthalpy rise along the line. This enthalpy rise in turn determines whether the fluid being discharged is subcooled or is saturated and partly vaporized. A second application is in the computation of cooldown time. During cooldown the heat from the atmosphere adds to the vaporization rate due to cooling of the pipe walls and thus lengthens the cooldown time.

After the pipeline has cooled down to a stable operating temperature, the resistance to heat transfer is primarily in the outside film that is, between the pipe wall and the ambient air. The heat flux then depends on the ambient air conditions and the build-up of frost on the transfer line. A minimum heat flux of about $0.076 \mathrm{~W} / \mathrm{cm}^{2}\left(240 \mathrm{BTU} / \mathrm{hr} \mathrm{ft}^{2}\right)$ is expected in still dry air after the maximum thickness of insulating frost is established. Heat flux under the worst conditions should be less than $0.95 \mathrm{~W} / \mathrm{cm}^{2}\left(3000 \mathrm{BTU} / \mathrm{hr} \mathrm{ft}{ }^{2}\right)$. These values lie within the nucleate boiling range for liquid oxygen (Brentari, et al. [1965]) the refore, film boilir with its large wall-to-LOX temperature differences, should not be necessary to consider.

The heat flux after steady state is reached depends on the frost thickness and surface temperature. These factors are at least partially self-regulating in that the frost tends to build up to a stable thickness then begin to slough off. A frost surface temperature drop causes additional frost thickness to build up, increases the insulating effect, and thus re-establishes the higher frost surface temperature. This regulation is imperfect, however, and determination of this frost surface temperature is probably the most questionable factor in the heat flux prediction. The value of frost surface temperature calculated by Holten [1961] 
and measured by Richards et al. [1962] for liquid nitrogen cooled surfaces -- corrected for the higher temperature of LOX -- was used in the present calculations and appears to give reasonable predictions judging by comparisons with the liquid nitrogen data of Richards et al. as well as Ruccia and Mohr's [1960] LOX data. Our method over-predicts Holten's LOX data by 20 to $30 \%$; however, the heat flux in those experiments may have been reduced from the freeair values by the partially sheltered placement of the test vessels. Holten's correlation fits his own data but underpredicts the other data. Heat flux occurring after cooldown, but before the frost has established a stable thickness, is considerably higher than the steady state values. This initial heat flux is predicted satisfactorily by assuming the surface temperature equal to the liquid saturation temperature. An empirical curve fitting was used to obtain the variation of heat flux with time between the initial and steady state values. Our developments of the correlations and comparisons with data are summarized in the following sections. A1. Mass Diffusion Heat Flux

In heat transfer to surfaces at cryogenic temperatures condensation of water vapor (or air) can along with convection and radiation, comprise a significant part of the total heat flux. Whe re condensation is present with forced convection, it is assumed that the convective effect is not altered by the mass transfer and the heat fluxes resulting from the two effects may be added. Radiation is the third component to be added.

The heat transfer effect of mass diffusion is due to the giving up of sensible heat and latent heats of vaporization and fusion by the water at the condensing surface. The mass diffusion heat flux is 


$$
(\mathrm{Q} / \mathrm{A})_{\text {dif }}=\dot{\mathrm{w}}\left(\mathrm{I}_{\mathrm{a}}-\mathrm{I}_{\mathrm{i}}\right)
$$

$\dot{\mathrm{w}} \quad=$ rate of condensation per unit area

I $\quad=$ enthalpy of the water vapor in the ambient air

$I_{i} \quad=$ enthalpy of the water in the condensed state

$\mathrm{I}_{\mathrm{a}}-\mathrm{I}_{\mathrm{i}} \cong 2990 \mathrm{~J} / \mathrm{g}(1287 \mathrm{BTU} / 1 \mathrm{~b})$.

In terms of the diffusion coefficient

$$
\dot{w}=h_{\text {dif }}\left(\frac{P_{\text {wa }}}{R T_{a}}-\frac{P_{\text {wi }}}{R T_{i}}\right)=h_{\text {dif }} \frac{P_{\text {wa }}}{R T_{a}}=h_{\text {dif }} H_{a}
$$

$\mathrm{h}_{\text {dif }}=$ mass diffusion coefficient

$\mathrm{P}_{\text {wa }} \quad$ partial pressure of water vapor in ambient air

$P_{\text {wi }} \quad$ partial pressure of water vapor at the condensing surface

$\mathrm{R} \quad=$ gas constant

$\mathrm{T}=$ temperature

$(P, R, T$ in consistent units)

$\mathrm{H} \quad$ = specific humidity

$\rho_{\mathrm{a}} \quad$ density of ambient air (due to the approximate nature of this calculation a standard value of $0.0012 \mathrm{~g} / \mathrm{cm}^{3}\left(0.075 \mathrm{lb} / \mathrm{ft}^{3}\right)$ was assumed).

The mass transfer of water vapor is treated through an empirical analogy between heat and mass transfer. The ChiltonColburn analogy (Rohsenow and Choi [1961])gives

or

$$
\frac{h_{\text {dif }}}{\mathrm{V}}\left(\mathrm{Sc}^{2 / 3}=\frac{\mathrm{h}^{2 / 3}}{\rho_{\mathrm{a}} \mathrm{C}_{\mathrm{pa}} \mathrm{V}}(\mathrm{Pr})^{2 / 3}\right.
$$

$$
h_{\text {dif }}=\frac{h}{\rho_{a} C_{p a}}\left(\frac{P r}{S c}\right)^{2 / 3}
$$


where $\mathrm{C}_{\mathrm{pa}}=$ specific heat of air at constant pressure

$\operatorname{Pr}=$ Prandtl number for air, $C_{p} \mu / K$

$=$ viscosity

$\mathrm{K}=$ thermal conductivity

Sc $=$ Schmidt number $=\mu / \rho D$

$\mathrm{D}=$ mass diffusivity

$\mathrm{V}=$ velocity .

From A1, A2, A3

$$
(\mathrm{Q} / \mathrm{A})_{\mathrm{dif}}=\frac{\mathrm{h}}{\mathrm{C}_{\mathrm{p}}}\left(\frac{\mathrm{Pr}}{\mathrm{Sc}}\right)^{2 / 3} \mathrm{H}\left(\mathrm{I}_{\mathrm{a}}-\mathrm{I}_{\mathrm{i}}\right) .
$$

If it were not for mechanical failure of the frost, one would expect the outer surface to reach approximately $273 \mathrm{~K}\left(32^{\circ} \mathrm{F}\right)$; however, the frost surface continually sloughs off, exposing a colder layer. Therefore, as the water vapor diffuses toward the cold surface, it encounters a temperature at which it condenses before it actually reaches the surface, and much of the condensate falls or is swept away without attaching itself to the surface. Then some of the heat given up by the water vapor is indirectly transmitted to the pipe surface through the air convection currents.

Holten [1961] calculated from his heat transfer data a steady state LOX container frost surface temperature, $\mathrm{T}_{\mathrm{f}}$, of about $210 \mathrm{~K}$ $\left(-80^{\circ} \mathrm{F}\right)$. Exactly the same figure can be derived from the frost surface temperature of $204 \mathrm{~K}$ measured by Richards, et al. (1962) for a liquid nitrogen test section if one assumes that the fractional temperature drop across the frost layer is the same for LOX as for $\mathrm{LN}_{2}$. That is;

$$
\begin{aligned}
& \Delta \mathrm{T}_{\text {frost, } \mathrm{LOX}} / \Delta \mathrm{T}_{\text {over-all, LOX }}=\Delta \mathrm{T}_{\text {frost, } L N_{2}} / \Delta \mathrm{T}_{\text {over-all, } \mathrm{LN}_{2}} \\
& \left(\mathrm{~T}_{\mathrm{f}}-90\right) /(300-90)=(204-76) /(300-76) \\
& \mathrm{T}_{\mathrm{f}}=210 \mathrm{~K} .
\end{aligned}
$$

The average film temperature is $(210+300) / 2=255 \mathrm{~K}\left(0^{\circ} \mathrm{F}\right)$. 
The following properties are evaluated at $255 \mathrm{~K}$ (Rohsenow and Choi [1961]).

$$
\begin{aligned}
& \text { for air } \operatorname{Pr}=0.722 \text { and } \mathrm{C}_{\mathrm{pa}}=1.0 \mathrm{~J} /(\mathrm{g} \cdot \mathrm{K})\left(\text { or } 0.239 \frac{\mathrm{BTU}}{1 \mathrm{~b}^{\circ} \mathrm{F}}\right) \\
& \text { for water } \mathrm{Sc}=0.6 .
\end{aligned}
$$

Substitution of these constant values gives

$$
\mathrm{Q} / \mathrm{A}_{\operatorname{dif}}\left(\frac{\mathrm{W}}{\mathrm{cm}^{2}}\right)=3.38(10)^{3} \mathrm{hH}\left(\mathrm{h}[=] \frac{\mathrm{W}}{\mathrm{cm}^{2} \mathrm{~K}}, \mathrm{H}[=] \frac{\mathrm{g}\left(\mathrm{H}_{2} \mathrm{O}\right)}{\mathrm{g}(\operatorname{air})}\right.
$$

or

$$
(\mathrm{Q} / \mathrm{A}) \operatorname{dif}\left(\frac{\mathrm{BTU}}{\mathrm{hrft}}\right)=0.868 \mathrm{hH}\left(\mathrm{h}[=] \frac{\mathrm{BTU}}{\mathrm{hr} \cdot \mathrm{ft}^{2}{ }^{2} \mathrm{~F}}, \mathrm{H}[=] \frac{\mathrm{grains}}{1 \mathrm{~b}}\right) .
$$

A 2. Convection Heat Flux

A2.1 Natural Convection (still air)

McAdams [1942] gives the following expression for natural convection across single horizontal tubes,

$\mathrm{Nu}=\mathrm{h} \frac{\mathrm{D}}{\mathrm{K}}=0.47[\text { Gr Pr }]^{0.25}$

Gr is the Grashof number evaluated at the film temperature

$\mathrm{Gr}=\left(\frac{\rho^{2} \beta g}{\mu^{2}}\right) \mathrm{D}^{3} \Delta \mathrm{T}$

where $\beta=$ thermal coefficient of volume expansion .

The group in parenthesis is given by Rohsenow and Choi

for air at $0^{\circ} \mathrm{F}$.

$\frac{\rho^{2} \beta g}{\mu^{2}}=267 \frac{1}{\mathrm{~cm}^{3} \mathrm{~K}} \quad\left(\right.$ or $\left.4.2(10)^{6} \frac{1}{\mathrm{ft}^{3} \mathrm{o} \mathrm{F}}\right)$ 
From the same source

$$
\begin{aligned}
\operatorname{Pr} & =0.722 \\
\mathrm{~K} & =2.25(10)^{-4} \frac{\mathrm{W}}{\mathrm{cm} \mathrm{K}} \quad\left(\text { or } 0.013 \frac{\mathrm{BTU}}{\mathrm{hrft}{ }^{\circ} \mathrm{F}}\right. \text { ). }
\end{aligned}
$$

Substitution of the constant values into (A6) yields

$$
\left(\frac{\mathrm{Q}}{\mathrm{A}}\right)_{\mathrm{c}} \frac{\mathrm{W}}{\mathrm{cm}^{2}}=\mathrm{h} \Delta \mathrm{T}=3.94(10)^{-4} \frac{\Delta \mathrm{T}^{1.25}}{\mathrm{D}^{0.25}}(\Delta \mathrm{T}[=] \mathrm{K}, \mathrm{D}[=] \mathrm{cm})
$$

or

$$
\left(\frac{\mathrm{Q}}{\mathrm{A}}\right)_{\mathrm{c}} \frac{\mathrm{BTU}}{\mathrm{hrft}^{2}}=0.255 \frac{\Delta \mathrm{T}^{1.25}}{\mathrm{D}^{0.25}}\left(\Delta \mathrm{T}[=]^{\circ} \mathrm{F}, \quad \mathrm{D}[=] \mathrm{ft}\right) .
$$

From (A5) we get

$$
\begin{aligned}
& \left(\frac{\mathrm{Q}}{\mathrm{A}}\right)_{\text {dif }} \frac{\mathrm{W}}{\mathrm{cm}^{2}}=10.2\left(\frac{\Delta \mathrm{T}}{\mathrm{D}}\right)^{0.25} \mathrm{H} \\
& \Delta \mathrm{T}[=] \mathrm{K}, \mathrm{D}[=] \mathrm{cm}, \mathrm{H}[=] \frac{\mathrm{g}}{\mathrm{g}}
\end{aligned}
$$

or

$$
\begin{aligned}
& \left(\frac{\mathrm{Q}}{\mathrm{A}}\right)_{\operatorname{dif}} \frac{\mathrm{BTU}}{\mathrm{hrft}^{2}}=0.221\left(\frac{\Delta \mathrm{T}}{\mathrm{D}}\right)^{0.25} \mathrm{H} \\
& \Delta \mathrm{T}[=]^{\circ} \mathrm{F}, \mathrm{D}[=] \mathrm{ft}, \mathrm{H}[=] \frac{\text { grains }}{\mathrm{lb}} .
\end{aligned}
$$

A2.2 Transition Velocity - Natural Convection to Forced Convection

The transition velocity is obtained by equating Nusselt number for natural convection to Nusselt number for forced convection. For forced convection in the Reynolds number range 1,000 to 50,000 


$$
\mathrm{Nu}=0.26 \operatorname{Re}^{0.6} \operatorname{Pr}^{0.3} \quad \text { (Mc Adams [1942]) }
$$

By equating (A6) and (A9) we get

$$
\operatorname{Re}=\frac{\rho V D}{\mu}=\left[\frac{0.47}{0.26} \mathrm{Gr}^{0.25} \frac{\mathrm{Pr}^{0.25}}{\operatorname{Pr}^{0.3}}\right]^{1 / 0.6} .
$$

Substitution of the constant values listed previously gives

$$
\mathrm{V}\left(\frac{\mathrm{cm}}{\mathrm{s}}\right)=3.18 \mathrm{D}^{0.25} \Delta \mathrm{T}^{0.417}(\mathrm{D}[=] \mathrm{cm}, \Delta \mathrm{T}[=] \mathrm{K})
$$

or

$$
\mathrm{V}\left(\frac{\mathrm{ft}}{\mathrm{hr}}\right)=690 \quad \mathrm{D}^{0.25} \Delta \mathrm{T}^{0.417}\left(\mathrm{D}[=] \mathrm{ft}, \Delta \mathrm{T}[=]^{\circ} \mathrm{F}\right) .
$$

For $D=30.5 \mathrm{~cm}(1 \mathrm{ft})$ and $\Delta T=90 \mathrm{~K}(162 \mathrm{~F})$

$$
\mathrm{V} \cong 49 \frac{\mathrm{cm}}{\mathrm{s}} \text { or } 1.76 \mathrm{Km} / \mathrm{hr} \text { or } 1.1 \mathrm{mi} / \mathrm{hr} \text {. }
$$

Therefore, if the wind velocity is less than approximately $1 \mathrm{mi} / \mathrm{hr}$, the natural convection expression will be used. If $\mathrm{V}$ is greater than $1 \mathrm{mi} / \mathrm{hr}$, one of the following forced convection expressions will be used.

\section{A2.3 Forced Convection}

Equation (A9) fits experimental data given by McAdams up to $\mathrm{Re} \cong 10^{5}$. This corresponds to a wind velocity of about $12.1 \mathrm{Km} / \mathrm{hr}$ $(7.5 \mathrm{mi} / \mathrm{hr})$. Equation (A9) diverges rapidly from the experimental data above $\operatorname{Re}=10^{5}$ so that at $24.1 \mathrm{Km} / \mathrm{hr}(15 \mathrm{mi} / \mathrm{hr})$ (A9) underpre dicts the data by $40 \%$. For $\operatorname{Re}>10^{5}(\mathrm{~V}>7.5 \mathrm{mi} / \mathrm{hr})$ we have developed the following equation, assuming the same $\operatorname{Pr}$ dependence: 
$N u=0.00332 \operatorname{Re}^{0.982} \operatorname{Pr}^{0.3}$.

A2.3.1 Heat Flux for $1.76<\mathrm{V}<12.1 \mathrm{Km} / \mathrm{hr}$

$(1<\mathrm{V}<7.5 \mathrm{mi} / \mathrm{hr})$.

From (A9) we get

$\mathrm{h}=0.26 \frac{\mathrm{K}}{\mathrm{D}}\left(\frac{\rho \mathrm{VD}}{\mu}\right)^{0.6}(\mathrm{Pr})^{0.3}$.

Substitution of the constant values yields

$$
\mathrm{h}\left(\frac{\mathrm{W}}{\mathrm{cm}^{2} \mathrm{~K}}\right)=1.75(10)^{-4} \frac{\mathrm{V}^{0.6}}{\mathrm{D}^{0.4}}\left(\mathrm{~V}[=] \frac{\mathrm{cm}}{\mathrm{s}}, \mathrm{D}[=] \mathrm{cm}\right)
$$

or

$$
h\left(\frac{B T U}{h r \mathrm{ft}^{2} \circ \mathrm{F}}\right)=0.608 \frac{\mathrm{V}^{0.6}}{\mathrm{D}^{0.4}}(\mathrm{~V}[=] \mathrm{ft} / \mathrm{s}, \mathrm{D}[=] \mathrm{ft})
$$

From (All)

$$
\left(\frac{\mathrm{Q}}{\mathrm{A}}\right)_{\mathrm{c}} \frac{\mathrm{W}}{\mathrm{cm}^{2}}=1.754(10)^{-4} \frac{\mathrm{V}^{0.6}}{\mathrm{D}^{0.4}} \Delta \mathrm{T}\left(\mathrm{V}[=] \frac{\mathrm{cm}}{\mathrm{s}}, \mathrm{D}[=] \mathrm{cm}\right.
$$

or

$$
\left(\frac{\mathrm{Q}}{\mathrm{A}}\right)_{\mathrm{c}} \frac{\mathrm{BTU}}{\mathrm{hrft} \mathrm{ft}^{2}}=0.666 \frac{\mathrm{V}^{0.6}}{\mathrm{D}^{0.4}} \Delta \mathrm{T}\left(\mathrm{V}[=] \mathrm{ft} / \mathrm{s}, \mathrm{D}[=] \mathrm{ft}, \Delta \mathrm{T}={ }^{\circ} \mathrm{F}\right)(\mathrm{Al} 2)
$$

From (A5) and (Al1)

$$
\left(\frac{\mathrm{Q}}{\mathrm{A}}\right)_{\text {dif }} \frac{\mathrm{W}}{\mathrm{cm}^{2}}=.590 \frac{\mathrm{V}^{0.6}}{\mathrm{D}^{0.4}} \mathrm{H}\left(\mathrm{V}[=] \frac{\mathrm{cm}}{\mathrm{s}}, \Delta \mathrm{T}[=] \mathrm{K}, \mathrm{H}[=] \frac{\mathrm{g}}{\mathrm{g}}, \mathrm{D}[=] \mathrm{cm}\right)
$$

or

$$
\begin{gathered}
\left(\frac{\mathrm{Q}}{\mathrm{A}}\right)_{\mathrm{dif}} \frac{\mathrm{BTU}}{\mathrm{hr} \mathrm{ft}^{2}}=0.578 \frac{\mathrm{V}^{0.6}}{\mathrm{D}^{0.4}} \mathrm{H}\left(\mathrm{V}[=] \mathrm{ft} / \mathrm{s}, \Delta \mathrm{T}[=]^{\circ} \mathrm{F}, \mathrm{H}[=] \frac{\mathrm{grains}}{\mathrm{lb}},\right. \\
\mathrm{D}[=] \mathrm{ft}) .
\end{gathered}
$$




\section{A2.3.2 Heat Flux for $\mathrm{V}>7.5 \mathrm{mi} / \mathrm{hr}$}

From (A10) we get

$$
h=0.00332 \frac{K}{D}\left(\frac{\rho V D}{\mu}\right)^{0.982}(\operatorname{Pr})^{0.3} .
$$

Substitution of the constant values gives

$$
\begin{aligned}
& \mathrm{h}\left(\frac{\mathrm{W}}{\mathrm{cm}^{2} \mathrm{~K}}\right)=4.75(10)^{-6} \frac{\mathrm{V}^{.982}}{\mathrm{D}^{.018}}\left(\mathrm{~V}[=] \frac{\mathrm{cm}}{\mathrm{s}}, \mathrm{D}[=] \mathrm{cm}\right) \\
& \mathrm{h}\left(\frac{\mathrm{BTU}}{\mathrm{hr} \mathrm{ft}^{2} \mathrm{~K}}\right)=8.428(10)^{-5} \frac{\mathrm{V}^{0.982}}{\mathrm{D}^{0.018}}\left(\mathrm{~V}[=] \frac{\mathrm{ft}}{\mathrm{hr}}, \mathrm{D}[=] \mathrm{ft}\right) .
\end{aligned}
$$

Due to the small exponent of $D$, and the value of $D$ being on the order of $30.5 \mathrm{~cm}(1 \mathrm{ft})$,

$$
\begin{aligned}
& \left(\frac{D}{30.5}\right)^{0.018} \cong 1.0 . \text { Then, } \\
& h\left(\frac{W}{\mathrm{~cm}^{2} \mathrm{~K}}\right)=4.72(10)^{-6} \mathrm{~V}^{0.982}\left(\mathrm{~V}[=] \frac{\mathrm{cm}}{\mathrm{s}}\right)
\end{aligned}
$$

or

$$
\left(\frac{\mathrm{Q}}{\mathrm{A}}\right)_{\mathrm{C}}=4.72(10)^{-6} \mathrm{~V}^{0.982} \Delta \mathrm{T} .
$$

From (A5) and (A14)

$$
\begin{aligned}
& \left(\frac{\mathrm{Q}}{\mathrm{A}}\right)_{\text {dif }} \frac{\mathrm{W}}{\mathrm{cm}^{2}}=0.123 \mathrm{~V}^{0.982} \mathrm{H}\left(\mathrm{V}[=] \frac{\mathrm{cm}}{\mathrm{s}}, \mathrm{H}[=] \frac{\mathrm{g}}{\mathrm{g}}\right) \\
& \left(\frac{\mathrm{Q}}{\mathrm{A}}\right)_{\text {dif }} \frac{\mathrm{BTU}}{\mathrm{hr} \mathrm{ft}^{2}}=0.2272 \mathrm{~V}^{0.982} \mathrm{H}\left(\mathrm{V}[=] \frac{\mathrm{ft}}{\mathrm{s}}, \mathrm{H}[=] \frac{\mathrm{grains}}{\mathrm{lb}}\right) .
\end{aligned}
$$


A3. Radiant Heat Flux

The heat flux due to radiation from the ground and sky is

$$
\frac{\mathrm{Q}}{\mathrm{A}}=\sigma \mathrm{F}\left[\mathrm{T}_{\mathrm{a}}^{4}-\mathrm{T}_{f}^{4}\right] \text {. }
$$

For diffuse radiation from a distant enclosure the emissivity factor F may be taken as the emissivity of the frost surface. Holten [1961] and others assign values of about 0.9 to this factor. The Stefan-Boltzman constant $\sigma$ is

$$
\sigma=5.67(10)^{-12} \frac{W}{\mathrm{~cm}^{2} K^{4}}
$$

or

$$
0.174(10)^{-8} \mathrm{BTU} / \mathrm{hr} \mathrm{ft}^{2} \circ \mathrm{R}^{4}
$$

$\mathrm{T}_{\text {frost }}=210 \mathrm{~K}\left(378^{\circ} \mathrm{R}\right)$ as before. Substitution of the se values give

$$
\begin{aligned}
& \frac{\mathrm{Q}}{\mathrm{A}}\left(\frac{\mathrm{W}}{\mathrm{cm}^{2}}\right)=5.1(10)^{-12}\left(\mathrm{~T}_{\mathrm{a}}^{4}-210^{4}\right)(\mathrm{T}[=] \mathrm{K}) \\
& \frac{\mathrm{Q}}{\mathrm{A}}\left(\frac{\mathrm{BTU}}{\mathrm{hr \textrm {ft } ^ { 2 } \circ \mathrm { F }}}\right)=0.15^{4}(10)^{-8}\left(\mathrm{~T}_{\mathrm{a}}^{4}-378^{4}\right)\left(\mathrm{T}[=]{ }^{\circ} \mathrm{R}\right) .
\end{aligned}
$$

In open sunlight the mean heat flux to an es sentially black surface is approximately

$$
\begin{aligned}
& \frac{\mathrm{Q}}{\mathrm{A}_{\mathrm{p}}}=0.068 \mathrm{~W} / \mathrm{cm}^{2} \\
& \frac{\mathrm{Q}}{\mathrm{A}_{\mathrm{p}}}=215 \mathrm{BTU} / \mathrm{hr} \mathrm{ft}^{2},
\end{aligned}
$$

assuming an atmospheric transmittance of $0.5 . A_{p}$ is the projected area (seen by the sun). In terms of the pipe surface area $A$ : 


$$
\frac{A}{A_{p}}=\frac{\pi D L}{D L}=\pi \text {. }
$$

Therefore

$$
\frac{\mathrm{Q}}{\mathrm{A}}=\frac{0.068}{\pi}=0.0216 \mathrm{~W} / \mathrm{cm}^{2} \text { or } 68.4 \frac{\mathrm{BTU}}{\mathrm{hr} \mathrm{ft}}
$$

To avoid unnecessary complication, we assume 50\% sunlight. Then the total radiant heat flux is

$$
\begin{aligned}
& \left(\frac{\mathrm{Q}}{\mathrm{A}}\right)_{\mathrm{rad}} \frac{\mathrm{W}}{\mathrm{cm}^{2}}=5.1(10)^{-12}\left(\mathrm{~T}_{\mathrm{a}}^{4}-210^{4}\right)+0.0216\left(\mathrm{~T}_{\mathrm{a}}[=] \mathrm{K}\right) \\
& \left(\frac{\mathrm{Q}}{\mathrm{A}}\right)_{\mathrm{rad} \mathrm{hr} \mathrm{ft}} \frac{\mathrm{BTU}}{2}=0.154(10)^{-8}\left(\mathrm{~T}_{\mathrm{a}}^{4}-378^{4}\right)+34.2\left(\mathrm{~T}_{\mathrm{a}}[=] \mathrm{R}\right)
\end{aligned}
$$

A4. Conversion of Relative Humidity to Specific Humidity

Specific humidity $\mathrm{H}$ may be expressed in terms of the total

(barometric) pressure $B$ and the vapor pressure $\mathrm{P}_{\mathrm{V}}$ as

$$
\mathrm{H}=\frac{1}{1.61\left(\frac{\mathrm{B}}{\mathrm{P}_{\mathrm{v}}}-1\right)} \frac{\mathrm{g} \mathrm{H}_{2} \mathrm{O}}{\mathrm{g} \text { air }}
$$

or

$$
\mathrm{H}=\frac{7000}{1.61\left(\frac{\mathrm{B}}{\mathrm{P}_{\mathrm{v}}}-1\right)} \quad \frac{\text { grains }}{1 \mathrm{~b}} .
$$

The vapor pressure corresponding to the dry bulb temperature $\mathrm{T}_{\mathrm{a}}{ }^{\circ} \mathrm{F}$ is, by the Antoine equation (Lange [1961])

$$
\mathrm{P}_{\mathrm{d}}=\exp \left(18.67-\frac{7254.4}{391+\mathrm{T}_{\mathrm{a}}}\right) \mathrm{mm} \mathrm{Hg}
$$


From the definition of relative humidity, $\mathrm{H}_{\mathrm{r}}$

$$
P_{v}=H_{r} P_{d}
$$

Then,

$$
\mathrm{H}=\frac{1}{1.61\left(\mathrm{~B} / \mathrm{H}_{\mathrm{r}} \mathrm{P}_{\mathrm{d}}-1\right)}
$$

An average value of $B=760 \mathrm{~mm} \mathrm{Hg}$ yields

$$
\mathrm{H}=\frac{\mathrm{l}}{\frac{1224}{\mathrm{H}_{\mathrm{r}} \mathrm{P}_{\mathrm{d}}}-1.61} \frac{\mathrm{g}}{\mathrm{g}}
$$

or

$$
\begin{aligned}
& \mathrm{H}=\frac{7000}{\frac{1224}{\mathrm{H}_{\mathrm{r}} \mathrm{P}_{\mathrm{d}}}-1.61} \frac{\text { grains }}{\mathrm{lb}} \\
& \left(\mathrm{P}_{\mathrm{d}} \text { from eq }(\mathrm{A} 17)\right) .
\end{aligned}
$$

A5. Comparisons With Experimental Data

Calculations of heat flux to uninsulated liquid and liquid oxygen transfer lines and vessels are compared with experimental data from the following sources:

\section{Author Fluid Apparatus}

Richards et al $\quad \mathrm{LN}_{2}$ Horizontal cylindrical test section $5.08 \mathrm{~cm}$ (1962) $O D \times 15.2 \mathrm{~cm}$ long ( 2 in $O D \times 6$ in long) in a wind tunnel. Controlled velocity and humidity.

Ruccia, Mohr LOX Vertical cylindrical tank $45.7 \mathrm{~cm}$ OD $\times 6.71 \mathrm{~m}$ (1960) (18 in OD $\times 22 \mathrm{ft}$ ) high. Engine driven propeller provided wind. Humidity not controlled but measured.

Holten

(1961)
LOX Spherical tanks $13.7 \mathrm{~cm}$ OD ( $5-3 / 8 \mathrm{in})$. Natural convection. 
A5. 1 Comparison with Data of Richards et al. [1962]

Since liquid nitrogen was used in these experiments the value of $T_{f}$ was $204 \mathrm{~K}\left(368^{\circ} \mathrm{R}\right)$ and $\Delta \mathrm{T}$ was $95.6 \mathrm{~K}\left(172^{\circ} \mathrm{F}\right)$ (Sec A1). The average frost thicknes 8 was approximately $0.952 \mathrm{~cm}(3 / 8 \mathrm{in})$, so that effectively $1.91 \mathrm{~cm}(3 / 4 \mathrm{in})$, or $1.91 \mathrm{~cm}(0.0625 \mathrm{ft})$ is added to the outside diameter. That $\mathrm{i}, \mathrm{D}=5.08+1.91=6.99 \mathrm{~cm}$. Equation (A12) becomes

$$
(\mathrm{Q} / \mathrm{A})_{\mathrm{c}} \frac{\mathrm{W}}{\mathrm{cm}^{2}}=0.00770 \mathrm{~V}^{0.6}(\mathrm{~V}[=] \mathrm{cm} / \mathrm{s})
$$

or

$$
(\mathrm{R} / \mathrm{A})_{\mathrm{c}} \frac{\mathrm{BTU}}{\mathrm{hr} \mathrm{ft}^{2}}=206.6 \mathrm{~V}^{0.6}(\mathrm{~V}[=] \mathrm{ft} / \mathrm{s}) .
$$

Equation (A13) becomes

$$
(\mathrm{Q} / \mathrm{A}))_{\operatorname{dif}} \frac{\mathrm{W}}{\mathrm{cm}^{2}}=.272 \mathrm{~V}^{.6} \mathrm{H}(\mathrm{V}[=] \mathrm{cm} / \mathrm{s}, \mathrm{H}[=] \mathrm{g} / \mathrm{g})
$$

or

$$
(\mathrm{Q} / \mathrm{A})_{\mathrm{dif}}=1.042 \mathrm{~V}^{0.6} \mathrm{H}(\mathrm{V}[=] \mathrm{ft} / \mathrm{s}, \mathrm{H}[=] \mathrm{grains} / \mathrm{bb}) .
$$

And the heat flux due to radiation without sunlight is, from (Al6)

$$
(\mathrm{Q} / \mathrm{A})_{\mathrm{rad}}=0.0328 \mathrm{~W} / \mathrm{cm}^{2} \text { or } 104 \mathrm{BTU} / \mathrm{hr} \mathrm{ft}^{2} .
$$

The calculated heat flux for the experimental conditions are summarized in the following table.

The comparison between these calculated heat fluxes and experimental data of Richards et al. [1962] may be seen in Figure Al. 


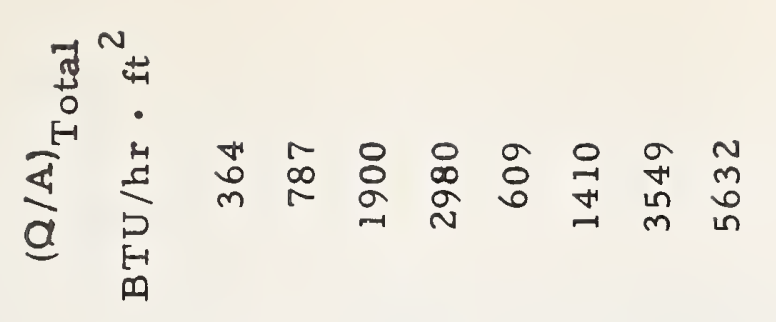

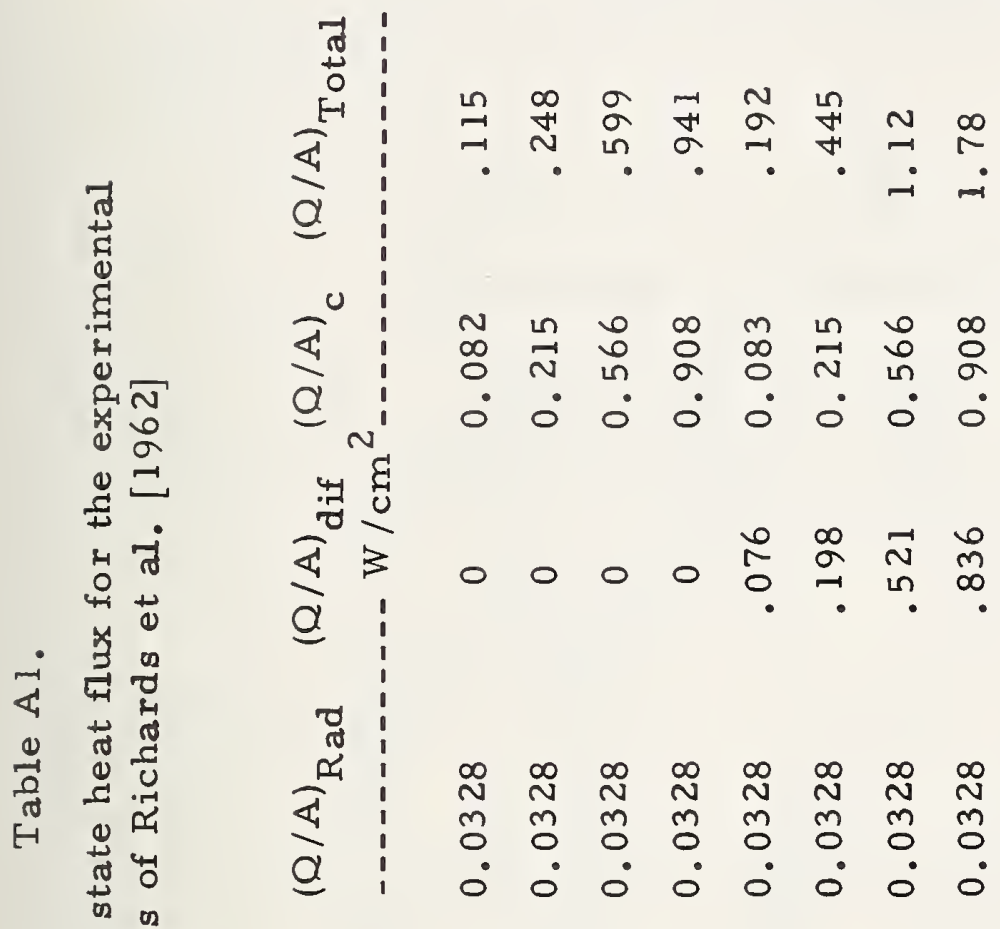

$$
\begin{aligned}
& \text { 究哭 }
\end{aligned}
$$

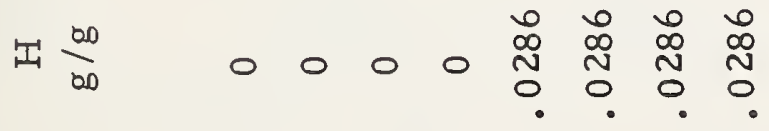

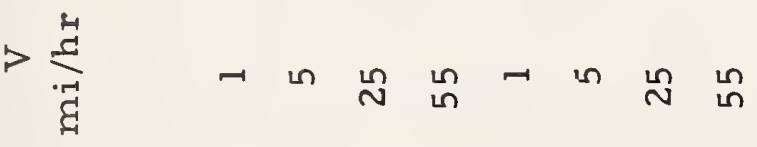

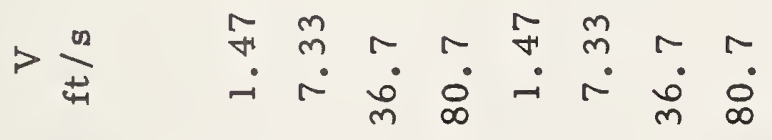

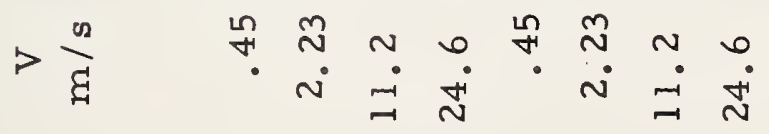




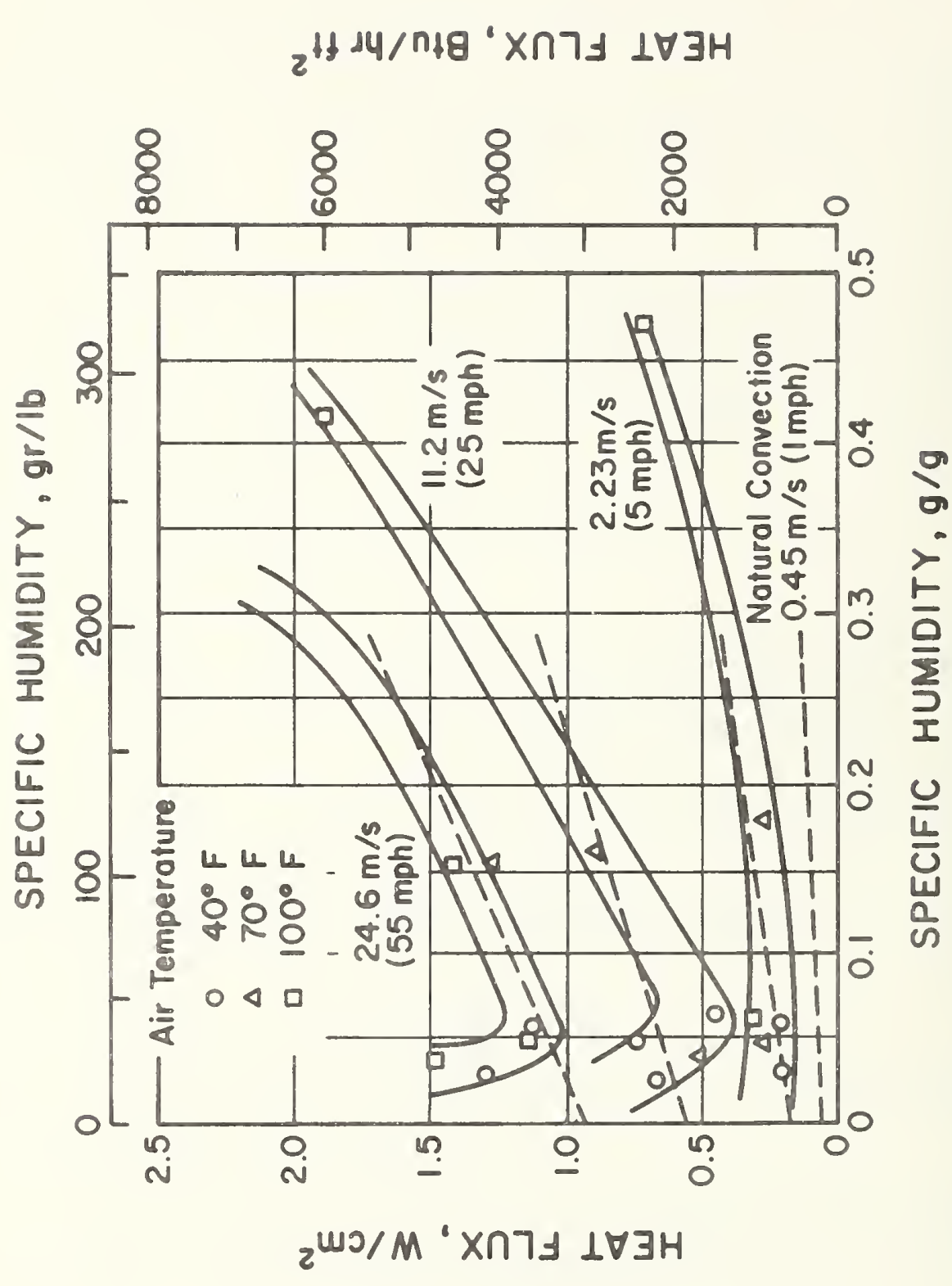

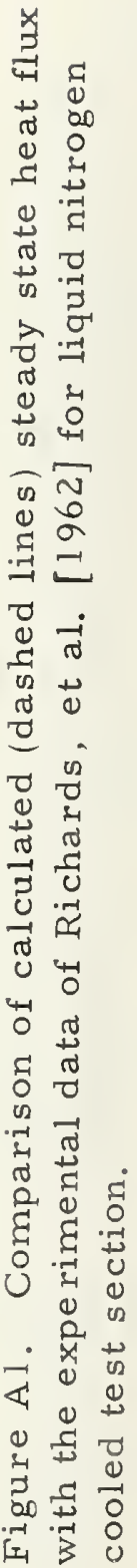


A5.2 Comparison with the Data of Ruccia and Mohr [1960]

Ruccia and Mohr present data for natural convection, and $5.33 \mathrm{~m} / \mathrm{s}(10 \mathrm{knot})$ and $12.6 \mathrm{~m} / \mathrm{s}(24.4 \mathrm{knot})$ wind velocities.

For natural convection over vertical flat plates McAdams [1942] recommends the following form of correlation (assumed applicable to vertical cylinders):

$$
\mathrm{Nu}=\mathrm{a}(\mathrm{Gr} \text { Pr })^{\mathrm{b}} \text {. }
$$

For $\mathrm{L}=6.71 \mathrm{~m}(22 \mathrm{ft})$ and $\Delta \mathrm{T}=90 \mathrm{~K}\left(162^{\circ} \mathrm{F}\right)$, and the properties of air of sec A2.1 we get $\operatorname{Gr} \operatorname{Pr}=5.22(10)^{12}$, which is beyond the range of the equation given by McAdams. We have fit the data given by McAdams at high Gr Pr by the following equation

$$
\mathrm{Nu}=0.0325(\mathrm{Gr} \operatorname{Pr})^{0.384}
$$

from which we obtain

$$
(\mathrm{Q} / \mathrm{A})_{\mathrm{c}}=\mathrm{K} / \mathrm{L} \mathrm{Nu} \Delta \mathrm{T}=0.0751 \mathrm{~W} / \mathrm{cm}^{2}\left(238 \mathrm{BTU} / \mathrm{hr} \mathrm{ft}^{2}\right)
$$

and from (A5)

$$
(\mathrm{Q} / \mathrm{A})_{\mathrm{dif}}=\mathrm{K} / \mathrm{L} \mathrm{Nu} 3.38(10)^{3} \mathrm{H}=2.82 \mathrm{HW} / \mathrm{cm}^{2}(\mathrm{H}[=] \mathrm{g} / \mathrm{g})
$$

or

$(\mathrm{Q} / \mathrm{A})_{\mathrm{dif}}=1.275 \mathrm{HBTU} / \mathrm{hr} \mathrm{ft}^{2}(\mathrm{H}[=]$ grains (lb).

In Ruccia's and Mohr's experiments the humidity varied from $0.006 \mathrm{~g} / \mathrm{g}$ (42 grains/1b) to $0.014 \mathrm{~g} / \mathrm{g}$ (98 grains $/ 1 \mathrm{~b})$.

The forced convection Reynolds numbers corresponding to the 10 and 24 knot points are respectively $1.98(10)^{5}$ and $4.83(10)^{5}$. The se fall within the range of equations (A14) and (A15). From these equations 


$$
(\mathrm{Q} / \mathrm{A})_{\mathrm{C}} \mathrm{BTU} / \mathrm{hrft}{ }^{2}=42.4 \mathrm{~V}^{0.982}(\mathrm{~V}[=] \mathrm{ft} / \mathrm{s})
$$

or

$$
\begin{aligned}
(\mathrm{Q} / \mathrm{A})_{\operatorname{dif}} \mathrm{BTU} / \mathrm{hr} \mathrm{ft}{ }^{2}=0.2272 \mathrm{~V}^{0.982} \mathrm{H} \quad(\mathrm{V}[=] \mathrm{ft} / \mathrm{s}, \\
\mathrm{H}[=] \mathrm{grains} / \mathrm{lb}) . \quad(\mathrm{A} 23)
\end{aligned}
$$

The radiation heat flux is, from (A16), assuming $\mathrm{T}_{\mathrm{a}}=540^{\circ} \mathrm{R}$

$$
(\mathrm{Q} / \mathrm{A})_{\mathrm{Rad}}=101 \mathrm{BTU} / \mathrm{hr} \mathrm{ft}^{2}
$$

$(\mathrm{Q} / \mathrm{A})_{\mathrm{C}} \mathrm{W} / \mathrm{cm}^{2}=4.25(10)^{-4} \mathrm{~V}^{0.982}(\mathrm{~V}[=] \mathrm{cm} / \mathrm{s})$

$(\mathrm{Q} / \mathrm{A})_{\mathrm{dif}} \mathrm{W} / \mathrm{cm}^{2}=0.123 \mathrm{~V}^{0.982} \mathrm{H}(\mathrm{V}[=] \mathrm{cm} / \mathrm{s}, \mathrm{H}=\mathrm{g} / \mathrm{g})$.

The calculations are summarized in Table A2 and compared with the experimental data in Figure A2.

\section{Table A2}

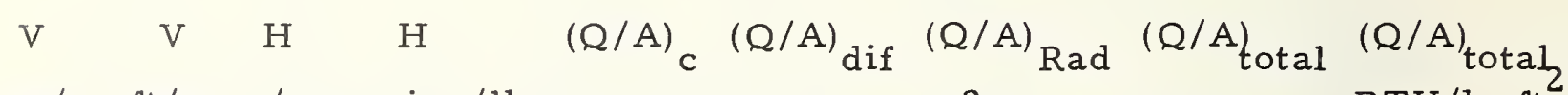

\begin{tabular}{|c|c|c|c|c|c|c|}
\hline - & 0.006 & 42 & 0.0751 & .0170 & 0.0318 & 0.124 \\
\hline - & 0.014 & 98 & 0.0751 & .0394 & & 0.146 \\
\hline
\end{tabular}

$\mathrm{cm} / \mathrm{s} \mathrm{ft} / \mathrm{s} \mathrm{g} / \mathrm{g}$ grains/lb

$\mathrm{BTU} / \mathrm{hr} \mathrm{ft}$

Natural Convection

Forced Convection

$\begin{array}{llll}533 & 17.5 & 0.006 \quad 42\end{array}$

$0.223 \quad .0501$

0.305

967

$1260 \quad 41.20 .006 \quad 42$

$0.515 \quad .116$

0.663

2101

$\begin{array}{llll}533 & 17.5 & 0.014 & 98\end{array}$

0.223 .117

0.372

1179

$\begin{array}{llll}1260 & 41.2 & 0.014 & 98\end{array}$

$0.515 \quad .270$

0.817

2591 


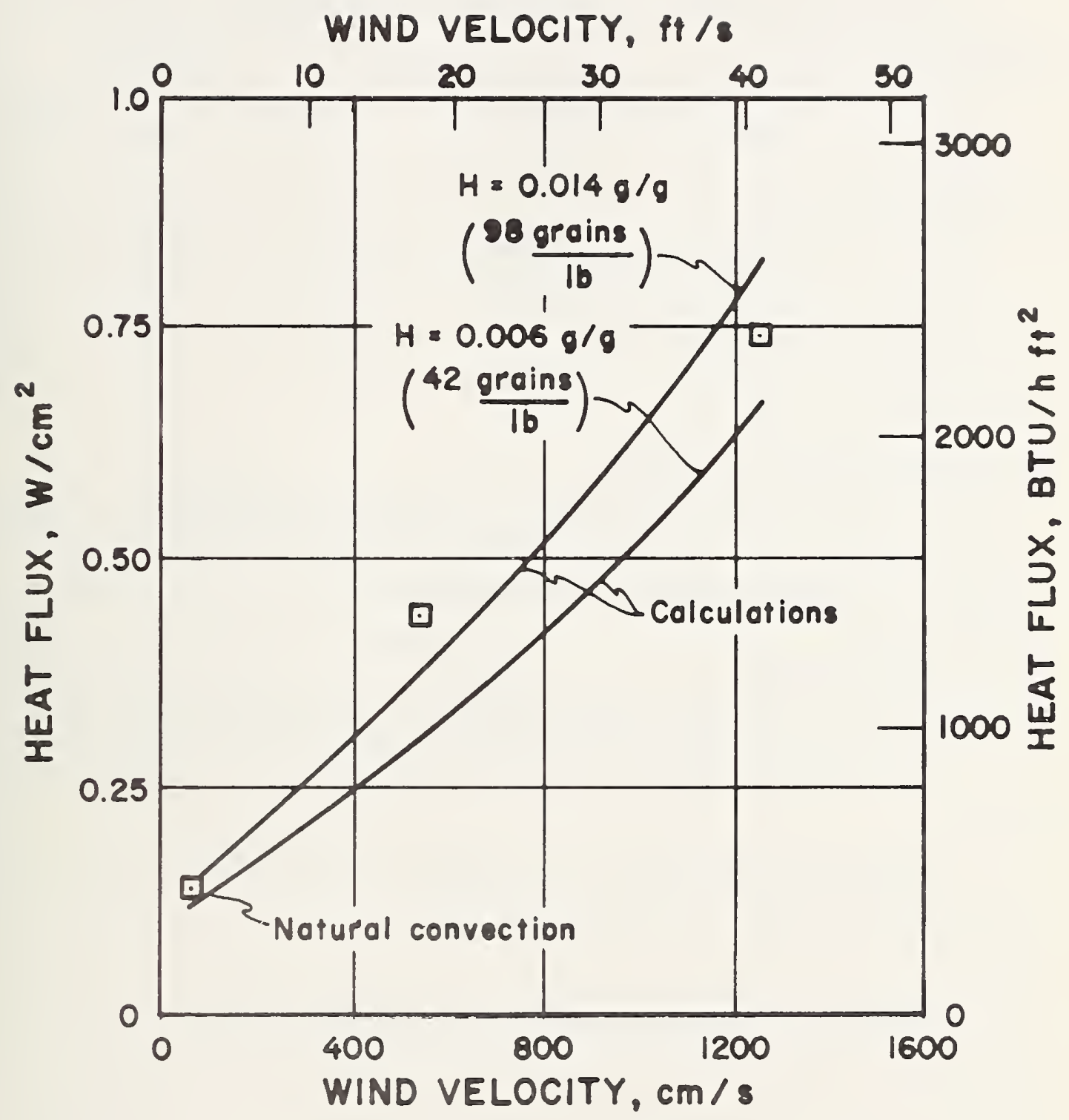

Figure A2. Comparison of calculated steady state heat flux with the experimental data of Ruccia and Mohr [1960] for a liquid oxygen cooled

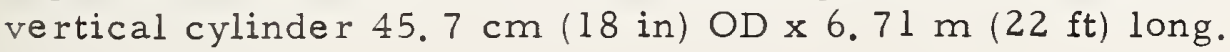


A5.5 Comparison with Data of Holten [1961]

For natural convection heat transfer to spheres Bird et al. [1964] recommends

$$
\mathrm{Nu}=2+0.6(\mathrm{Gr})^{1 / 4}(\mathrm{Pr})^{1 / 3} \text {. }
$$

The constants are

$D=13.6 \mathrm{~cm}+0.6 \mathrm{~cm}$ (approximate frost thickness $\mathrm{x} 2$ )

$=14.2 \mathrm{~cm}$ ( or $0.469 \mathrm{ft}$ ).

$\Delta \mathrm{T}=90 \mathrm{~K}\left(\right.$ or $\left.162^{\circ} \mathrm{F}\right)$.

(Other constants from Sec. A.2.1).

From (A24) and the constants,

$$
\mathrm{h}=8.16(10)^{-4} \mathrm{~W} / \mathrm{cm}^{2} \cdot \mathrm{K}\left(\text { or } 1.44 \mathrm{BTU} / \mathrm{hr} \cdot \mathrm{ft}^{2} \cdot{ }^{\circ} \mathrm{F}\right)
$$

$(\mathrm{Q} / \mathrm{A})_{\mathrm{C}}=0.0735 \mathrm{~W} / \mathrm{cm}^{2}$ (or $\left.233 \mathrm{BTU} / \mathrm{hr} \cdot \mathrm{ft}^{2}\right)$.

From (A25) and (A.5),

$$
(\mathrm{Q} / \mathrm{A})_{\text {dif }} \mathrm{W} / \mathrm{cm}^{2}=3.38(10)^{3} \mathrm{hH}=2.75 \mathrm{H}(\mathrm{H}[=] \mathrm{g} / \mathrm{g})
$$

or

$$
(\mathrm{Q} / \mathrm{A})_{\operatorname{dif}} \mathrm{BTU} / \mathrm{hr} \cdot \mathrm{ft}^{2}=1.25 \mathrm{H}(\mathrm{H}[=] \text { grains } / \mathrm{lb}) .
$$

The radiant heat flux is, from Sec A 5.2

$$
(\mathrm{Q} / \mathrm{A})_{\operatorname{Rad}}=0.0319 \mathrm{~W} / \mathrm{cm}^{2}\left(\text { or } 101 \mathrm{BTU} / \mathrm{hr} \cdot \mathrm{ft}^{2}\right) .
$$


Calculated steady state heat flux compared to the experimental values are as follows:
$\mathrm{H}$
$\mathrm{H}$
$(\mathrm{Q} / \mathrm{A}) \operatorname{Exp}$
$(\mathrm{Q} / \mathrm{A}) \mathrm{Calc}$
$(\mathrm{Q} / \mathrm{A}) \operatorname{Exp} \quad(\mathrm{Q} / \mathrm{A}) \mathrm{Calc}$
g/g grains/lb $-\mathrm{BTU} / \mathrm{hr} \mathrm{ft}^{2}-\cdots$ $\mathrm{W} / \mathrm{cm}^{2}$

$\begin{array}{llllll}0.0065 & 45.5 & 325 & 391 & 0.102 & 0.123 \\ 0.0070 & 49 & 315 & 395 & 0.099 & 0.125 \\ 0.0074 & 52 & 330 & 399 & 0.104 & 0.126 \\ 0.0076 & 53 & 340 & 400 & 0.107 & 0.126 \\ 0.0097 & 68 & 336 & 419 & 0.106 & 0.132 \\ 0.0120 & 84 & 345 & 439 & 0.109 & 0.138\end{array}$

It is apparent that the calculated heat flux is 20 to $30 \%$ higher than the experimental data. A possible explanation is that the heat flux in Holten's apparatus was impeded to some degree by the sheltered placement of the spherical vessels.

Since this over-prediction is not apparent in the other comparisons we assume that the predictive method is satisfactory. 


\section{Appendix B. Cooldown Surge}

\section{B1. Introduction}

Large amplitude pressure surges are often observed when a cryogenic liquid is forced into a warm transfer line. While water hammer pulses (sec. 4.2) are associated with the impingement of liquid on a closing valve or other restrictions, these cooldown surges are associated with the opening of an inlet valve or the starting of a pump. Cooldown surges have been analyzed by means of computer solutions of the unsteady two phase flow equations (Steward et al. [1968]), the result of which being a stepwise calculation of all the variables in time and space coordinates. Not only are such detailed calculations too lengthy for this system analysis, but they produce unneeded infor mation. In the present case only the peak amplitude which results from a particular mode of operation is required; therefore, a correlation of peak surge pressure as a function of the operating conditions is desirable. The following sections describe the development of the correlation used in the present system analysis and show some of the results in comparison with previous experimental data.

The usual dimensional analysis approach to the development of an empirical correlation assumes that a proportionality exists between powers of dimensionless groups of parameters. It does not normally allow for the possibility of additive terms or other functional relationships such as trigonometric, exponential, etc. In the present approach both the dimensionless grouping of parameters and the forms of the relationships are derived from a model of the process. It should be understood that the derivations are not rigorous and leave empirical coefficients to be established from the experimental data. 
During cooldown of pipelines with length to diameter ratios of 450 and greater, observed stream and wall temperatures followed a "cold front" pattern. That is, at a given time temperatures upstream from a moving cold front were near the liquid saturation point; downstream from that point the temperatures rose sharply to near the initial temperature. The limiting extreme, in which the temperature distribution in the line is reduced to one moving temperature step, from liquid to ambient temperature has been used with good results as a basis for cooldown time and pressure surge analyses (Steward [1965] [1968]) and will be used here.

B2. Derivation

As liquid flows into the warm part of the pipe and, after a time delay, becomes saturated, vapor begins to form in the liquid stream. The vapor carries liquid with it as it moves downstream and thus further increases the heat transfer surface area. As the rate of vapor formation increases, the pressure in the liquid-vapor transition region (or at the assumed liquid warm gas interface) rises due to the resistance to the flow of gas. Experimental data show that the measured pressure is in phase with the gas velocity. Thus, the surge process is unlike a frictionless spring-mass oscillating system in which the spring force is $90^{\circ}$ out of phase with the velocity. Therefore, we conclude that the inertial effects (time derivitives of velocity) are small compared to the frictional effects. This conclusion is supported by detailed computations using the complete momentum, energy, and mass conservation equations (Steward et al. [1968]) in which the magnitude of individual terms can be examined. Experimental measurements and computations show that the peak pressure occurs approximately at 
the interface between liquid and vapor. The compressible gas in the warm part of the pipe expands and accelerates in the direction of flow to a maximum velocity at the discharge. The discharge velocity may be subsonic or sonic; however, for high peak pressure conditions which would be of concern, the discharge velocity would be sonic. For example in Fanno flow with $\mathrm{f}_{\mathrm{g}} / \mathrm{D}$ (friction factor times gas length to diameter ratio) greater than 15 a ratio of peak pressure to discharge pressure, $\mathrm{P}_{\mathrm{p}} / \mathrm{P}_{\mathrm{d}}$ greater than 5.5 would produce sonic (choked) discharge.

For choked Fanno flow (constant area ideal gas flow with friction, without heat transfer) Shapiro [1953] gives

$$
\frac{f L}{D}=\frac{1-M_{1}^{2}}{\gamma M_{1}^{2}}+\frac{\gamma+1}{2 \gamma} \ln \frac{(\gamma+1) M_{1}^{2}}{2\left(1+\frac{\gamma-1}{2} M_{1}^{2}\right)}
$$

where $M_{1}$ is the upstream Mach number and $\gamma$ is the ratio of specific heats. For the purpose of correlation the logarithm term may be eliminated with no more than $20 \%$ loss of accuracy. Then,

$$
M_{1} \cong \frac{1}{\sqrt{\frac{\gamma f L g+1}{D}}}
$$

The mass flow rate corresponding to $M_{1}$ is

$$
\dot{\mathrm{w}}=\mathrm{M}_{1} \mathrm{P}_{\mathrm{g}} \mathrm{AV}{ }_{\mathrm{s}} \text { where } \mathrm{A} \text { is pipe area. }
$$

Substitution of ideal gas relations for density $\rho_{\mathrm{g}}$ and speed of sound $\mathrm{V}$, and equation (B1) for $M_{1}$ yields, 


$$
\dot{\omega}=\frac{P_{P} A}{\sqrt{\frac{\gamma+L_{g}+1}{D}}} \sqrt{\frac{\gamma}{R T}}
$$

where $R$ is the gas constant, $T_{t}$ is gas temperature, and $\mathrm{P}_{\mathrm{p}}$ is the peak pressure.

The total gas flow rate $\dot{w}$ may be expressed as the sum of an equilibrium flow rate $\dot{w}_{\text {eq }}$, and an excess vapor formation rate $\dot{w}_{\text {ex }}$.

$$
\dot{w} \equiv \dot{w}_{\text {eq }}+\dot{w}_{\text {ex }} .
$$

The equilibrium flow rate $\dot{w}_{\text {eq }}$ is that which would exist in a steady cooldown without surging. In such a steady cooldown process most of the pressure drop $P_{1}-P_{d}\left(P_{1}\right.$ is the upstream pressure) appears across the gas stream until the liquid front very nearly reaches the discharge end, i. e., until cooldown is nearly complete. Then, for

$$
\frac{\log }{\lg } \frac{\rho_{g}}{\rho_{l}}<1 \text {, }
$$

$$
\dot{\omega}_{\mathrm{eq}}=\frac{P_{1} A}{\sqrt{\frac{\gamma f L}{D} q+1}} \sqrt{\frac{\gamma}{R T}}
$$

From (B2),

$$
p_{p}-p_{1}=\frac{\dot{w}_{\text {ex }}}{A} \sqrt{\frac{R T}{\gamma}} \sqrt{\frac{\gamma f L_{q}+1}{D}}
$$


Equation (BI) is not strictly correct when the pressure $P_{I}$ is (as it is likely to be) below the value which would produce choking. The error in using equation (B1) for subsonic flow is not great, however, because the upstream Mach number for a given mass flow $r$ ate and fL/D depends only slightly on the discharge mach number. The following example illustrates this point:

Let $f L / D=15$ and the discharge mach number $M_{d}=0.57$. Fanno flow calculations for $\gamma=1.4$ gives an upstream mach number $M_{1}$ of 0.194 . When the discharge mach number is sonic $\left(M_{d}=1\right)$, then $M_{1}=0.197$-- only $1.6 \%$ higher. However, the corresponding pressure ratios are quite different, being $\mathrm{P}_{1} / \mathrm{P}_{\mathrm{d}}=3$ for the subsonic and $\mathrm{P}_{1} / \mathrm{P}_{\mathrm{d}}=$ 5.5 for the sonic case. Thus, equation (B1) which indicates that the upstream mach number is independent of the pressure ratio is approximately correct.

The excess vapor formation rate $\dot{w}_{\text {ex }}$ is that which would result from liquid flows into the warm pipe faster than the rate which would result in steady cooldown. Such would be the case if the entering liquid were subcooled; then vaporization, which limits the inflow, would be delayed. The excess vapor formation rate is:

$$
\dot{w}_{e x} \propto \frac{q \pi D L_{q}}{\Delta h_{v}+F \Delta h_{s}}
$$

where $L_{q}$ is the added heat transfer length, $\Delta_{h_{v}}$ is the heat of vaporization and $F$ is some fraction of the enthalpy change of the gas, $\Delta h$, between the saturation temperature and ambient temperature.

The heat transfer length is assumed proportional to a reference liquid velocity $\overline{\mathrm{U}}_{\&}$ and the saturation delay time ${ }_{\text {sd' }}$ '

$$
\mathrm{L}_{\mathrm{q}} \propto \overline{\mathrm{U}}_{\ell}{ }^{\mathrm{t}}{ }_{\mathrm{sd}} \cdot
$$


The delay time, i.e., the time required for a mass of fluid entering the warm region to become saturated, is

$$
t_{s d}=\Delta h_{s e}\left(\frac{\rho_{e} \pi D^{2} L_{e x}}{4}\right)\left(\frac{1}{q \pi D L_{e x}^{\prime}}\right)
$$

where $\Delta \mathrm{h}_{\mathrm{sc}}$ is the subcooling enthalpy, $\mathrm{q}$ is the heat flux per unit surface area and $L_{e x}$ is a length corresponding to the excess mass of fluid entering. $L_{e x}^{\prime}$ is an effective heat transfer length during the time $t_{\text {sd }}$. If we assume $\mathrm{L}_{\text {ex }} / L_{\text {ex }}^{\prime}=C^{\prime}$ then

$$
t_{\text {sd }}=C^{\prime} \frac{\Delta h_{s c} \rho_{R} D}{4 q}
$$

We assume the reference liquid velocity $\overline{\mathrm{U}}_{\ell}$ is proportional to the velocity of liquid before saturation, the vapor and gas in the pipe merely being displaced by the liquid. An additional restriction is imposed by a valve which may be in the process of opening. Alternately, a pump starting up may be thought of as a constant pressure source followed by a variable restriction.

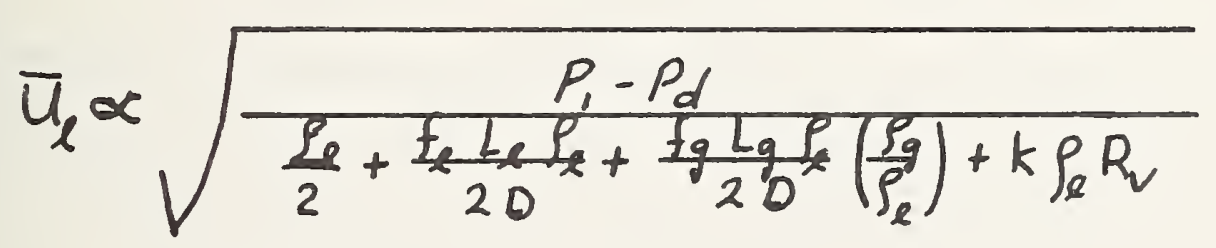

where $R_{v}={\frac{\mathrm{v}}{t_{\mathrm{Sd}}}}^{2}-1, t_{\mathrm{v}}>\frac{\mathrm{t}_{\mathrm{sd}}}{2}$

$$
R_{v}=0 \quad t_{v} \leq \frac{t_{s d}}{2}
$$

$\mathrm{K}$ is a restriction factor.

Substitution of (B8) and (B9) into (B7) gives

$$
\dot{w}_{e_{x}}=\frac{\pi D^{2}}{A} c \frac{\Delta h_{s c}}{\Delta h_{r}+F \Delta h_{3}} \rho_{l} \bar{u}_{l}
$$

where $C$ is a new constant of proportionality which includes $C^{\prime}$.

77 
As sume:

$$
\begin{aligned}
& f_{e}=c_{3}\left(\frac{E}{D}\right)^{\frac{1}{3}} \\
& f_{g}=c_{4}\left(\frac{E}{D}\right)^{\frac{1}{3}}
\end{aligned}
$$

where $\frac{\varepsilon}{D}$ is the pipe relative roughness

For an ideal gas $\rho_{g}=\frac{P_{1}}{R T}$

From (B10), (B11) and (B12) and (B13) we get

$$
\frac{\left(P_{p}-P_{1}\right)^{2}}{\left(P_{1}-P_{d}\right) P_{1}}=\frac{C_{1}\left(A+\frac{1}{\gamma} B\right)}{1+C_{3}\left(\frac{E}{D}\right)^{\frac{1}{3}} \frac{L_{l}}{D}+C_{4}\left(\frac{\epsilon}{D}\right)^{\frac{1}{3}} \frac{L g}{D} \frac{\rho_{g}}{\rho_{l}}+2 K R_{V}}
$$

where

$$
\begin{aligned}
& A=C_{f}\left(\frac{\epsilon}{D}\right)^{\frac{1}{3}}\left(\frac{\Delta h_{s c}}{\Delta h_{v}+F \Delta h_{s}}\right)^{2} \frac{\rho_{g}}{\rho_{g}} \frac{L g}{D} \\
& B=\left(\frac{\Delta h_{s c}}{\Delta h_{v}+F \Delta h_{s}}\right)^{2} \frac{\rho_{g}}{\rho_{g}}
\end{aligned}
$$

The fraction of superheat $F$ was determined from the detailed computer analyses for nitrogen and hydrogen as 0.43 . This value was considered constant. Also from the computer analysis liquid and gas friction factors vary from 0.01 to 0.014 for an apparatus in which $\frac{\epsilon}{D} \cong 0.0001$. Therefore, assuming an average $\mathrm{f}$ of 0.012 , we get $\mathrm{C}_{3}, \mathrm{C}_{4}$ and $\mathrm{C}_{\mathrm{f}}=0.26$.

From liquid nitrogen experimental data for short valve opening time $\left(\mathrm{t}_{\mathrm{v}}<\mathrm{t}_{\mathrm{sd}} / 2\right)$

$$
C_{1}=0.326
$$

From liquid nitrogen data with 16 second valve opening time

$$
2 \mathrm{~K}=0.624
$$


Comparisons of peak pressures from equation (B14) (solid, and dashed lines) with experimental data points are shown in figures B 1 through $B 5$. In all cases, the experimental points symbolized by circles are for various degrees of subcooling with highest peak pressures corresponding to maximum subcooling (storage temperature at atmospheric boiling point). The solid lines also correspond to maximum subcooling in equation (B14).

The square symbols and dashed lines denote saturated inlet liquid. It may be seen from these figures that the correlation gives upper and lower limits of peak pressure which envelope eventually al of the experimental data as desired. 


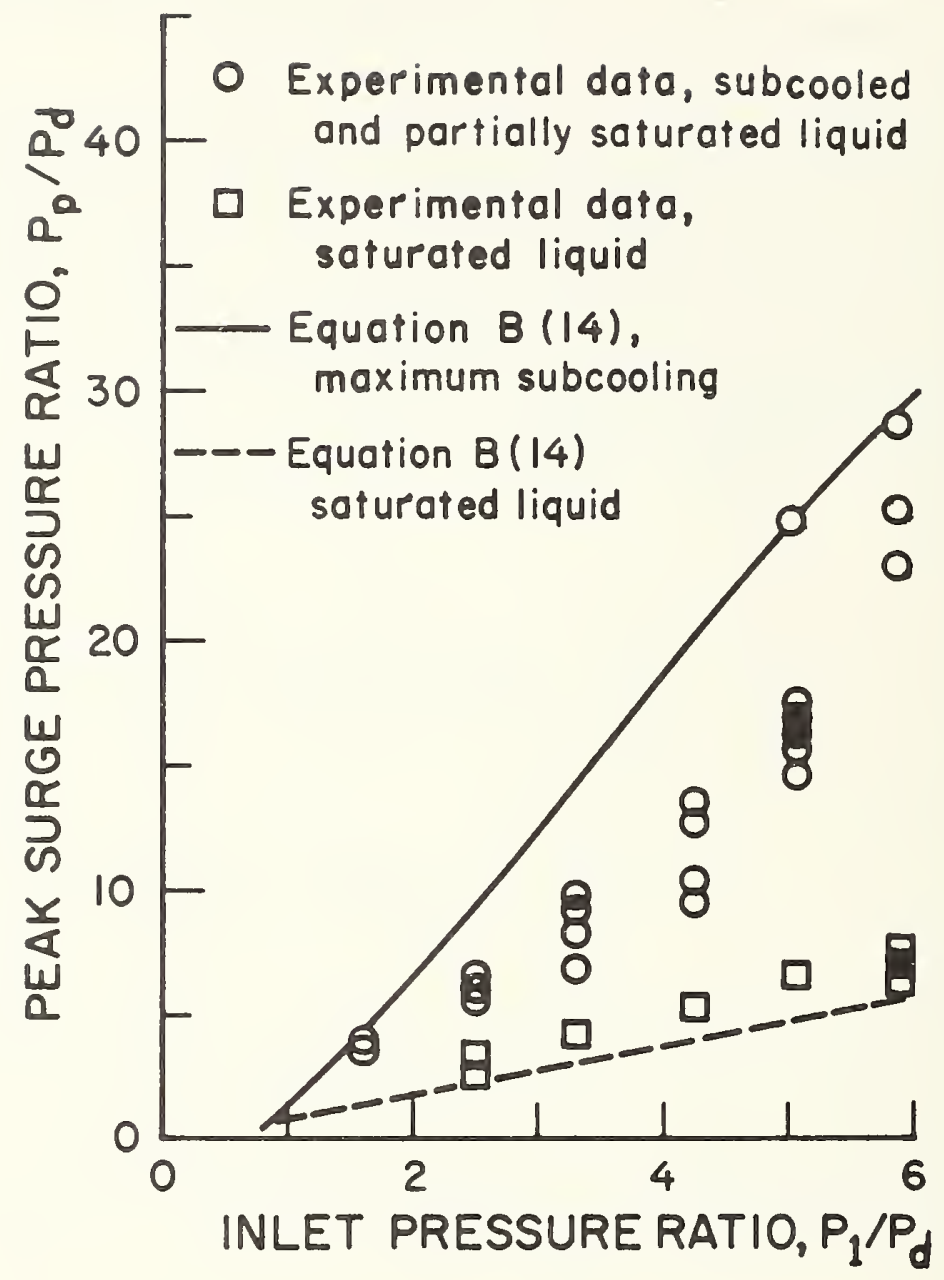

Figure B1. Peak surge pressure for liquid nitrogen in a $61 \mathrm{~m}$ (200 ft), $1.6 \mathrm{~cm}(0.625 \mathrm{in}) \mathrm{OD}$ copper tube transfer line. 


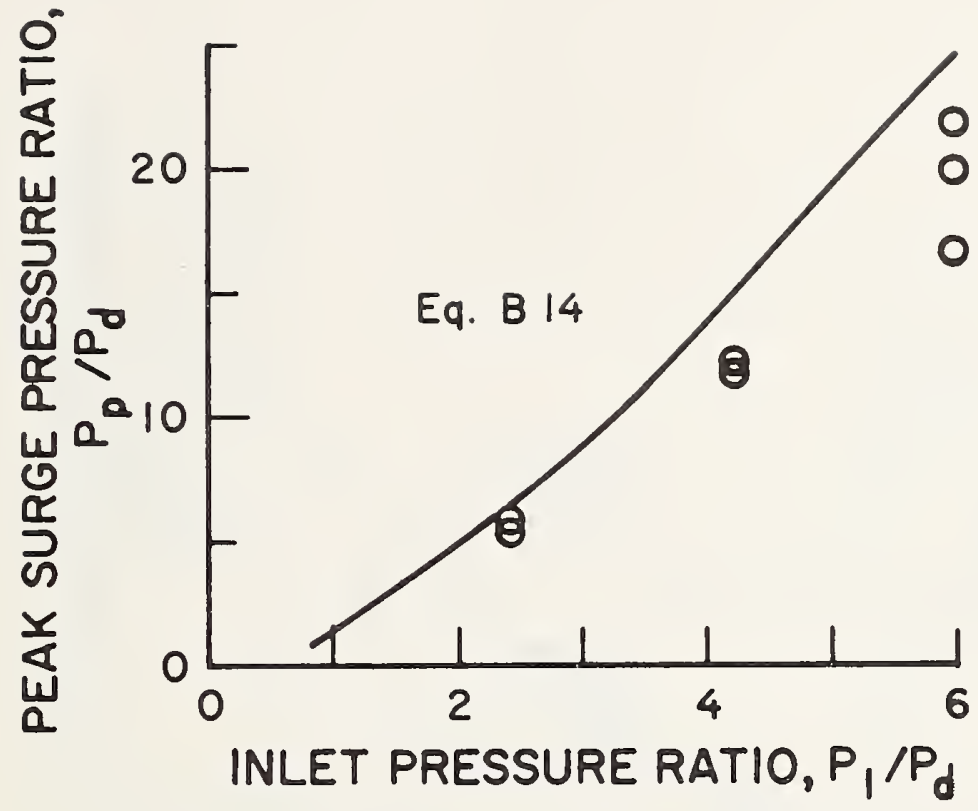

Figure B2. Peak surge pressure for subcooled nitrogen in a $46 \mathrm{~m}$ (150 ft), $1.6 \mathrm{~cm}(0.625 \mathrm{in}) \mathrm{OD}$ copper transfer line. 


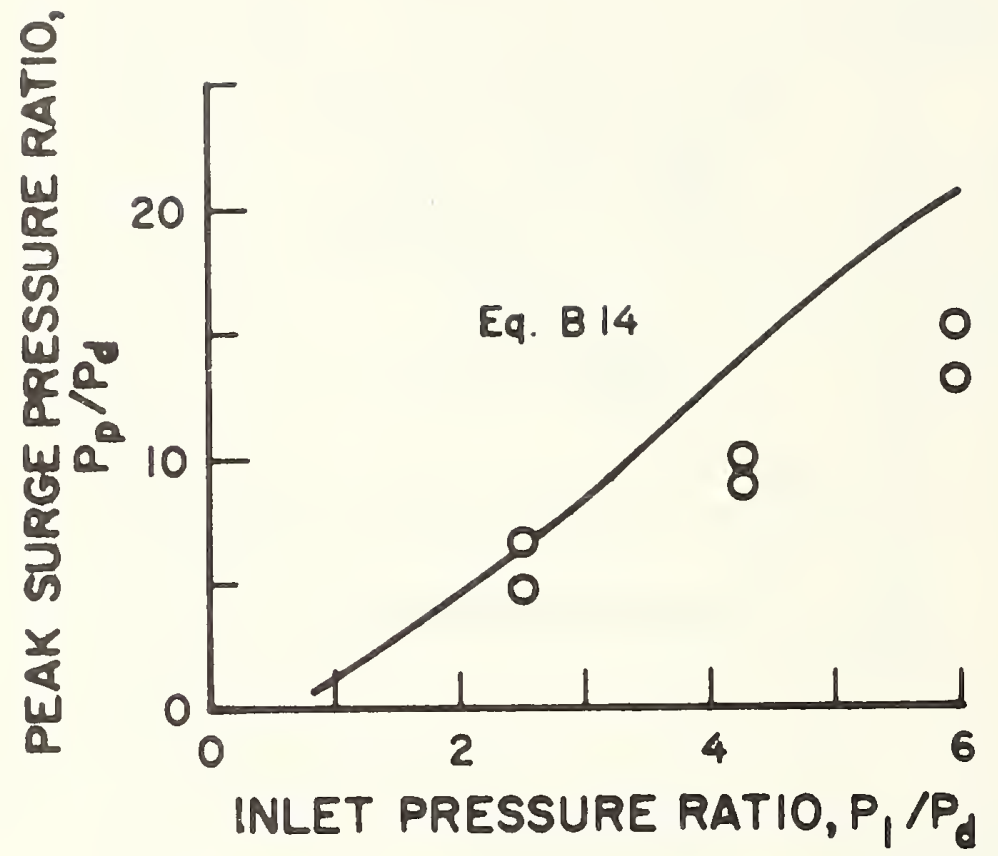

Figure B3. Peak surge pressure for liquid nitrogen in a $25 \mathrm{~m}$ ( $82 \mathrm{ft}$ ), $1.6 \mathrm{~cm}(0.625$ in) OD copper transfer line. 


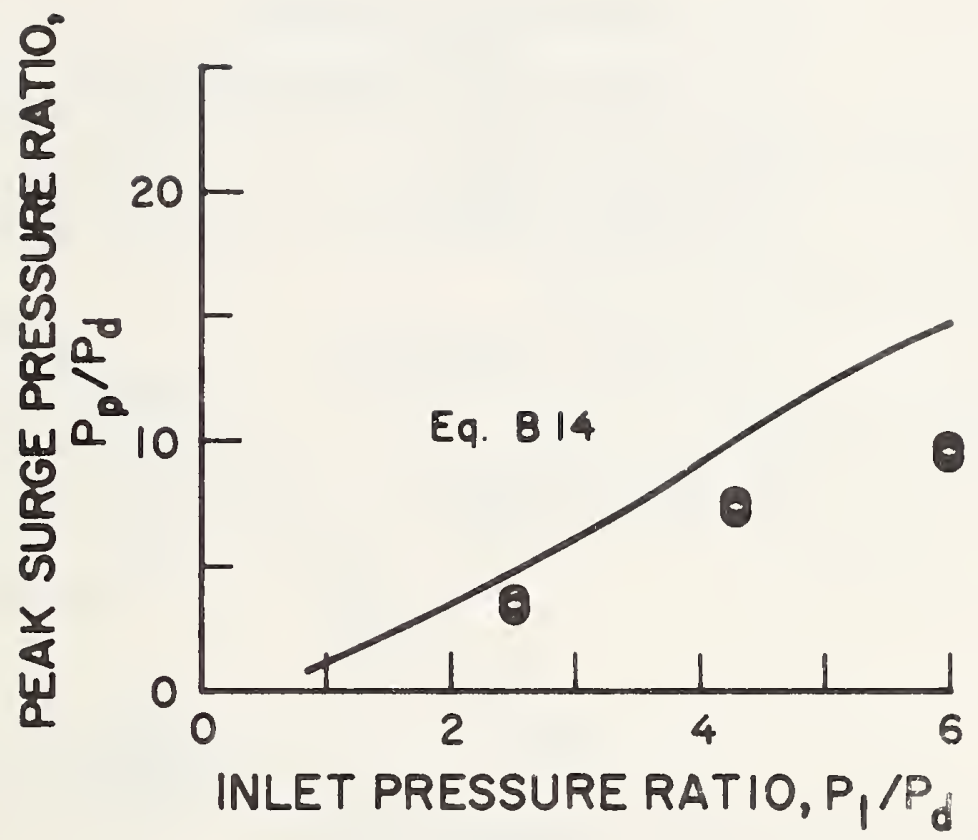

Figure B4. Peak surge pressure for liquid nitrogen in a $7.6 \mathrm{~m}$ (25 ft), $1.6 \mathrm{~cm}(0.625$ in) $O D$ copper transfer line. 


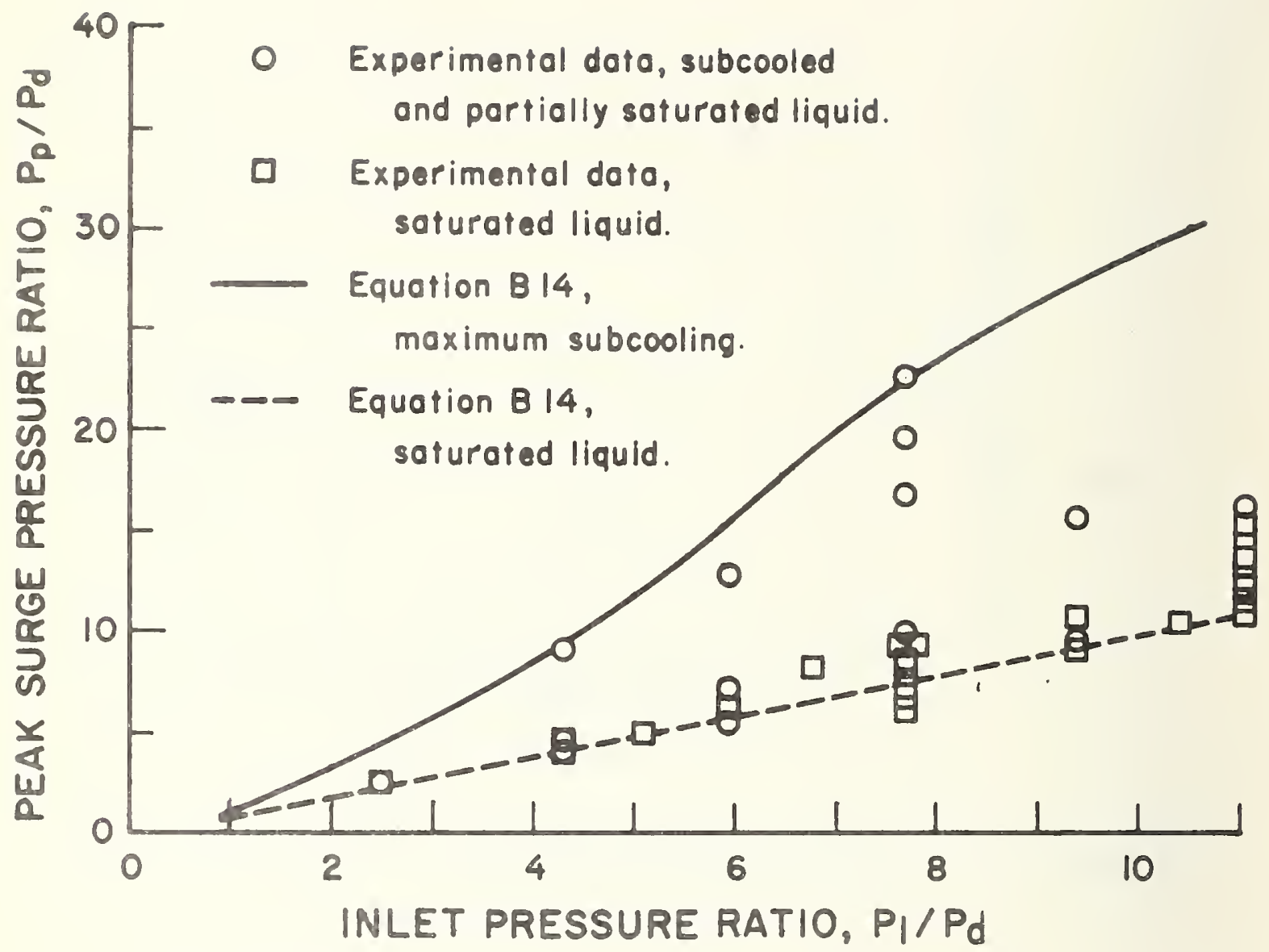

Figure B5. Peak surge pressure for liquid hydrogen in a $61 \mathrm{~m}$ (200 ft), $1.6 \mathrm{~cm}(0.625$ in) OD copper transfer line. 
Appendix C. Loading of the Minicomputer

The method of loading programs into the minicomputer is described in Section 3.3 of the manual "How to Use the NOVA Computers" (1971). This appendix is an elaboration of the procedure described there.

The Binary Loader

The binary loader is usually in the minicomputer and is not destroyed by any of the programs. For that reason, following the procedure below should be sufficient to load any program in the minicomputer.

However, occasionally a sharp spike on the power lines or a malfunction of the memory in the computer can cause the binary loader to be destroyed. If this should happen, the "Bootstrapping'" procedure must be performed first.

\section{Preparing the teletype}

The minicomputer and CRT display must be turned on but not running and the CRT display LOCAL/LINE switch set to LOCAL. The teletype is plugged into the back of the CRT display. Turn the teletype power switch, LINE/OFF/LOCAL, to LINE. With the teletype reader switch in $O F F$ position, place the paper tape containing the program in the reader with the tape coming out toward the front of the teletype and the narrower side from the sprocket holes in the tape toward the outside of the teletype. Position the tape so that unpunched tape is over the read position. Set the reader switch to ON. 


\section{Loading the Program}

On the minicomputer, the upper row of switches is called the Switch Register, and are labeled 0 through 15. The lower row of switches are all momentary switches used for control and their functions are listed on the panel.

Set the Switch Register 0, 1, 2 down and 3 thru 15 up. Press control switch RESET and then START. The teletype should start reading paper tape. At the end of each binary block on the tape, the printer mechanism should receive some null character and, thus, cycle or 'chuckle'". Should it fail to do this, back up to the beginning of the paper tape and try again. Should it still fail it may be necessary to follow the "Bootstrapping" procedure and then try again. If the program loads correctly, it may self start or it may halt the computer. If the computer halts, set all the Switch Register switches down except 14, which must be up, and press START. If subsequent operations are to be between the minicomputer and the CRT display, the LOCAL/LINE switch on the CRT should be set to LINE before pressing START, and the teletype turned to OFF.

If the computer halts in the middle of the tape reading, the teletype has made an error while reading the tape. It is not necessary to start the tape over completely. Merely back the tape up at least one block and start the computer again. The beginning of a block is fairly easy to recognize. It consists of two frames with no punches in the tape except the sprocket hole. followed by a frame with at least the four top most positions punched followed by a frame with all positions punched. Reposition the tape on one of the two unpunched positions, set the teletype reader to ON and push START on the minicomputer. If the teletype fails to start 'Chuckling', the tape should be restarted at the beginning. 
page 3

\section{Bootstrapping}

It may occasionally be necessary to restart the minicomputer from a completely oblite rated condition. To do this, turn on the minicomputer and the CRT display. Set the CRT display LOCAL/LINE switch to LOCAL. Prepare the teletype with the tape marked "CHUCKLING LOADER"' in the reader just as you would for any other program tape. Next, follow the instructions in TABLE A-1. After the last line of the table has been executed the computer should read the tape and stop at the end. It will not "chuckle" the teletype. If it does not, read the tape the computer or teletype is likely in need of repair. If it does read the tape correctly, proceed to load program as described in the section, Binary Loader. 


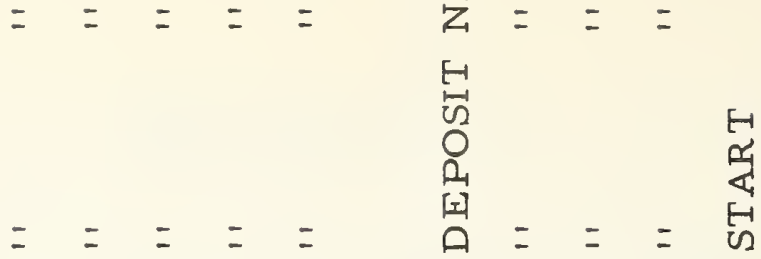

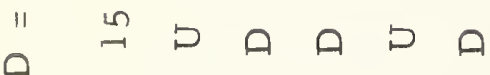

$\triangle ค \triangleright ค ค$

ค ค ค ค

$\ddot{p}$

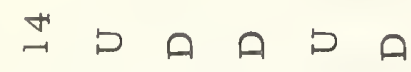

$\triangle ค \triangleright \triangleright ค$

ค $口 ค ค$

$\longmapsto$

$\stackrel{n}{\rightarrow} \cap A \mapsto A$

ค $ค$ ค $ค$

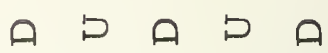

$\stackrel{\sim}{\sim} ロ \mapsto \triangleright$

ค ค คค

๖คคค

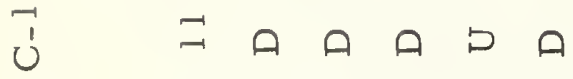

ค ค ค

ค ค $\triangleright$

$\frac{0}{\pi}$

$\stackrel{\circ}{\neg} \odot \triangleright \oplus$

ค ค คค

คคคค

$\curvearrowleft \triangleright ค ค \triangleright \triangleright$

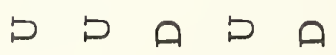

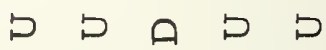

$\infty \triangleright ค \triangleright \mapsto$

ค ค คค

$\triangle \triangleright ค \triangleright \triangleright$

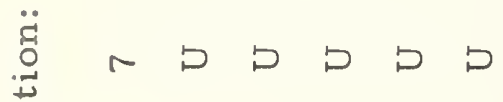

คคคคค

$ค \mapsto \triangleright \triangleright \triangleright$

○คคคคค

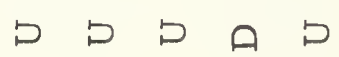

คคคค ค

๓ $\triangleright \triangleright \triangleright \bullet$

$\triangleright \mapsto \triangleright ค ค$

ค ค ค ค

$* \triangleright \triangleright A A A$

$\triangleright \mapsto \mapsto A \cap$

$\triangle \triangleright \triangleright \triangleright \triangleright$

$m \triangleright A ค A$

- $A$ A

คคคคค

$\dot{\sim}$
$\ddot{\nu}$

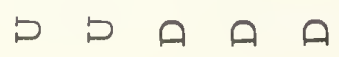

๑ $ค$ ค ค

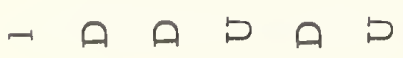

- $A$ a

$\triangleright ค \mapsto A$

- $口 ロ A$ a

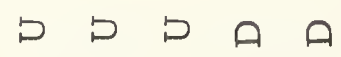

ค $\triangle$ ค 
FORM NBS-114A (1.71)

\begin{tabular}{|c|c|c|c|}
\hline $\begin{array}{l}\text { U.S. DEPT. OF COMM. } \\
\text { BIBLIOGRAPPHC DATA } \\
\text { SHEET DATA }\end{array}$ & $\begin{array}{l}\text { 1. PUBLICAT ION OR REPORT NO. } \\
\text { N BSIR 74-366 }\end{array}$ & $\begin{array}{l}\text { 2. Gov't Accession } \\
\text { No. }\end{array}$ & 3. Recipient's Accession No. \\
\hline \multicolumn{3}{|c|}{$\begin{array}{l}\text { 4. TITLE AND SUBTITLE } \\
\text { Study of Cryogenic Propellant Systems for Loading } \\
\text { the Space Shuttle }\end{array}$} & \begin{tabular}{|l|} 
5. Publication Date \\
April 1974 \\
6. Performing Organization Code
\end{tabular} \\
\hline \multicolumn{3}{|c|}{$\begin{array}{l}\text { 7. AUTHOR(S) R. O. Voth, W. G. Steward, and } \\
\text { W. H. Hall }\end{array}$} & 8. Performing Organization \\
\hline \multicolumn{3}{|c|}{$\begin{array}{l}\text { 9. PERF ORMING ORGANIZATION NAME AND ADDRESS } \\
\text { NATIONAL BUREAU OF STAND ARDS } \\
\text { DEPARTMENT OF COMMERCE } \\
\text { Washington, D.C. } 20234\end{array}$} & $\begin{array}{l}\text { 10. Project/Task/Work Unit No. } \\
2750458 \\
\text { 11. Contract/Grant No. } \\
\text { CC- } 03420 \mathrm{~A}\end{array}$ \\
\hline \multirow{2}{*}{\multicolumn{3}{|c|}{$\begin{array}{l}\text { 12. Sponsoring Organization Name and Address } \\
\text { National Aeronautics and Space Administration } \\
\text { John F. Kennedy Space Center } \\
\text { Kennedy Space Center, Florida } 32899\end{array}$}} & $\begin{array}{l}\text { 13. Type of Report \& Period } \\
\text { Covered }\end{array}$ \\
\hline & & & 14. Sponsoring Agency Code \\
\hline
\end{tabular}

16. ABSTRACT ( 1 200-word or less factual summary of most significant information. If document includes a significant bibliography or literature survey, mention it here.)

Computer programs have been written to model the liquid oxygen loading system for the space shuttle. The programs allow selection of input data through graphic displays which schematically depict the part of the system being modeled. The computed output is also displayed in the form of graphs and printed messages. Any one of six computation options may be selected. The first four of these pertain to thermal stresses, pressure surges, cooldown times, flow rates and pressures during cooldown. Options five and six deal with possible water hammer effects due to closing of valves, steady flow and transient response to changes in ope rating conditions after cooldown.

Procedures are given for operation of the graphic display unit and mini computer.

17. KEY WORDS (Alphabetical order, separated by semicolons)

Computer modeling; cooldown; cryogenic flow; stresses; surges; transient flow; wate $\mathrm{r}$ hammer.

18. AVAILABILITY STATEMENT

$\mathrm{X}$ UNLIMIT ED.

FOR OFFICIAL DISTRIBUTION. DO NOT RELEASE TO NTIS.

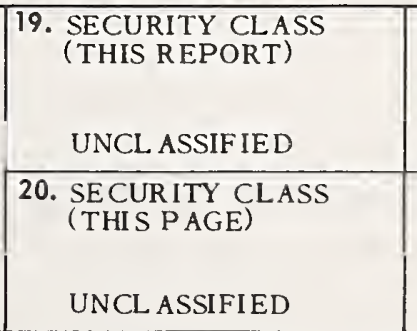

21. NO. OF PAGES

22. Price 




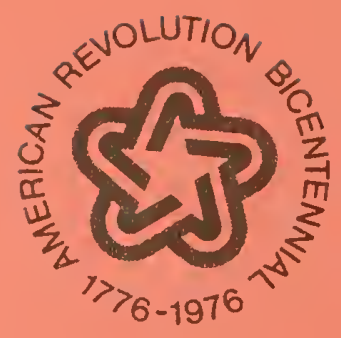




速 
